Effects Of Receiving-Water Quality And Wastewater Treatment On Injury, Survival, And Regrowth Of Fecal-Indicator Bacteria And Implications For Assessment Of Recreational Water Quality

By Donna S. Francy, Teresa L. Hart, and Cathy M. Virosteck

U.S. Geological Survey

Water-Resources Investigations Report 96-4199

Prepared in cooperation with

OHIO WATER DEVELOPMENT AUTHORITY, NORTHEAST OHIO REGIONAL SEWER DISTRICT, SUMMIT COUNTY

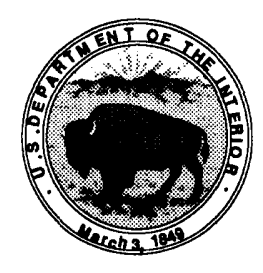

Columbus, Ohio 1996 


\section{U.S. DEPARTMENT OF THE INTERIOR \\ BRUCE BABBITT, Secretary}

\section{U.S. GEOLOGICAL SURVEY}

Gordon P. Eaton, Director

For additional information write to:

District Chief

U.S. Geological Survey

975 West Third Avenue

Columbus, Ohio 43212-3192
Copies of this report can be purchased from:

USGS Branch of Information Services Box 25286

Denver, Colorado 80225 


\section{CONTENTS}

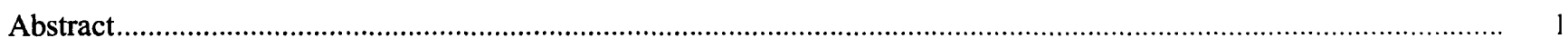

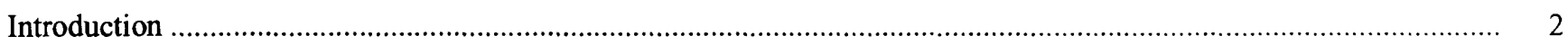

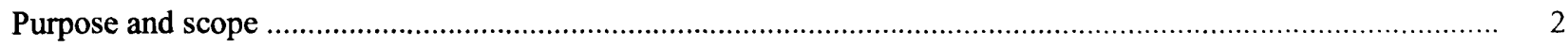

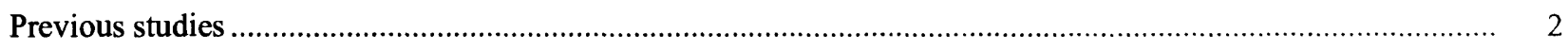

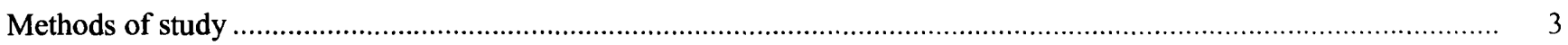

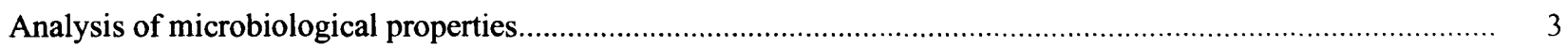

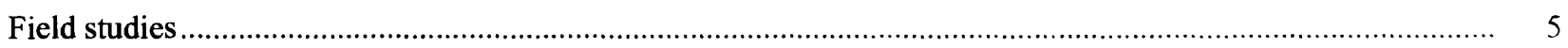

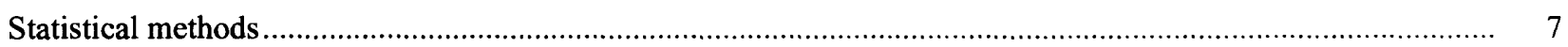

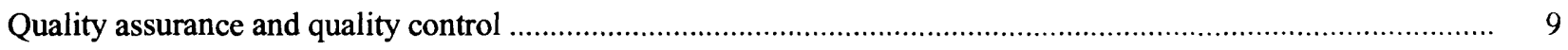

Evaluation of enhanced-recovery methods for use in field studies ..................................................................... 10

Effects of receiving-water quality and wastewater treatment on injury, survival, and regrowth of fecal-indicator

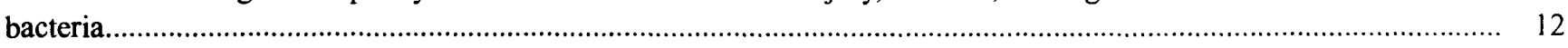

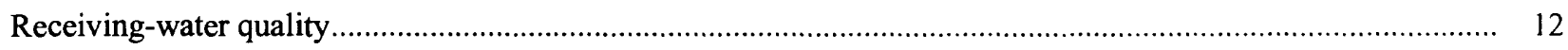

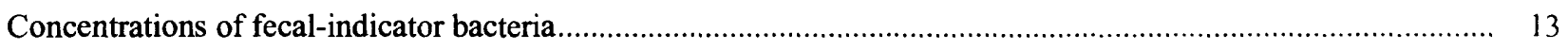

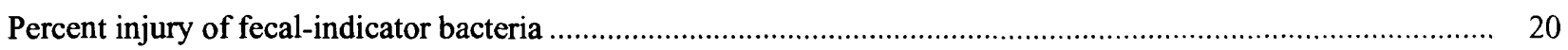

Percent survival of fecal-indicator bacteria .................................................................................... 26

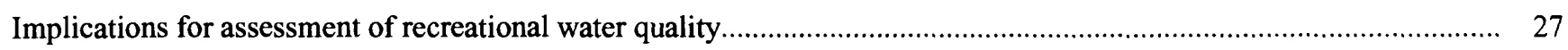

Relation of enhanced-recovery method concentrations to standard-method concentrations ............................... 27

Relation of enhanced-recovery and standard-method concentrations to Ohio recreational water-quality

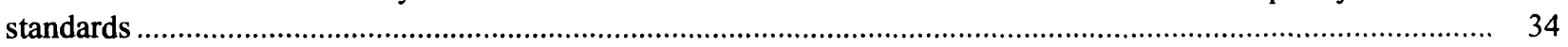

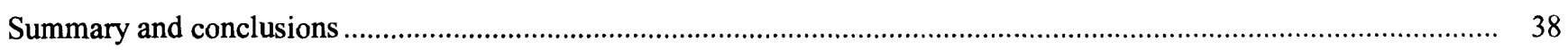

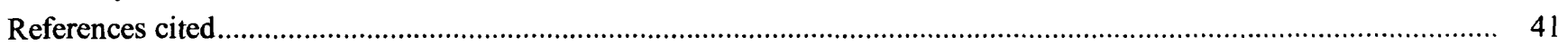

\section{FIGURES}

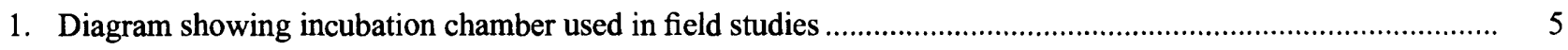

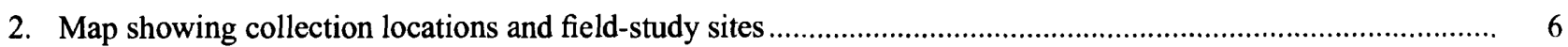

3-7. Graphs showing mean fecal-coliform concentrations determined by use of standard and enhanced-recovery methods in:

3. Wastewater effluent during May 1994 and August 1994 field studies at Lake Erie, Cleveland, Ohio: unchlorinated, chlorinated, and dechlorinated samples

4. Unchlorinated wastewater effluent during June 1994, August 1995, and September 1995 field studies at Cuyahoga River sites, Ohio.

5. Chlorinated wastewater effluent during June 1994, August 1995, and September 1995 field studies at Cuyahoga River sites, Ohio.

6. Dechlorinated wastewater effluent during June 1994, August 1995, and September 1995 field studies at Cuyahoga River sites, Ohio.

7. Combined-sewer-overflow effluent during May and June 1995 field studies at Cuyahoga River at Independence, Ohio: unchlorinated, chlorinated, and dechlorinated samples 
8-10. Boxplots showing percent injury of fecal coliforms in relation to treatment type in:

8. Wastewater effluent collected from Easterly Wastewater Treatment Plant and incubated at Lake Erie field site, Cleveland, Ohio: May 1994 and August 1994

9. Wastewater effluent collected from Southerly Wastewater Treatment Plant and incubated at Cuyahoga River at Peninsula and West Third field sites, Cleveland area, Ohio: June 1994 and August 1995

10. Combined-sewer-overflow effluent collected from Mill Creek and incubated at Cuyahoga River at Independence, Cleveland area, Ohio: May 1995 and June 1995.

11-14. Graphs showing:

11. Regression relation between enhanced-recovery and standard-method concentrations of fecal coliforms in seven field studies of wastewater and combined-sewer-overflow effluent collected in the Cleveland area, Ohio

12. Residuals from regression relation between enhanced-recovery and standard-method concentrations of fecal coliforms in seven field studies against predicted enhanced-recovery concentrations, elapsed time, and treatment type

13. Regression relation between enhanced-recovery and standard-method concentrations of fecal coliforms and associated residuals against predicted enhanced-recovery concentrations for data grouped by magnitude of standard-method concentrations: $\leq 5,000$ colonies per 100 milliliters and $>5,000$ colonies per 100 milliliters

14. Regression relation between enhanced-recovery and standard-method concentrations of fecal coliforms and associated residuals against predicted enhanced-recovery concentrations for data grouped by treatment: unchlorinated, chlorinated, and dechlorinated

15-17. Bar graphs showing percentage of samples, by treatment type, in which fecal-coliform concentrations determined by standard and enhanced-recovery methods:

15. Met and exceeded Ohio's bathing-water single-sample standard: (A) wastewater effluent, low concentrations of bacteria, (B) wastewater effluent, high concentrations of bacteria, and

(C) combined-sewer-overflow effluent

16. Met and exceeded Ohio's primary-contact single-sample standard: (A) wastewater effluent, low concentrations of bacteria, (B) wastewater effluent, high concentrations of bacteria, and

(C) combined-sewer-overflow effluent

17. Met and exceeded Ohio's secondary-contact single-sample standard: (A) wastewater effluent, low concentrations of bacteria, (B) wastewater effluent, high concentrations of bacteria, and

(C) combined-sewer-overflow effluent

\section{TABLES}

1. Differences in mean rank of concentrations of fecal coliforms obtained by use of enhanced-recovery methods and concentrations of fecal coliforms obtained by use of standard method in unchlorinated, chlorinated, and dechlorinated wastewater effluent

2. Dates, sites, and durations of field studies done with wastewater or combined-sewer-overflow effluent from three collection locations, 1994-1995

3. Mean values of water-quality field measurements and constituent concentrations for wastewater and combined-sewer-overflow effluent field studies

4. Percent verifications of fecal coliforms in wastewater or combined-sewer-overflow effluent by use of standard or enhanced-recovery method

5. Mean percent injury of fecal coliforms in unchlorinated, chlorinated, and dechlorinated wastewater or combined-sewer-overflow effluent field studies

6. Mean percent survival of fecal coliforms in unchlorinated, chlorinated, and dechlorinated wastewater or combined-sewer-overflow effluent in field studies

7. Regression statistics for enhanced-recovery and standard-method concentrations of fecal coliforms in wastewater and combined-sewer-overflow effluent collected in the Cleveland area, Ohio 
CONVERSION FACTORS AND ABBREVIATED WATER-QUALITY UNITS

\begin{tabular}{rll}
\hline Multiply & By & To obtain \\
\hline liter $(\mathrm{L})$ & 0.03531 & $\begin{array}{l}\text { cubic foot } \\
\text { cubic inch } \\
\text { pound per square inch }\end{array}$ \\
milliliter $(\mathrm{mL})$ & 0.0607 & colonies per cubic foot \\
milligram per liter $(\mathrm{mg} / \mathrm{L})$ & 0.00006243 & inch \\
colonies per 100 milliliters & 283.2 & inch \\
$($ col/ $100 \mathrm{~mL})$ & 0.00003937 &
\end{tabular}

Water and air temperatures in degrees Celsius $\left({ }^{\circ} \mathrm{C}\right)$ can be converted to degrees Fahrenheit $\left({ }^{\circ} \mathrm{F}\right)$ by the following equation: ${ }^{\circ} \mathrm{F}=1.8\left({ }^{\circ} \mathrm{C}\right)+32$.

Abbreviated water-quality units used in this report: Chemical concentrations are given in metric units. Chemical concentration is given in milligrams per liter $(\mathrm{mg} / \mathrm{L})$. Milligrams per liter is a unit expressing the concentration of chemical constituents in solution as weight (milligrams) of solute per unit volume (liter) of water.

Specific conductance of water is expressed in microsiemens per centimeter at 25 degrees Celsius $(\mu \mathrm{S} / \mathrm{cm})$.

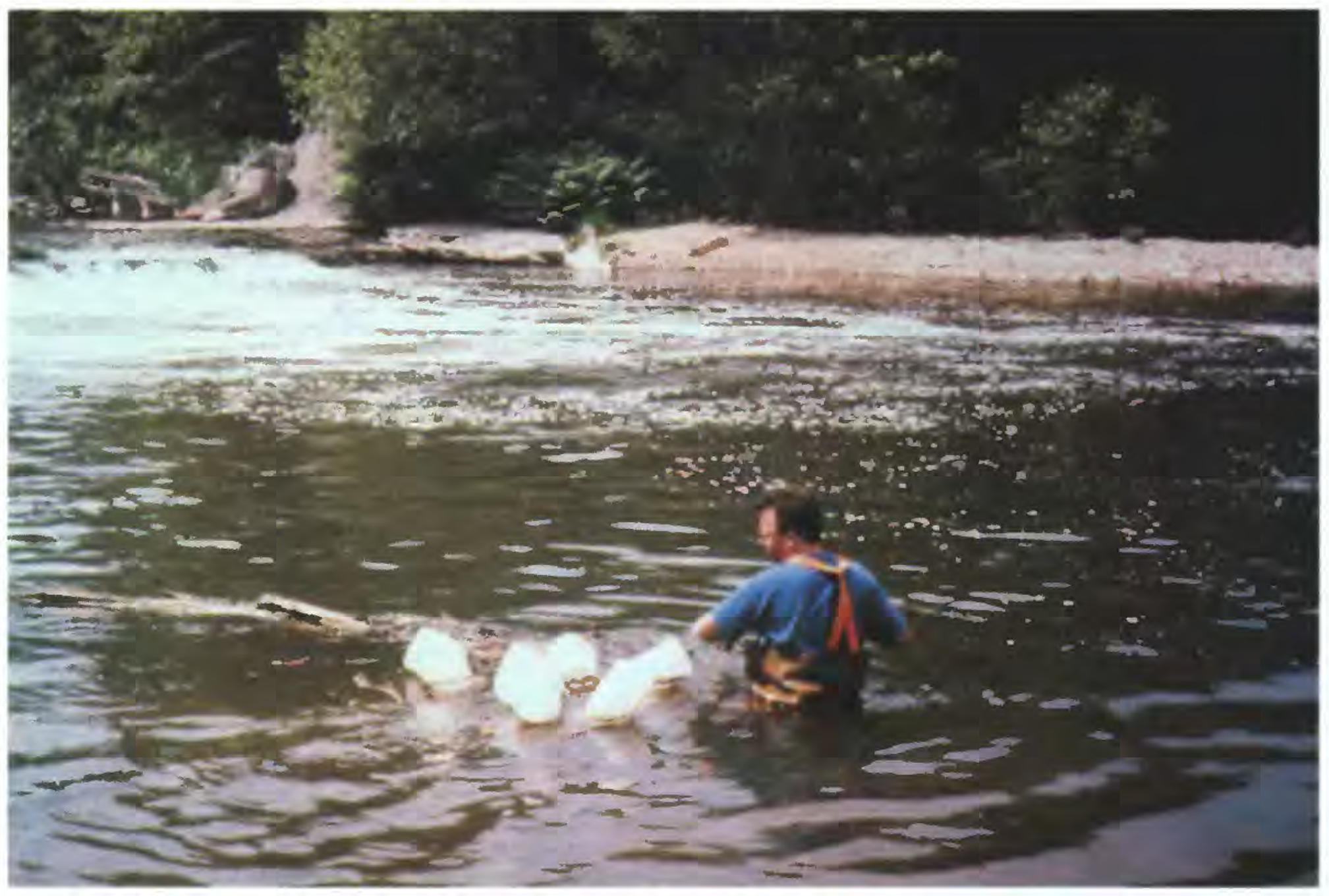

U.S. Geological Survey scientist retrieving chambers in the river. 


\title{
Effects of Receiving-Water Quality and Wastewater Treatment on Injury, Survival, and Regrowth of Fecal- Indicator Bacteria and Implications for Assessment of Recreational Water Quality
}

\author{
By Donna S. Francy, Teresa L. Hart, and Cathy M. Virosteck
}

\section{Abstract}

Bacterial injury, survival, and regrowth were investigated by use of replicate flow-through incubation chambers placed in the Cuyahoga River or Lake Erie in the greater Cleveland metropolitan area during seven 4-day field studies. The chambers contained wastewater or combined-sewer-overflow (CSO) effluents treated three ways - unchlorinated, chlorinated, and dechlorinated. At timestep intervals, the chamber contents were analyzed for concentrations of injured and healthy fecal coliforms by use of standard selective and enhanced-recovery membranefiltration methods.

Mean percent injuries and survivals were calculated from the fecal-coliform concentration data for each field study. The results of analysis of variance (ANOVA) indicated that treatment affected mean percent injury and survival, whereas site did not. In the warm-weather Lake Erie field study, but not in the warm-weather Cuyahoga River studies, the results of ANOVA indicated that dechlorination enhanced the repair of injuries and regrowth of chlorine-injured fecal coliforms on culture media over chlorination alone. The results of ANOVA on the percent injury from CSO effluent field studies indicated that dechlorination reduced the ability of organisms to recover and regrow on culture media over chlorination alone. However, because of atypical patterns of concentration increases and decreases in some CSO effluent samples, more work needs to be done before the effect of dechlorination and chlorination on reducing fecal-coliform concentrations in CSO effluents can be confirmed. The results of ANOVA on percent survivals found statistically significant differences among the three treatment methods for all but one study. Dechlorination was found to be less effective than chlorination alone in reducing the survival of fecal coliforms in wastewater effluent, but not in CSO effluent.

If the concentration of fecal coliforms determined by use of the enhanced-recovery method can be predicted accurately from the concentration found by use of the standard method, then increased monitoring and expense to detect chlorine-injured organisms would be unnecessary. The results of linear regression analysis, however, indicated that the relation between enhancedrecovery and standard-method concentrations was best represented when the data were grouped by treatment. The model generated from linear regression of the unchlorinated data set provided an accurate estimate of enhanced-recovery concentrations from standard-method concentrations, whereas the models generated from the chlorinated and dechlorinated data sets did not. In addition, evaluation of fecal-coliform concentrations found in field studies in terms of Ohio recreational water-quality standards showed that concentrations obtained by standard and enhanced-recovery methods were not comparable. Sample treatment and analysis methods were 
found to affect the percentage of samples meeting and exceeding Ohio's bathing-water, primarycontact, and secondary-contact standards. Therefore, determining the health risk of swimming in receiving waters was often difficult without information on enhanced-recovery method concentrations and was especially difficult in waters receiving high proportions of chlorinated or dechlorinated effluents.

\section{Introduction}

The U.S. Environmental Protection Agency (USEPA) required States to develop new chlorine water-quality standards for protection of aquatic life, such that chlorine concentrations in receiving waters must be substantially reduced (U.S. Environmental Protection Agency, 1985). To meet these new chlorine standards, many wastewater treatment plants in Ohio and elsewhere that chlorinate for disinfection must now dechlorinate effluents before discharging them to inland waterways. This process results in a reduction in chlorine-contact time for fecal-indicator bacteria and pathogenic microorganisms whose concentrations water-resource managers seek to control. However, little information exists on the effect of dechlorination on the repair and survival of chlorine-injured fecalindicator bacteria and the possible increased risk of swimming in waters with an undetected population of injured bacteria.

To augment the literature on recovery of injured fecal-indicator bacteria and to explore the implications of bacteria recovery for recreational water-quality standards, the U.S. Geological Survey (USGS), in cooperation with the Northeast Ohio Regional Sewer District (NEORSD), the Ohio Water Development Authority, and Summit County, Department of Environmental Services, studied the effects of receivingwater quality and wastewater-plant chlorination practices on fecal-coliform injury and survival in receiving waters and on fecal-coliform regrowth on growth medium.

\section{Purpose and Scope}

This report describes seven field studies done during the recreational seasons of 1994 and 1995 at one Lake Erie location and three Cuyahoga River locations in the greater Cleveland, Ohio, metropolitan area. For each field study, bacterial injury, survival, and regrowth were investigated by use of replicate flow-through incubation chambers placed in the water column of the receiving stream or lake. The chambers contained wastewater or combined-sewer-overflow (CSO) effluents treated three ways: unchlorinated, chlorinated, and dechlorinated. At timestep intervals, the chamber contents were analyzed for concentrations of injured and healthy fecal coliforms by use of standard selective and enhanced-recovery membranefiltration (MF) methods. Physical and chemical waterquality characteristics also were monitored at timestep intervals. Percent injury and survival were calculated for each timestep. The effects of treatment and ambient water-quality characteristics on percent injury and survival were determined by use of analysis of variance (ANOVA). The relation between concentrations of fecal coliforms by use of standard and enhancedrecovery methods was determined by use of linear regression analysis. Concentrations of fecal coliforms were compared to Ohio water-quality standards to determine the importance of bacteria injury, survival, and regrowth on growth medium in the assessment of bacterial water quality. This report provides waterresource managers with information on the use of enhanced-recovery methods to assess recreational water quality and on the effectiveness of different chlorination practices in reducing fecal-coliform concentrations.

\section{Previous Studies}

Considerable information is available from laboratory studies showing that fecal-indicator bacteria surviving chlorination are able to repair injuries and survive in the aquatic environment. Investigators determined that the proportion of bacteria surviving chlorination increased when chlorinated wastewater was diluted with streamwater or distilled water (Heukelekian, 1951), as chlorine-contact time decreased (Braswell and Hoadley, 1974), or as residual chlorine concentration decreased (Shuval and others, 1973). In another study (Kinney and others, 1978), investigators found that the concentration of coliform bacteria in unchlorinated wastewater effluent, including those in the fecal-coliform group, steadily declined during a 5day study, whereas the concentration of coliforms in the same effluent increased after chlorination. Because of the natural die-off pattern noted in the unchlorinated wastewater, the authors attributed the increase in 
bacteria concentration in chlorinated wastewater to repair of injured organisms rather than growth of healthy organisms. It was also suggested that standard selective MF methods for enumerating fecal-indicator bacteria do not support the growth of chlorine-injured bacteria (Kinney and others, 1978). Standard methods, defined as those methods believed to represent the best current practice of American water analysts, are generally applicable to ordinary problems of sanitary investigations (American Public Health Association and others, 1992). Selective methods are defined as those methods that inhibit growth of nontarget bacteria groups in order to encourage growth of target organisms.

The most probable number (MPN) method, containing a nonselective enrichment step, was superior to the standard selective MF method in parallel tests for enumerating chlorine-injured fecal coliforms (Lin, 1973) and in parallel tests for enumerating unchlorinated and chlorine-injured coliforms (Mowat, 1976). The USEPA (U.S. Environmental Protection Agency, 1978) recommends that the standard selective MF method should not be used with chlorinated wastewaters and that any decision to use this test requires parallel MF/MPN evaluations to determine applicability of the MF method. However, because the MPN method is time-consuming, cumbersome, and an estimate of the "most probable number," many investigators sought improvements to the standard-selective MF method that would enhance growth of chlorineinjured bacteria (Camper and McFeters, 1979). Many enhanced-recovery MF methods have a pre-enrichment step on nonselective media, a temperature acclimation time, and (or) an alternate media devoid of inhibitory chemicals.

Several investigators used standard-selective MF methods and (or) MPN methods to investigate survival of chlorine-injured bacteria in the field. Silvey and others (1974) determined concentrations of total coliforms and fecal coliforms by use of MPN methods in the Trinity River in Texas, downstream from four wastewater treatment plants. The investigators suggested that nonfecal-coliform strains exhibited significant regrowth following chlorination, whereas fecalcoliform strains failed to regrow in the river. In a study in the Chicago area (Haas and others, 1988), investigators used standard selective MF methods to compare concentrations of fecal coliforms in receiving waters before and after a wastewater treatment plant discontinued chlorination. They suggested that, beyond a certain affected zone, chlorination of an effluent may not improve microbiological water quality in the receiving stream. However, these studies were not done by use of a controlled group of fecal-indicator bacteria; and contributing influences from surfacewater runoff and combined-sewer overflows could not be ruled out.

Bissonnette and others (1975) investigated the influence of environmental stress on Escherichia coli (E. coli) injury and survival by use of membrane-filter chambers containing a controlled population of bacteria. $E$. coli is a major species in the fecal-coliform group and a natural inhabitant of the intestinal tract of warm-blooded animals. The investigators observed that, upon exposure to the aquatic environment, concentrations of $E$. coli obtained by use of a selective method were less than those obtained by use of an enhanced-recovery method. They also observed substantial variation in percentage of injury and survival of $E$. coli in various stream environments.

Information regarding the effects of ambient water-quality conditions and wastewater-plant chlorination practices on injury and survival of fecal-indicator bacteria in receiving waters is lacking. However, the survival of chlorine-injured fecal-indicator bacteria may have implications from a public-health and water-quality perspective. Fecal-indicator bacteria that survive but are injured from chlorination may be able to repair their injuries and regrow, provided that a suitable growth medium is available. That growth medium may be enhanced-recovery medium or the gastrointestinal tract of an unsuspecting swimmer. Standard selective methods may not detect injured organisms; therefore, the enumeration of fecal-indicator bacteria and the pathogenic bacteria whose presence they indicate may be underestimated.

\section{Methods of Study}

\section{Analysis of Microbiological Properties}

Sterile techniques were used throughout all phases of collecting and processing samples for microbiological analysis. All samples for microbiological determinations were analyzed by MF techniques and were filtered onto 0.45 - $\mu \mathrm{m}$-pore-size membrane filters within 6 hours of collection and treatment. Several volumes of sample were plated in order to obtain countable plates within the ideal range of 20-60 
colonies per plate (Britton and Greeson, 1989). Dilutions of more concentrated samples were made in buffered dilution water with peptone (Britton and Greeson, 1989).

Enumeration of fecal-indicator bacteria. Samples were analyzed for concentrations of fecal coliforms by use of two MF methods: (1) the standard selective method (Britton and Greeson, 1989) and (2) an enhanced-recovery method designed to support growth of chlorine-injured organisms. Several enhanced-recovery methods for fecal coliforms have been developed by other researchers and are listed in "Standard Methods for the Examination of Water and Wastewater" (American Public Health Association, 1992).

Standard selective methods for enumeration of fecal coliforms are widely used for monitoring recreational waters and wastewater effluents. The fecal coliform MF method ( $\mathrm{mFC}$ ) involves incubation of the filtered water sample on $\mathrm{mFC}$ agar (Difco Laboratories, Detroit, Mich. ${ }^{1}$ ) for 22 to 24 hours at $44.5^{\circ} \mathrm{C}$. After incubation, all blue colonies are counted as fecal coliforms. The mFC agar contains growth substances, salts, and several compounds to inhibit growth of nontarget organisms.

Several enhanced-recovery methods were tested for use in field studies. One method tested was a twolayer method in which a nonselective, enriched overlay of agar-lactose broth (Difco) was added to plates containing $\mathrm{mFC}$ agar less than 1 hour prior to use (Rose and others, 1975). The plates were incubated for 2 hours at $35^{\circ} \mathrm{C}$ which allowed for repair and resuscitation of damaged cells, after which the temperature was increased to $44.5^{\circ} \mathrm{C}$ for 22 hours to attain the necessary selectivity. Investigators also tested a method that used bovine liver catalase (Sigma Chemical Co., St. Louis, Mo.) or sodium pyruvate (Sigma) with $\mathrm{mFC}$ agar and a 24 -hour incubation at $44.5^{\circ} \mathrm{C}$ (Calabrese and Bissonnette, 1990). The developers of this method hypothesized that chlorine reduces activity of the enzyme catalase, causing the accumulation of toxic hydrogen peroxide. Pyruvate is a hydrogen peroxidedegrading compound. Another modification of $\mathrm{mFC}$ agar that was tested in this investigation was the elimination of rosolic acid (Difco) from the media with or without a resuscitation time at a lower temperature.

\footnotetext{
${ }^{1}$ Use of trade, brand, or firm names in this report is for identification purposes only and does not constitute endorsement by the U.S. Geological Survey.
}

Presswood and Strong (1978) showed that the elimination of rosolic acid from $\mathrm{mFC}$ agar resulted in improved recovery of chlorine-injured cells. Other investigators found that a 5-hour (Green and others, 1977) or 4-hour (LeChevallier and others, 1984) resuscitation at $35^{\circ} \mathrm{C}$ followed by an 18 - or 19-hour incubation at $44.5^{\circ} \mathrm{C}$ yielded the highest recovery of fecal coliforms from chlorinated effluents, without excessive background growth. Finally, the investigators tested a new enhanced-recovery medium, mT7 agar, developed by LeChevallier and others (1983) for recovery of chlorine-injured fecal coliforms. This agar contains growth substances, a surfactant (Tergitol-7), and penicillin G. After an 8-hour resuscitation at $35^{\circ} \mathrm{C}$, and a 12 -hour incubation at $44.5^{\circ} \mathrm{C}$, all yellow colonies on $\mathrm{mT} 7$ agar were counted as fecal coliforms.

Treatment of cell suspensions. Secondarytreated wastewater (hereinafter called wastewater) or CSO effluent was collected, kept on ice, and transported to the laboratory for treatment. The wastewater or CSO effluent (hereinafter called cell suspension) was split into two containers. In one container, one part cell suspension was diluted with two parts autoclaved receiving water and refrigerated (the "unchlorinated" sample). A chlorine stock solution, prepared daily from dilution of commercially purchased bleach (5.25 percent sodium hypochlorite), was added to the other cell suspension to achieve a total-residual chlorine concentration of 0.3 to $0.5 \mathrm{mg} / \mathrm{L}$. Total residual chlorine was measured by use of a residual chlorine electrode. The chlorinated cell suspension was mixed intermittently for contact times from 8 to 30 minutes (during testing of enhanced-recovery methods before field studies) or 25 minutes (during field studies). The chlorinated cell suspension was then split in half. One-half of the cell suspension was diluted with two parts sterile receiving water to one part cell suspension; this is the "chlorinated" sample. The other half of the cell suspension was dechlorinated by adding 0.1 $\mathrm{mL}$ of a sterile, 10 percent sodium thiosulfate solution per $100 \mathrm{~mL}$ cell suspension (American Public Health Association, 1992, Section $9060 \mathrm{~A})$ and then diluted as above; this is the "dechlorinated" sample. After treatment, the cell suspensions were filtered and plated on various media formulations by use of standard and enhanced-recovery methods. 


\section{Field Studies}

Injury, survival, and regrowth were investigated by use of replicate incubation chambers submerged in the water column of the receiving stream or lake. Incubation chambers were constructed of autoclavablepolycarbonate cylinders with 142-mm diameter, 0.45 $\mu \mathrm{m}$-pore-size sterile membrane filters placed at the two open ends (fig. 1). Similar incubation chambers and their use are described by Bissonnette and others (1975), McFeters and Stuart (1972), Hazen and Esch (1983), and Carillo and others (1985). The chambers were laboratory and field tested for another USGS project (D.N. Myers, U.S. Geological Survey, oral comm., 1994). The membranes were kept in place by securing screened endplates with stainless steel hardware. Outer endplates made of polycarbonate were used during transport or filling of the chambers and were removed while chambers were submerged in river or lake water. Each chamber has a capacity of approximately $600 \mathrm{~mL}$. The incubation chambers retain bacteria while maintaining diffusion of water and nutrients, and they do not restrict the transmission of ultraviolet light.

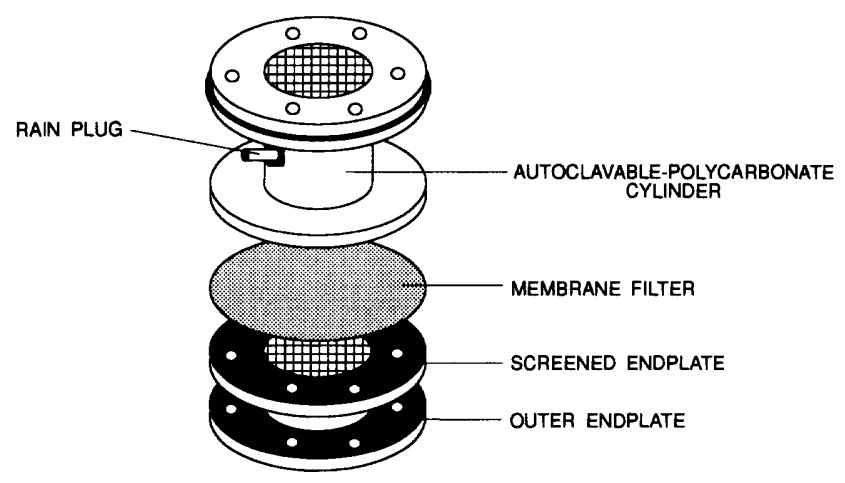

Figure 1. Incubation chamber used in field studies.

Site selection and sampling frequency. Field studies were done during recreational seasons (MayOctober) in 1994-95. The field studies were done by use of chambers containing cell suspensions from three collection locations: (1) a CSO that discharges untreated sewage combined with storm water into Mill Creek, Garfield Heights, Ohio, (2) the Cleveland Southerly Wastewater Treatment Plant that discharges tertiary-treated effluent into the Cuyahoga River, and (3) the Cleveland Easterly Wastewater Treatment plant that discharges secondary-treated effluent into Lake
Erie (fig. 2). The Cleveland Easterly and Southerly plants receive the same proportions of domestic and industrial inputs in their influent waste streams; however, because the Easterly plant pumps activated sludge to Southerly for treatment, concentrations of metals and other constituents may be higher in the activated sludge process at Southerly than at Easterly.

Because bacteria survival has been shown to be affected by temperature (Flint, 1987), field studies were done at some locations when water temperatures were between (1) $10^{\circ} \mathrm{C}$ and $19.5^{\circ} \mathrm{C}$ and (2) $20^{\circ} \mathrm{C}$ and $30^{\circ} \mathrm{C}$. To determine the effect of receiving-water quality on injury, survival, and regrowth, some river studies were done at two field sites simultaneously. Seven field studies were done for this investigation, each one lasting approximately 4 days.

Field study sites consisted of three sites in the Cuyahoga River and a site in Lake Erie (fig. 2). At the Cuyahoga River at Peninsula, Ohio (Peninsula), chambers were placed in a pooled reach of the river within the Cuyahoga Valley National Recreation Area, downstream from the city of Akron. The water quality at Peninsula is affected by CSO's and treated wastewater upstream, and to a lesser extent, by industrial sources. The Cuyahoga River at Independence (Independence) is 16.5 river miles downstream from Peninsula in a residential and light industrial area. The Cuyahoga River at West Third Street, Cleveland, Ohio (West Third) is in a highly industrialized section of the Cuyahoga River in the Cleveland Ship Channel. At this site, water temperatures vary the least of all the field study sites and are elevated because of thermal effluents from industrial processes. The Lake Erie site is on a breakwall on the property of the Westerly Wastewater Treatment Plant, less than a mile from a bathing beach at Edgewater Park. All sites are in areas that support recreational uses such as boating and canoeing.

Measurement of fecal-indicator injury, survival, and regrowth. Fecal-indicator injury, survival, and regrowth were measured in cell suspensions of wastewater or CSO effluent. Wastewater-effluent samples were collected at both treatment plants from a final clarifier before chlorination. CSO effluent was collected by use of an automatic sampler having the intake and flow-triggering sensor in the CSO pipe. The sampler was set to collect the first flush of CSO effluent into a sterile 10-L sample bottle. A technician checked the sampler after a heavy rain, and if sufficient water was collected, removed the CSO effluent. All cell suspensions were kept at $4^{\circ} \mathrm{C}$ during transport 


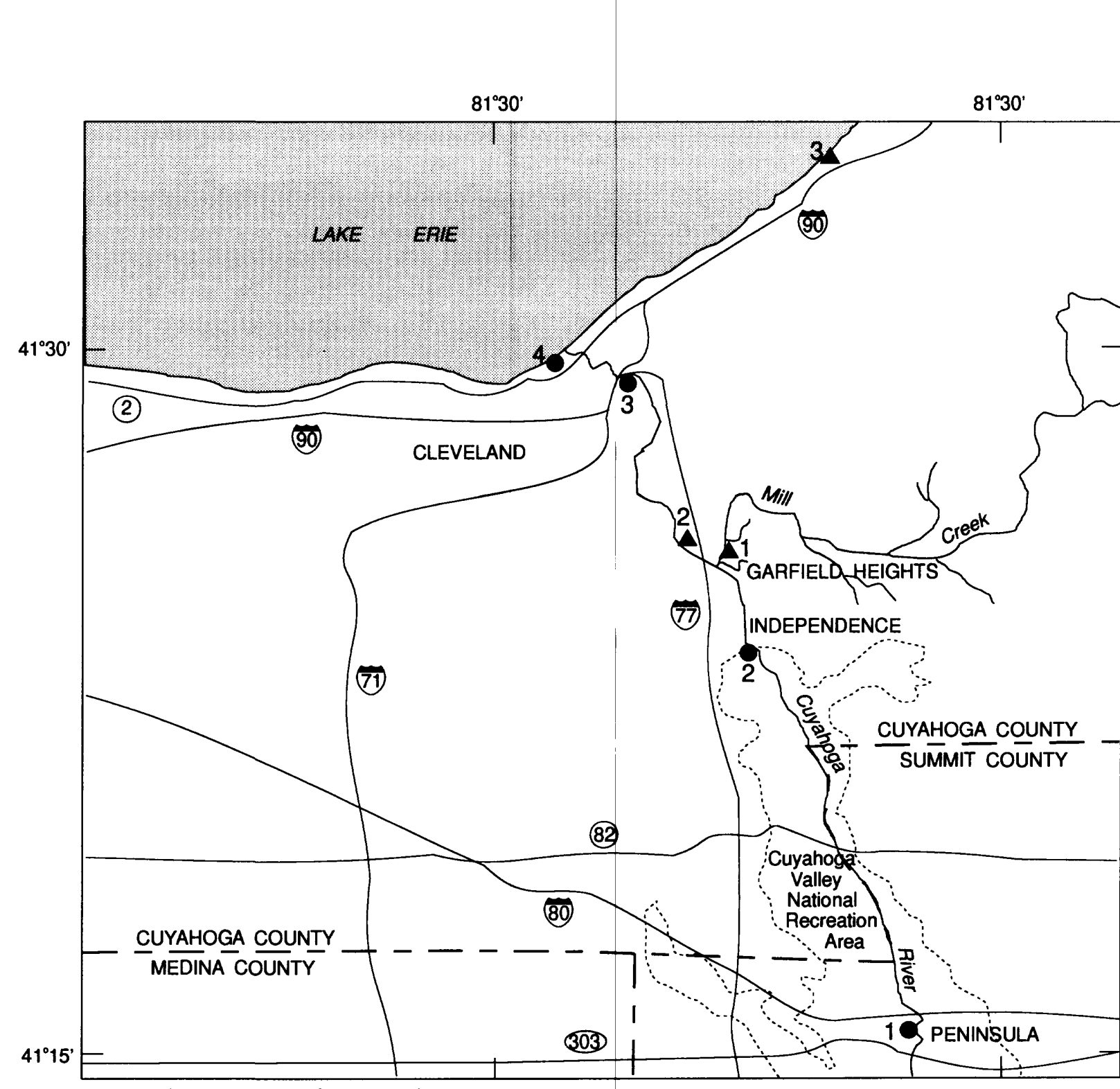

Base modified from U.S. Geological Survey Cleveland, 1:250,000, 1956, revised 1972

\section{EXPLANATION}
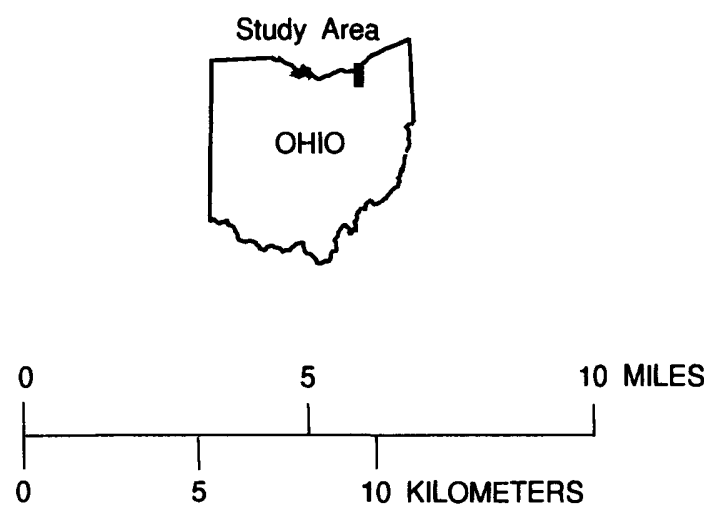

- FIELD STUDY SITES

1 Cuyahoga River at Peninsula

2 Cuyahoga River at Independence

3 Cuyahoga River at West Third Street

4 Lake Erie at Cleveland

- COllection locations

1 Combined-sewer overflow effluent

2 Cleveland Southerly Wastewater Treatment Plant

3 Cleveland Easterly Wastewater Treatment Plant

Figure 2. Collection locations and field study sites. 
and storage. At a local laboratory (the Fishcreek Wastewater Treatment Plant in Stow, Ohio, or the Cuyahoga County Sanitary Engineers laboratory in Valley View, Ohio), the cell suspensions were treated and analyzed by USGS employees within 2 hours for wastewater effluent or 24 hours for CSO effluent.

Cell suspensions were treated three ways: unchlorinated, chlorinated, or dechlorinated. (Details of the treatment scheme were described previously.) An initial sample of each type of cell suspension was plated in triplicate for fecal coliforms by use of standard selective (standard) and enhanced-recovery methods. Six to eight replicate chambers were filled with each type of treated cell suspension, kept on ice, and transported to the site within 4 hours after treatment. At the Peninsula and West Third sites, chambers were suspended in crates in the water column, approximately 18 in. below the water surface. The crates were held in place by tethers tied to cement blocks. At the Lake Erie and Independence sites, chambers were suspended in a plastic swimming pool through which the lake or river water was constantly circulated by a progressive-cavity pump. The pool ( $8 \mathrm{ft}$ diameter and $4 \mathrm{ft}$ deep) was lined with a green plastic sheet to mimic the color and reflectiveness of the receiving water.

One type of each replicate chamber (unchlorinated, chlorinated, and dechlorinated) was retrieved at approximately $8,16,24,36,48$, and 72 hours. The retrieved chambers were then placed on ice and transported to the laboratory for microbiological analysis within 6 hours after removal from the stream or lake. In the laboratory, the entire chamber contents were emptied into sterile bottles, and fecal-coliform concentrations were determined by use of standard and enhanced-recovery methods in the same manner as the initial samples.

Analysis of receiving-water quality. Field measurements of dissolved-oxygen concentration, specific conductance, temperature, and $\mathrm{pH}$ were measured in the lake, river, and pool at the time of chamber removal by use of a four-parameter water-quality meter. The meter was calibrated according to manufacturer's guidelines each time it was used. At sites where chambers were incubated in the river, field measurements were made near the chambers about 18 in. below the water surface. At sites where chambers were placed in the pool, field measurements were made at the pump intake and at the center and outflow of the pool. The average of the three pool measurements was used in this report. Field measurements were also made in the river or lake about $3 \mathrm{ft}$ from the pump intake line.

Water samples for chemical analyses were collected daily in river and lake field studies according to USGS sampling methods (Ward and Harr, 1990). At river sites, a single-vertical sample was collected near the chambers by use of the US-DH81 depth-integrating sampler. At lake sites, a single weighted-bottle sampler was submerged $2 \mathrm{ft}$ below the lake surface about $3 \mathrm{ft}$ off the breakwall. In field studies in which chambers were placed in the pool, three vertically integrated subsamples from the pool were collected into a single bottle or composited in a churn splitter and then poured into a sample bottle. Water-quality samples for determination of nutrients and total nonfilterable residue were collected into clean polypropylene sample bottles, kept in ice chests, and transported to the NEORSD laboratory in Cuyahoga Heights, Ohio, within 24 hours after sample collection. Samples for determination of total-organic carbon concentration were collected into $125-\mathrm{mL}$ amber glass bottles, kept in ice chests or refrigerated, and sent to the USGS National Water Quality Laboratory in Arvada, Colo. within 3 days after sample collection.

All determinations of inorganic constituents were made by use of methods recommended by the USEPA for analysis of water and wastes (U.S. Environmental Protection Agency, 1979a). Samples were analyzed for total nonfilterable residue $\left(103-105^{\circ} \mathrm{C}\right)$ (EPA 160.3), nitrate- plus nitrite-nitrogen (EPA 350.4), ammonia as nitrogen (EPA 350.1), total kjeldahl nitrogen (EPA 351.2), and total phosphorus (EPA 365.2). Samples were analyzed for total organic carbon by use of the method described by Wershaw and others (1987).

\section{Statistical Methods}

Analysis of variance (ANOVA) was used throughout this investigation to compare more than two groups of data. Groups of data were defined by one or more factors, a factor being a variable that influences the magnitude of the data. ANOVA is based on the assumption that all groups of data are normally distributed and have equal variances (Helsel and Hirsch, 1992). Therefore, the groups were tested for normality by use of the probability plot correlation coefficient (PPCC) test (Looney and Gutledge, 1985) and for equal variances by use of Hartley's test (Ott, 1993). If any of the groups did not pass either test at 
$\alpha=0.05$, the nonparametric rank transformation test was used (Conover and Iman, 1981) instead of the parametric ANOVA. The $\alpha$-value, or significance level, is the probability of rejecting the null hypothesis when it is in fact true. In the rank transformation test, all data are combined and ranked from lowest to highest value, and an ANOVA is computed on the ranks.

The parametric and nonparametric ANOVA determines whether the mean or mean rank, respectively, differs between groups. The null hypothesis is that each group mean or mean rank is the same; the alternative is that at least one is different. In a two-way ANOVA, the factor effect explains whether or not deviations from the overall mean or mean rank are due to one or more factors. In a two-way ANOVA, an interaction effect is present if the effects of each factor on deviations from the overall mean or mean rank are not independent from each other.

Tukey's multiple comparison test was used to compare pairs of means or mean ranks (Helsel and Hirsch, 1992). This test computes a least significant range (LSR), the distance between any two means or mean ranks that must be exceeded in order for the two groups to be considered statistically different at $\alpha=$ 0.05 . The two groups can be considered different if the difference between the two group means or mean ranks is greater than the LSR.

Evaluation of enhanced-recovery methods. Because enhanced-recovery methods have not been widely used, several of these methods were evaluated before field studies to determine recovery enhancement of chlorine-injured fecal coliforms and suitability for use in large-scale field studies. Recovery was measured by determining concentrations of fecal coliforms in unchlorinated, chlorinated, and dechlorinated cell suspensions. In initial experiments, qualitative examinations of the fecal-coliform concentrations and enhanced-recovery protocols were done. The enhanced-recovery methods that were relatively easy to use and had higher recoveries of chlorine-injured cells over the standard method were tested further and evaluated statistically.

The statistical analysis of recoveries was done by use of two-way ANOVA and Tukey's multiple comparison test. The effects of method type and treatment type (unchlorinated, chlorinated, and dechlorinated) on recovery of fecal coliforms were determined. Use of a suitable enhanced-recovery method should result in higher concentrations of chlorine-injured bacteria compared with the standard method. At the same time, the difference between the standard and enhanced-recovery methods in recovery of bacteria in unchlorinated samples should be statistically insignificant.

Analysis of data collected during field studies. Percent injury was calculated for each replicate plating at each timestep. The standard method supports the growth of healthy organisms, whereas the enhanced-recovery method supports the growth of both healthy and injured organisms. Therefore, the percent injury at each timestep for each replicate plating was computed as follows (Bissonnette and others, 1975):

$$
P i=\left(1-\frac{S S M}{E R M}\right) \times 100
$$

where $P i$ is percent injury,

$S S M$ is concentration of fecal coliforms by use of standard method, and

$E R M$ is concentration of fecal coliforms by use of enhanced-recovery method.

The percent survival at each timestep for each replicate plating was computed as follows:

$$
P s=\left(\frac{E R M_{t}}{E R M u n_{0}}\right) \times 100
$$

where $P s$ is percent survival, $E R M_{t}$ is concentration of fecal coliforms at time " $t$ " by use of enhanced-recovery method, and ERMun $_{0}$ is mean concentration of fecal coliforms at initial time in unchlorinated sample by use of enhanced-recovery method.

Regrowth, or cell division and multiplication, was not measured directly but was inferred from examining changes in standard- and enhanced-recovery-method concentrations. In this investigation, regrowth refers to the ability of the bacterial cells to be resuscitated on enhanced-recovery medium and does not refer to the ability of the bacterial cells to regrow in receiving waters.

The statistical relation between standard- and enhanced-recovery-method concentrations of fecal coliforms was determined by linear regression analysis of base 10 logarithmically transformed data. Regression diagnostics were done to test five assumptions that must be met to provide the best, unbiased estimator of concentrations obtained by use of the enhanced-recovery method from concentrations obtained by use of the standard method: (1) $y$ (the dependent variable) is linearly related to $x$ (the 
independent variable), (2) the data used to fit the model are representative of the data of interest, (3) the variance of the regression residuals is constant (it does not depend on the independent variable or other factors), (4) the regression residuals are independent, and (5) regression residuals are normally distributed (Helsel and Hirsch, 1992, p. 224-225).

Log transformations of fecal-coliform concentrations resulted in a linear fit of the data and satisfied the first assumption. The second assumption was met because the samples were analyzed by the best methods available and cell suspensions were incubated in waters used for recreation. To evaluate assumptions 3 and 4 , the investigators plotted regression residuals by predicted values, elapsed time, and treatment to determine whether residuals were similar in range and evenly distributed above and below the zero line throughout the entire range of observations. To evaluate assumption 5 , the regression residuals were tested to determine whether they were normally distributed by use of the Probability Plot Correlation Coefficient test (PPCC) (Looney and Gutledge, 1985).

Analysis of covariance (ANCOVA) was used to determine if the regression model would be more accurately described by grouping the data by some categorical variable. ANCOVA incorporates the use of dummy variables, blending regression and analysis of variance into one analysis (Helsel and Hirsch, 1992). The results of the ANCOVA determined the best way to group the data; data sets having statistically different slopes or $y$-intercepts would not be best represented in a model of the entire data set.

To determine whether concentrations obtained by standard and enhanced-recovery methods were comparable as indicators of recreational-water quality in the seven field studies, the percentage of samples by treatment type meeting and exceeding Ohio's bathingwater, primary-contact, and secondary-contact singlesample standards were determined.

\section{Quality Assurance and Quality Control}

Quality-assurance and quality-control (QA/QC) practices were done for all phases of data collection and analysis in the field and laboratory, and during data validation and assessment.

Field and laboratory quality assurance/quality control. Field and laboratory protocols were written and distributed to ensure that procedures were done according to established methods and in a uniform manner by all personnel.

In the field, 5 percent of the water-quality samples collected were field blanks — samples of inorganic-free water passed through the sampling equipment at the field site to detect contamination in sample collection, handling, and shipping. The integrity of the incubation chambers was tested by filling 5 percent of the chambers with sterile river or buffer water and plating the contents of the chambers after a 48-hour incubation in the stream or pool. Reproducibility of chamber bacterial contents was determined by enumerating the contents of at least 10 percent of the chambers placed in receiving waters as timestep replicates. In pool studies, field measurements were made hourly, when possible, to ensure that pool measurements were similar to river or lake measurements. If a large deviation in a field measurement was found, the pump rate on the pool was adjusted. In addition, concurrent water samples for chemical analyses were collected from the pool and the lake or river to compare the concentrations of chemical constituents.

In the laboratory, equipment and supplies were regularly checked to ensure proper performance. The incubators were monitored throughout experiments and field studies to ensure temperatures were $35^{\circ} \mathrm{C} \pm$ $0.5^{\circ} \mathrm{C}$ or $44.5^{\circ} \mathrm{C} \pm 0.2^{\circ} \mathrm{C}$. The sterility of the buffer water and media were tested by use of blanks - aliquots of buffer water filtered before each sample and after each third sample. Performance of media and buffer water was tested by use of lyophilized qualitycontrol bacterial isolates of $E$. coli obtained from the U.S. Environmental Protection Agency Quality Assurance Laboratory in Cincinnati, Ohio. Sample results were rejected if incubator temperatures were outside acceptable ranges or quality-control testing showed contaminated blanks or values outside the acceptable range for recovery of $E$. coli. The autoclave operating temperature and pressure were checked for each run and heat-indicating tape was used to identify supplies that had been sterilized. Other good laboratory practices_cleanliness, safety practices, procedures for media preparation, specifications for reagent water quality-were adopted by USGS employees as set forth by American Public Health Association (1992) and Britton and Greeson (1989).

The NEORSD laboratory's QA/QC program includes daily duplicates, standards, spiked samples, and check standards. Analysts update precision and accuracy control charts daily. The NEORSD 
laboratory participated each year in the USGS Standard Reference Water Sample Program and the USEPA Performance Evaluation Program. In addition, at least 15 percent of the samples in the field studies were QA/QC samples submitted to the NEORSD laboratory. These included duplicate samples, reference samples, and split samples analyzed by NEORSD and the USGS National Water Quality Laboratory.

\section{Management and validation of fecal-indica-}

tor data. Bacteriological data were checked for errors and monitored for precision. All data obtained from plates having less than 8 colonies were deleted from the data set. Data from colony counts outside the ideal range of 20-60 colonies per plate were flagged as "nonideal count," and data from colony counts with high numbers of nontarget colony types were flagged as "high background." Precision control limits were established on the replicate analyses done during the first field study according to the Shewhart method (described in detail in U.S. Environmental Protection Agency, 1979b). The differences between three log transformed replicate observations were calculated, and the average difference was determined. The Upper Warning Limit (UWL), corresponding to the 95-percent confidence level, was calculated. In the first field study, and in later studies, replicate samples with differences greater than the UWL were examined. An observation was omitted from the data set if (1) the observation differed from the other two replicate observations by more than the UWL, or (2) the observation differed from at least one other replicate observation by more than the UWL and was either (a) flagged as "nonideal" or "high background" or (b) looked suspicious for any other reason. Plots of elapsed time by bacteria concentrations were used to ensure the data were representative in a historical sense, and deviant observations were examined for error. Before statistical analysis, all data not meeting quality-control requirements were deleted.

Percent verifications were determined for colonies isolated from cell suspensions during evaluation of enhanced-recovery methods and during field studies. A verified membrane-filter test establishes the validity of colony differentiation and is recommended when new procedures are being used (U.S. Environmental Protection Agency, 1978). Tests were run to compare the number of false positive fecal coliforms from the standard method to the number of false positives from the enhanced-recovery method.
For data collected during field studies, percent verifications were determined on colonies from plates of standard and enhanced-recovery methods. To obtain a good cross-section of colonies isolated during each field study, plates were selected from initial and 24-hour samples for each treatment type (unchlorinated, chlorinated, and dechlorinated). Eight to twelve well-isolated colonies were randomly selected and verified from each plate. The colonies were transferred to lauryl tryptose broth (Difco Laboratories) and tryptic soy broth (Difco Laboratories). Tryptic soy broth was used to resuscitate any injured organisms unable to grow in lauryl tryptose broth and to detect nonviable cultures. Colonies failing to grow in either lauryl tryptose broth or tryptic soy broth within 48 hours were considered nonviable and were not included in the final count. Lauryl tryptose broth tubes having no growth after a 24 -hour incubation at $35^{\circ} \mathrm{C}$ were reinoculated from growth-positive tryptic soy broth test tubes. Gas-positive lauryl tryptose broth test tubes were transferred to EC broth (Difco Laboratories) and incubated at $44.5^{\circ} \mathrm{C}$. Cultures that produced gas in EC broth after a 24-hour incubation were interpreted as verified fecal coliforms (U.S. Environmental Protection Agency, 1978). A percent verification for each method was determined as follows:

$$
\left(\begin{array}{c}
\text { Percent verification }= \\
\left.\frac{\text { Number of positive verifications }}{\text { Number of verification tests performed }}\right) \times 100
\end{array}\right.
$$

Contingency-table analysis was done (Helsel and Hirsch, 1992) to measure the association between method and number of positive verifications. If method type was found to affect the number of positive verifications, then method-specific percent verifications would have to be applied to the data set.

\section{Evaluation of Enhanced-Recovery Methods for Use in Field Studies}

Several enhanced-recovery methods for fecal coliforms were evaluated qualitatively to determine whether they were suitable for use in field studies. The two-layer overlay method (Rose and others, 1975) was cumbersome and resulted in increased recoveries of chlorine-injured fecal coliforms that were only 1.4 times that of the standard method (mFC). The addition of catalase to $\mathrm{mFC}$ (Calabrese and Bissonnette, 1990) was found to be too time-consuming for a large-scale 
project, and the addition of pyruvate, although simple, resulted in increased recoveries of fecal coliforms in chlorinated wastewater of only 1.27 to 1.45 times that of $\mathrm{mFC}$. Two other modifications of $\mathrm{mFC}-\mathrm{mFC}$ with a 4-hour resuscitation at $35^{\circ} \mathrm{C} \mathrm{(mFC4)} \mathrm{and} \mathrm{mFC}$ without rosolic acid and a 4 -hour resuscitation at $35^{\circ} \mathrm{C}$ (mFC-R4)-increased recoveries of fecal coliforms in chlorinated wastewater effluent 3.3 to 14 times that of $\mathrm{mFC}$. At the same time, increased recoveries of fecal coliforms in unchlorinated wastewater were considerably lower-only 1.4 to 1.8 times that of mFC. This is expected from a suitable enhanced-recovery method, as described previously. Recoveries from the $\mathrm{mT} 7$ agar enhanced-recovery method (mT7) (LeChevallier and others, 1983) were 1.9 to 11.8 times those obtained from $\mathrm{mFC}$ in chlorinated samples; in unchlorinated samples, recovery ratios were 1.5 to 3.5 times those obtained from $\mathrm{mFC}$. Therefore, three enhancedrecovery methods tested ( $\mathrm{mFC} 4, \mathrm{mFC}-\mathrm{R} 4$, and $\mathrm{mT} 7$ ) were suitable for recovery of chlorine-injured fecal coliforms from wastewater effluent in field studies.

Recoveries of fecal coliforms by use of these three enhanced-recovery methods (mT7, mFC4, and mFC-R4) were evaluated statistically. Concentrations of fecal coliforms obtained by use of the enhancedrecovery methods and $\mathrm{mFC}$ in unchlorinated, chlorinated, and dechlorinated wastewater effluent on different days were combined and analyzed by use of twoway nonparametric ANOVA. The two factors (treatment and media type) were found to significantly affect concentrations of fecal coliforms $(p<0.0001)$; an interaction effect also was found between the two factors $(p=0.0192)$. Tukey's multiple comparison test was done to compare the differences in mean ranks of con- centrations obtained by use of each enhanced-recovery method to the mean rank of concentrations obtained by use of the standard method (table 1). For unchlorinated wastewater, the differences in mean ranks between $\mathrm{mT} 7, \mathrm{mFC}-\mathrm{R} 4$, and $\mathrm{mFC} 4$ as compared to the mean rank of $\mathrm{mFC}$ ranged from 5.5 to 9.8 ; these differences were statistically insignificant. For chlorinated wastewater, only the differences in mean ranks between $\mathrm{mFC}-\mathrm{R} 4$ and $\mathrm{mFC}$ (difference=25.6) were statistically significant. However, for dechlorinated wastewater, the mean ranks of all three enhancedrecovery methods were statistically different than the mean rank of $\mathrm{mFC}$, the differences ranging from 27.6 to 43.3 .

LeChevallier and others (1984) found that the mT7 method increased recoveries of chlorine-injured fecal coliforms and provided higher percent verifications when the fecal coliforms were resuscitated at $37^{\circ} \mathrm{C}$ instead of $35^{\circ} \mathrm{C}$. Using the $37^{\circ} \mathrm{C}$ resuscitation temperature, LeChevallier and others ( 1984 ) found 83.2-percent verification of colonies from chlorinatedwastewater effluent. In this investigation, however, aluminum-block incubators could only be operated at $35^{\circ} \mathrm{C}$ and $44.5^{\circ} \mathrm{C}$. Using the $35^{\circ} \mathrm{C}$ temperature in this investigation, only 58 percent of colonies isolated from $\mathrm{mT} 7$ agar could be verified as fecal coliforms from chlorinated wastewater effluent. In addition, heavy background growth often made counting of fecal coliforms difficult and inaccurate, especially in samples from chambers that had been incubated in the receiving water for more than 24 hours. Therefore, although $\mathrm{mT} 7$ increased recovery of chlorine-injured organisms over $\mathrm{mFC}$, the resulting low percent

Table 1. Differences in mean rank of concentrations of fecal coliforms obtained by use of enhanced-recovery methods (mT7, $\mathrm{mFC}-\mathrm{R} 4$, and $\mathrm{mFC} 4$ ) and concentrations of fecal coliforms obtained by use of standard method ( $\mathrm{mFC}$ ) in unchlorinated, chlorinated, and dechlorinated wastewater effluent

[The difference in concentrations was determined by ranking the data, doing two-way analysis of variance on the ranks with treatment and method as factors, and comparing the mean ranks of the treatment groups by use of Tukey's multiple comparison test]

\begin{tabular}{|c|c|c|c|}
\hline Treatment & $\mathrm{mT} 7^{\mathrm{a}}$ & mFC-R4 ${ }^{b}$ & $\mathrm{mFC4}^{\mathrm{c}}$ \\
\hline Unchlorinated & 7.7 & 9.8 & 5.5 \\
\hline Chlorinated & 22.7 & $25.6^{\mathrm{d}}$ & 18.7 \\
\hline Dechlorinated & $27.6^{d}$ & $43.3^{d}$ & $33.2^{d}$ \\
\hline
\end{tabular}

${ }^{\mathrm{a}} \mathrm{M}$-Tergitol-7 media (mT7) with an 8 -hour incubation at $35 \mathrm{C}$ folfowed by 12 -hour incubation at $44.5^{\circ} \mathrm{C}$.

${ }^{b} \mathrm{M}$-fecal coliform media ( $\mathrm{mFC}$ ) without rosolic acid (mFC-R4) with 4-hour incubation at $35^{\circ} \mathrm{C}$ followed by 20 -hour incubation at $44.5^{\circ} \mathrm{C}$.

${ }^{\mathrm{c}} \mathrm{M}$-fecal coliform media $(\mathrm{mFC})$ with 4 -hour incubation at $35^{\circ} \mathrm{C}$ followed by 20 -hour incubation at $44.5^{\circ} \mathrm{C}$.

${ }^{\mathrm{d}} \mathrm{A}$ statistically significant difference exists between the mean ranks of concentrations of fecal coliforms by use of the enhanced-recovery methods as compared to the standard method at $\alpha=0.05$. 
verifications and high background growth limited its usefulness in field studies.

On the basis of statistical results of recovery enhancement and because of problems encountered with $\mathrm{mT} 7$ agar, mFC-R4 was selected as the best available method for increased recovery of chlorineinjured fecal coliforms; mFC-R4 was used as the enhanced-recovery method in all subsequent field studies.

\section{Effects of Receiving-Water Quality and Wastewater Treatment on Injury, Survival, and Regrowth of Fecal-Indicator Bacteria}

\section{Receiving-Water Quality}

Dates, sites, and durations of seven field studies done during the 1994-95 recreational seasons are listed in table 2. In two field studies, May and August 1994, investigators used wastewater effluent from the Easterly Wastewater Treatment Plant and incubated chambers at the Lake Erie field site. The June 1994 and August 1995 Cuyahoga River studies were done at two sites with wastewater effluent from the Southerly
Wastewater Treatment Plant; however, chamber loss and breakage from an increase in streamflow at the Peninsula site caused early termination of field studies at this site. A September 1995 Cuyahoga River field study was done at the Independence site in the incubation pool to investigate injury, regrowth, and survival at cooler temperatures without risking chamber loss. In May and June 1995, investigators used CSO effluent from Mill Creek and incubated chambers at the Independence site in the pool.

Field measurements in the pool were similar to and showed the same fluctuations as field measurements in the lake or river (unpublished data on file at USGS, Columbus, Ohio). In all pool field studies, concentrations of nitrate- plus nitrite-nitrogen, ammonianitrogen, and total organic carbon in the incubation pool were similar to those concentrations found in the lake or river. However, concentrations of total nonfilterable residue and total phosphorus in the pool were often 2-3 times lower than those in the Cuyahoga River during the May and June 1995 CSO studies, especially when concentrations of total nonfilterable residue in the river were greater than $100 \mathrm{mg} / \mathrm{L}$ (unpublished data on file at USGS, Columbus, Ohio). These differences were likely due to the inability of

Table 2. Dates, sites, and durations of field studies done with wastewater or combined-sewer-overflow effluent from three collection locations, 1994-1995

\begin{tabular}{|c|c|c|}
\hline Date & Field site & $\begin{array}{c}\text { Duration of study } \\
\text { (hours) }\end{array}$ \\
\hline \multicolumn{3}{|c|}{ Easterly Wastewater Treatment Plant effluent, Cleveland, Ohio } \\
\hline May 1994 & Lake Erie at Westerly Wastewater Treatment Plant, Cleveland, Ohio & 69.0 \\
\hline August 1994 & Lake Erie at Westerly Wastewater Treatment Plant, Cleveland, Ohio & 69.0 \\
\hline \multicolumn{3}{|c|}{ Southerly Wastewater Treatment Plant effluent, Cuyahoga Heights, Ohio } \\
\hline \multirow[t]{2}{*}{ June 1994} & Cuyahoga River at Peninsula, Ohio & 36.5 \\
\hline & Cuyahoga River at West Third Street, Cleveland, Ohio & 70.0 \\
\hline \multirow[t]{2}{*}{ August 1995} & Cuyahoga River at Peninsula, Ohio & 48.0 \\
\hline & Cuyahoga River at West Third Street Bridge, Cleveland, Ohio & 46.5 \\
\hline September 1995 & Cuyahoga River at Independence, Ohio & 66.0 \\
\hline \multicolumn{3}{|c|}{ Combined-sewer-overflow effluent, Mill Creek, Garfield Heights, Ohio } \\
\hline May 1995 & Cuyahoga River at Independence, Ohio & 62.0 \\
\hline June 1995 & Cuyahoga River at Independence, Ohio & 67.5 \\
\hline
\end{tabular}


the pump to circulate water fast enough in the pool to keep up with increasing total nonfilterable residue concentrations in the river.

Mean values of water-quality field measurements and constituent concentrations for each study are reported as pool values (Lake Erie and Independence sites) or river values (Peninsula and West Third sites) in table 3. At the Lake Erie field site, the largest differences in water quality between May and August 1994 field studies were temperatures and dissolvedoxygen concentrations. In May, the mean temperature was $12.8^{\circ} \mathrm{C}$ compared to $22.6^{\circ} \mathrm{C}$ in August. Because solubility of oxygen is affected by temperature, mean dissolved-oxygen concentration was higher in May $(8.5 \mathrm{mg} / \mathrm{L})$ than in August $(5.8 \mathrm{mg} / \mathrm{L})$.

The major difference in water quality in June 1994 and August 1995 Cuyahoga River field studies was mean dissolved-oxygen concentration between sites (table 3). At Peninsula, mean dissolved-oxygen concentrations were 7.3 and $7.7 \mathrm{mg} / \mathrm{L}$, whereas at West Third concentrations were 5.2 and $4.3 \mathrm{mg} / \mathrm{L}$. Less apparent were differences in temperature between field studies or sites. Large differences in mean concentrations of water-quality constituents were not apparent between field studies or sites in June 1994 and August 1995 field studies. In

September 1995 at Independence, the mean water temperature was lower and mean dissolved-oxygen concentration was higher than those at Peninsula and West Third in June 1994 and August 1995.

The major water-quality differences between the May 1995 and June 1995 CSO field studies at the Cuyahoga River at Independence were temperature and dissolved-oxygen concentrations (table 3). In May, the mean water temperature and dissolved-oxygen concentration were $15.6^{\circ} \mathrm{C}$ and $8.6 \mathrm{mg} / \mathrm{L}$, whereas in June they were $23.1^{\circ} \mathrm{C}$ and $6.6 \mathrm{mg} / \mathrm{L}$. In addition, the mean concentration of total nonfilterable residue was higher in samples collected in June $(150 \mathrm{mg} / \mathrm{L})$ than in May $(50 \mathrm{mg} / \mathrm{L})$.

\section{Concentrations of Fecal-Indicator Bacteria}

Percent verifications were determined on colonies isolated during each field study except for September 1995 (table 4). Generally, percent verifications were higher for colonies isolated from standardmethod plates than colonies isolated from enhancedrecovery plates. Results of contingency table tests, however, showed that differences of percent verifica- tions between methods were not statistically significant $(p>0.05$ ) (unpublished data on file at USGS, Columbus, Ohio). Therefore, percent verifications were not applied to the data sets.

\section{Concentrations of fecal coliforms during}

Lake Erie wastewater-effluent field studies. Mean fecal-coliform concentrations in wastewater effluent from the Easterly Wastewater Treatment Plant during May and August 1994 field studies at Lake Erie are shown in figure 3. In unchlorinated (fig. 3A), chlorinated (fig. 3B), and dechlorinated (fig. 3C) wastewater effluent, concentrations of fecal coliforms determined by use of the enhanced-recovery method were 1.1 to 46 times greater than those concentrations determined by use of the standard method.

Seasonal differences of fecal-coliform concentrations can be found between the May 1994 and August 1994 field studies. Fecal-coliform concentrations were higher in August 1994 than in May 1994 for all treatments. In addition, during the August 1994 field study, concentrations of fecal coliforms in unchlorinated and dechlorinated samples increased during about the first 13 and 10 hours, respectively; however, in May 1994, concentrations of fecal coliforms remained fairly constant over the sampling period for all treatments. As temperature rises, chemical and enzymatic reactions in the cell proceed at more rapid rates and cell growth becomes faster (Brock and Madigan, 1988). High water temperatures in August, therefore, led to higher replication and decay rates of healthy organisms in unchlorinated and dechlorinated samples. In May 1994, concentrations in all samples remained fairly constant because of to lower water temperatures and slower bacteria metabolic rates.

In the chlorinated samples in August 1994 (fig. 3B), the pattern of fecal-coliform concentration increases and decreases was strikingly different from that found in unchlorinated and dechlorinated samples in August 1994 and all treatments in May 1994. In chlorinated samples in August 1994, fecal coliform concentrations on enhanced-recovery media dropped off sharply during the first 7 hours and remained low throughout the remainder of the study. A large proportion of the organisms recovered from initial chlorinated samples were, therefore, injured organisms. This suggests that a large proportion of the chlorine-injured cells in the chlorinated samples were unable to repair injuries and regrow on enhanced-recovery media during the August 1994 study. 


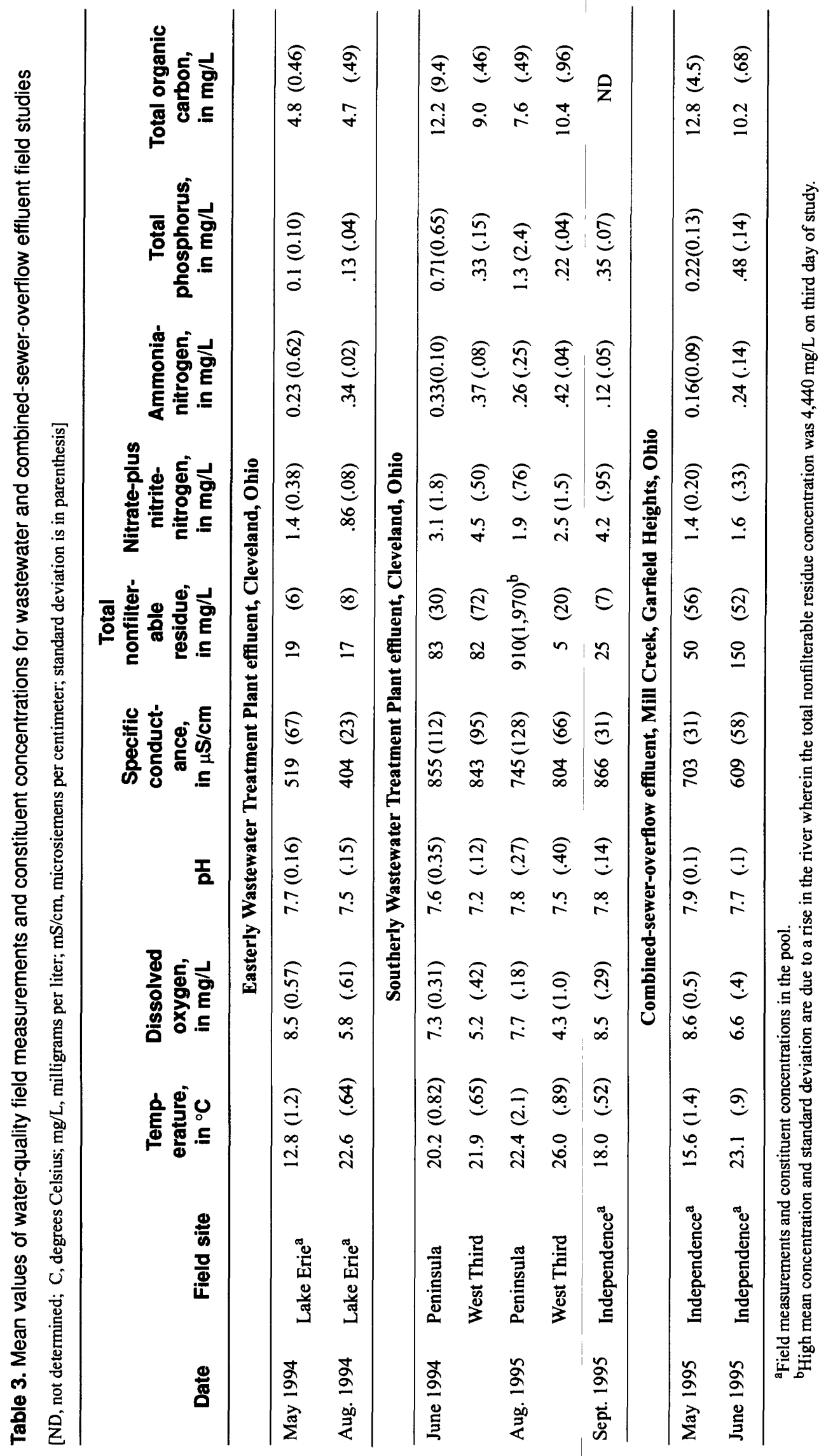


Table 4. Percent verifications of fecal coliforms in wastewater or combined-sewer-overflow effluent by use of standard or enhanced-recovery method

[Total number of colonies tested is shown in parentheses]

\begin{tabular}{lccc}
\hline & & \multicolumn{2}{c}{ Method } \\
\cline { 3 - 3 } \multicolumn{1}{c}{ Study date } & Easterly Wastewater Treatment Plant effluent, Cleveland, Ohio & \\
\hline May 1994 & $80.0(60)$ & $73.3(60)$ \\
Aug. 1994 & $74.6(59)$ & $72.4(58)$ \\
\hline & Southerly Wastewater Treatment Plant effluent, Cuyahoga Heights, Ohio \\
\hline June 1994 & $77.3(53)$ & $81.0(47)$ \\
Aug. 1995 & $75.0(60)$ & $60.0(60)$ \\
\hline & Combined-sewer-overflow effluent, Mill Creek, Garfield Heights, Ohio & \\
\hline May 1995 & $79.7(69)$ & $75.0(72)$ \\
June 1995 & $74.5(51)$ & $68.6(51)$ \\
\hline
\end{tabular}

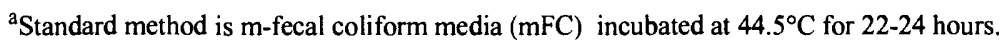

${ }^{b}$ Enhanced-recovery method is $\mathrm{mFC}$ agar without rosolic acid incubated at $35^{\circ} \mathrm{C}$ for 4 hours and $44.5^{\circ} \mathrm{C}$ for $18-20$ hours.

\section{Concentrations of fecal coliforms during} Cuyahoga River wastewater-effluent field studies.

Mean fecal-coliform concentrations in wastewater effluent from the Southerly Wastewater Treatment Plant during June 1994, August 1995, and September 1995 field studies are shown in figures 4 through 6. Chambers were incubated at the Cuyahoga River at Peninsula and West Third sites during June 1994 and August 1995 field studies and at the Cuyahoga River at Independence during the September 1995 field study. Concentrations in unchlorinated (fig. 4), chlorinated (fig. 5), and dechlorinated (fig. 6) wastewater effluent ranged from 10 to 20 times higher in June 1994 than in August 1995 or September 1995. In all studies, concentrations were highest in the unchlorinated samples, and concentrations in the dechlorinated samples were about an order of magnitude higher than those in the chlorinated samples. During all studies, concentrations of injured fecal coliforms varied considerably, indicating that the differences between enhanced-recovery and standard method concentrations were due not only to method differences, but also to population differences.

During the first half of the June 1994 study at Peninsula and West Third, fecal-coliform concentrations for all treatments generally increased slightly or remained the same. In the August 1995 unchlorinated samples at West Third and Peninsula, a pattern of decreasing fecal-coliform concentrations was found.
In the August 1995 chlorinated and dechlorinated samples, concentrations increased and decreased at West Third and remained about the same at Peninsula. Concentration increases in unchlorinated samples may be due to replication of healthy cells and (or) repair of nonchlorine-induced injures and regrowth on culture media. In dechlorinated and chlorinated samples, increases in concentrations may be due to these factors and one additional factor, the repair of chlorineinduced injuries and regrowth on culture media. A decrease in fecal-coliform concentrations in unchlorinated samples and a concomitant increase in fecalcoliform concentrations in dechlorinated and chlorinated samples at West Third indicates that the increases in chlorinated and dechlorinated samples were due in part to repair of chlorine-induced injuries and regrowth on culture media.

In September 1995, concentrations of fecal coliforms in unchlorinated samples fluctuated over time. The wide fluctuations may have been due to the fact that unchlorinated samples were plated only once during this field study (and not in triplicate as in other studies). Fecal-coliform concentrations in chlorinated and dechlorinated samples were very low throughout the September 1995 field study.

Concentrations of fecal coliforms during Cuyahoga River combined-sewer-overflow effluent field studies. Mean fecal-coliform concentrations in CSO effluent in May and June 1995 field studies at the 
A. UNCHLORINATED SAMPLES

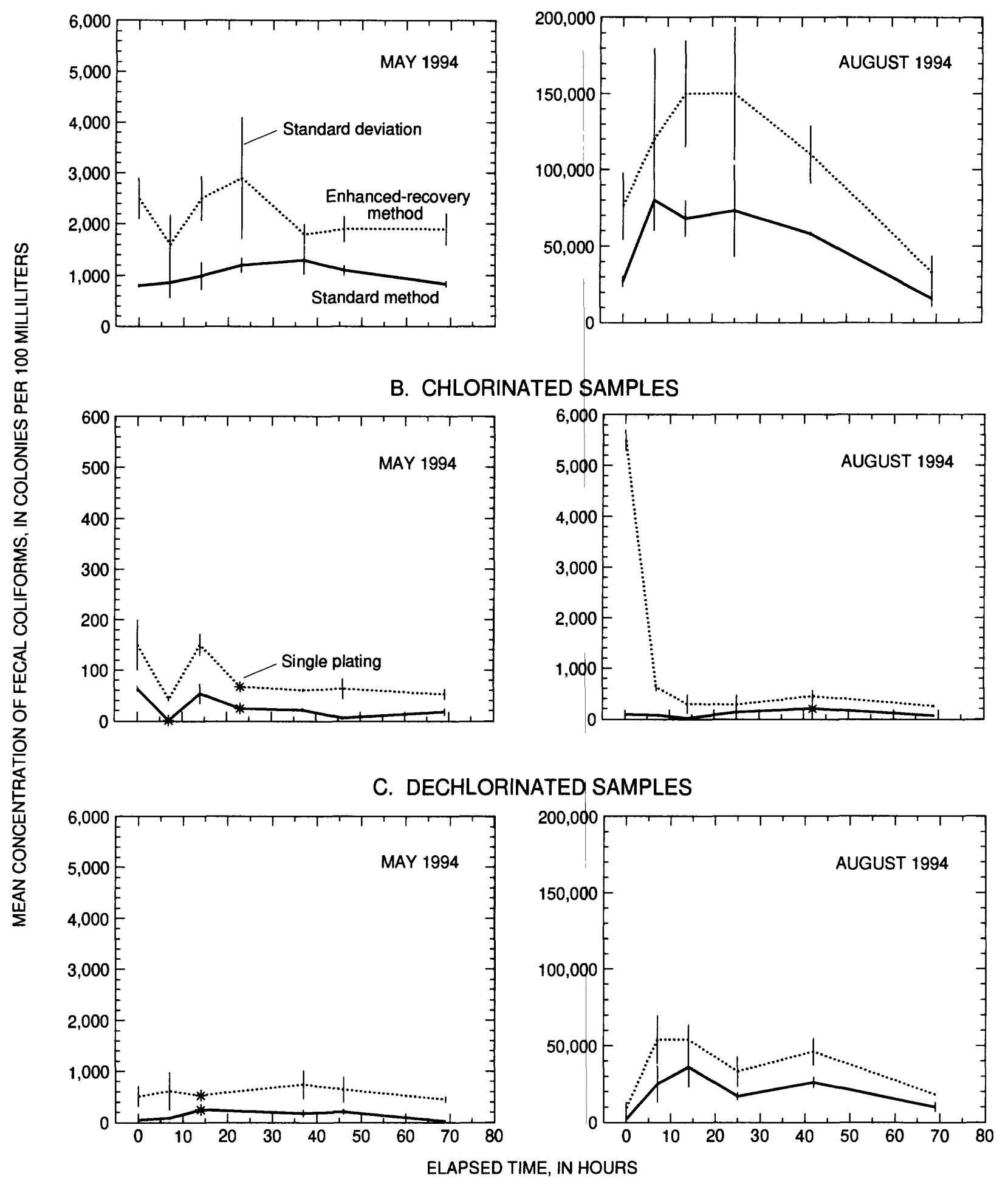

Figure 3. Mean fecal-coliform concentrations determined by use of standard and enhanced-recovery methods in wastewater effluent during May 1994 and August 1994 field studies at Lake Erie, Cleveland, Ohio in (A) unchlorinated, (B) chlorinated, and (C) dechlorinated samples. (Different scales were used for different magnitudes of data to enhance visual interpretations.) 

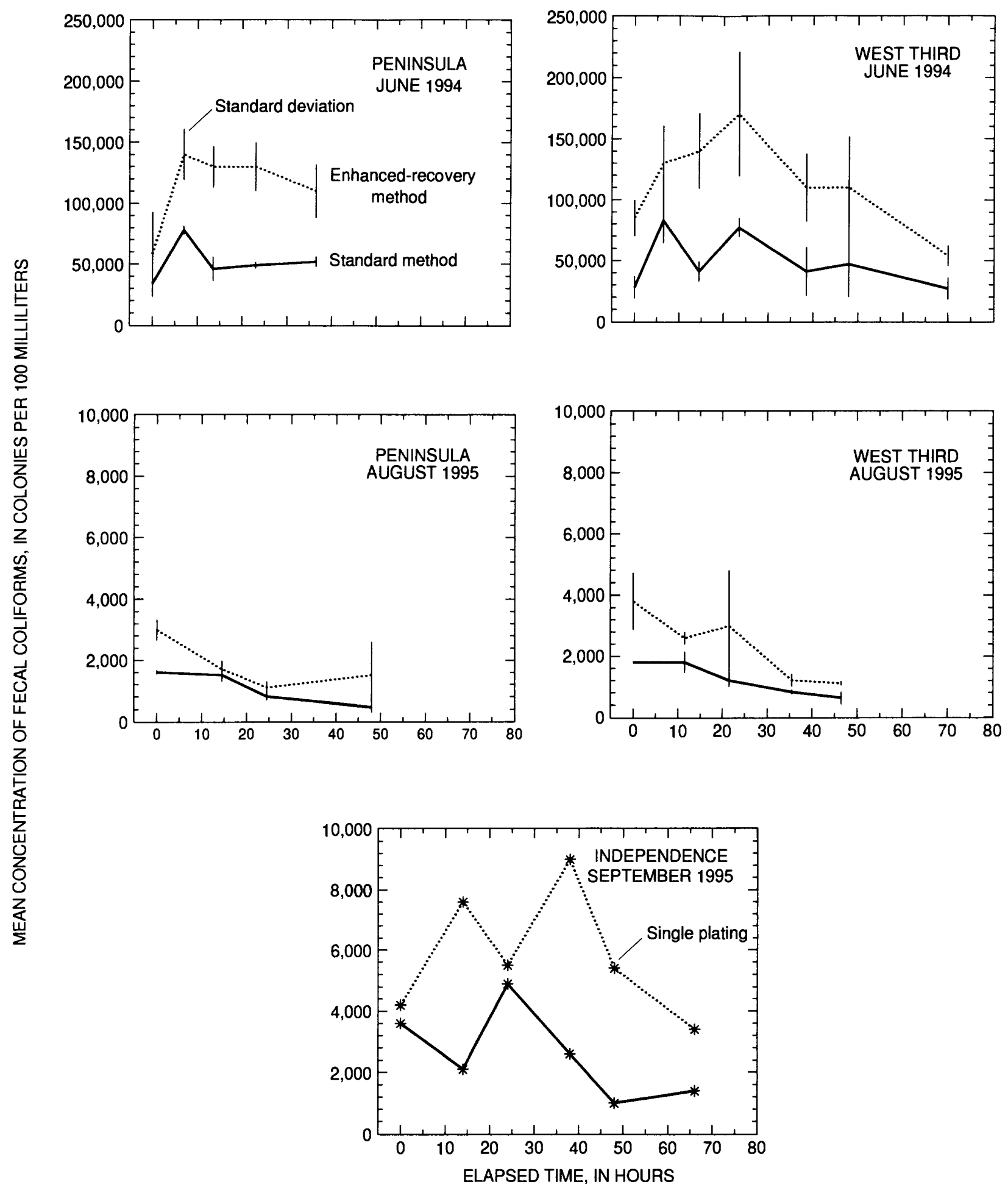

Figure 4. Mean fecal-coliform concentrations determined by use of standard and enhanced-recovery methods in unchlorinated wastewater effluent during June 1994, August 1995, and September 1995 field studies at Cuyahoga River sites, Ohio. (Different scales were used for different magnitudes of data to enhance visual interpretation.) 

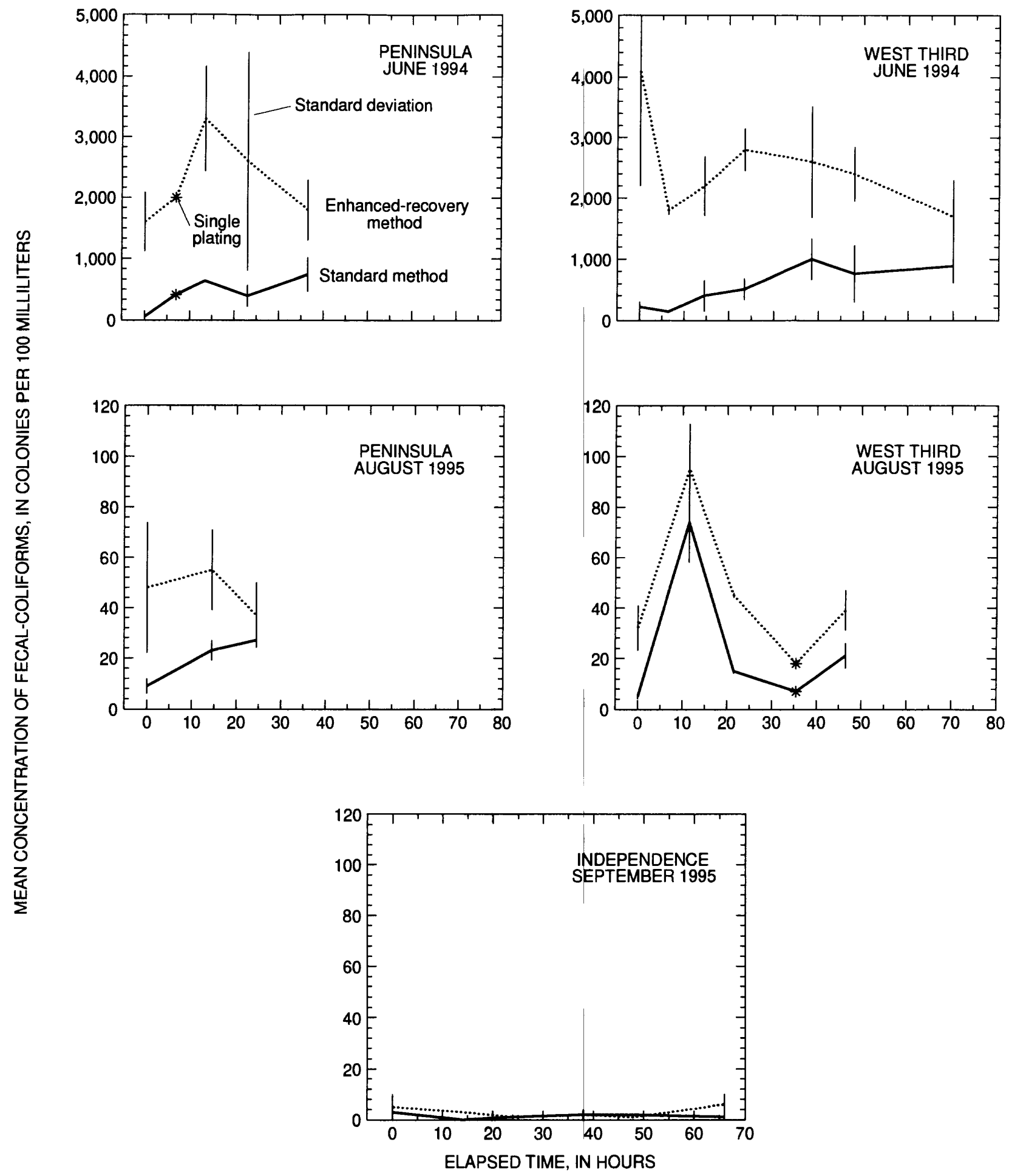

Figure 5. Mean fecal-coliform concentrations determined by use of standard and enhanced-recovery methods in chlorinated wastewater effluent during June 1994, August 1995, and September 1995 field studies at Cuyahoga River sites, Ohio. (Different scales were used for different magnitudes of data to visual interpretation.) 

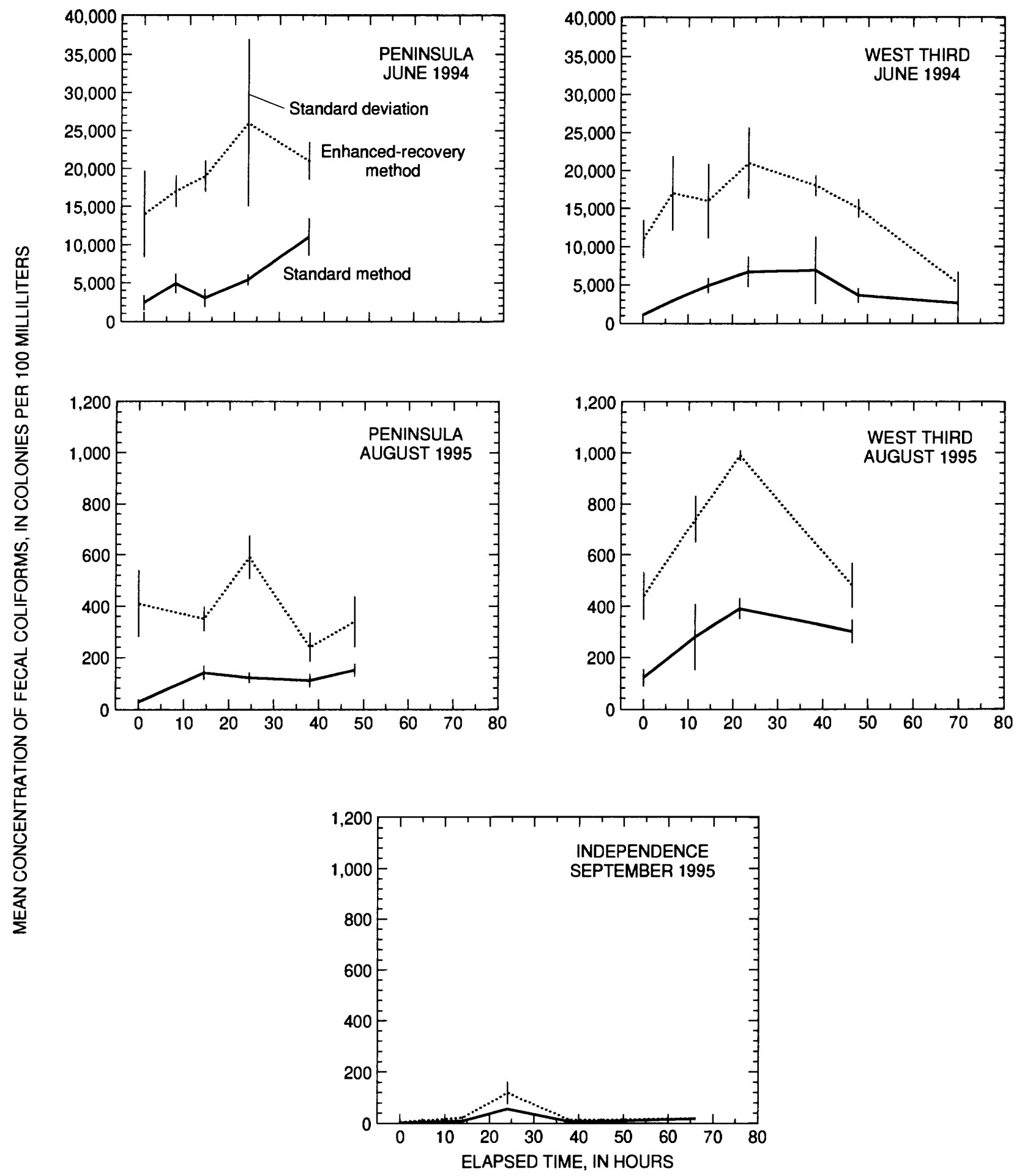

Figure 6. Mean fecal-coliform concentrations determined by use of standard and enhanced-recovery methods in dechlorinated wastewater effluent during June 1994, August 1995, and September 1995 field studies at Cuyahoga River sites, Ohio. (Different scales were used for different magnitudes of data to visual interpretation.) 
Independence site are shown in figure 7. In the unchlorinated (fig. 7A) and chlorinated (fig. 7B) samples, fecal-coliform concentrations were higher and increased more rapidly in June 1995 than in May 1995 , probably due to warmer water temperatures in June 1995. In the dechlorinated samples (fig. 7C), however, fecal-coliform concentrations were not higher in June 1995 than in May 1995.

During the first half of the May 1995 field study in the unchlorinated samples, the proportions of organisms obtained by use of the enhanced-recovery method remained about the same throughout the study. In dechlorinated and chlorinated samples in the May 1995 field study, fecal-coliform concentrations determined by use of the enhanced-recovery method increased more rapidly from about 20-32 hours than those determined by use of the standard method. In the May 1995 field study in chlorinated and dechlorinated samples, therefore, repair of chlorine-induced injuries from about 20-32 hours may have enabled some previously undetected organisms to grow on enhancedrecovery media.

In the chlorinated samples in June 1995, fecalcoliform concentrations peaked at 14 hours and again at 48 hours. CSO effluents contain more solid materials than treated wastewater effluent because they are a mixture of untreated wastewater and stormwater. Bacteria attach to solid materials, which offer a nutrientrich environment and protection from chlorination. Perhaps the second peak in fecal-coliform concentrations at 48 hours was due to solids breaking apart and releasing a reservoir of bacteria and nutrients into the water.

\section{Percent Injury of Fecal-Indicator Bacteria}

Mean percent injury (table 5) was calculated for each wastewater-effluent and CSO field study by site for unchlorinated, chlorinated, and dechlorinated samples. The lowest mean percent injuries among treatments were found in unchlorinated samples, ranging from 34.8 percent at Peninsula in August 1995 to 54.8 percent at West Third in June 1994. As expected, mean percent injuries in the chlorinated samples were higher than those in unchlorinated samples, ranging from 51 to 84.5 percent. Mean percent injuries for dechlorinated samples showed the largest spread, ranging from 46.3 to 90.3 percent. The two lowest mean percent injuries for dechlorinated samples were found in samples from the August 1994 (48.1 percent) and September 1995 (46.3 percent); these values were similar to those found in the corresponding unchlorinated samples.

Percent injury of fecal coliforms during Lake Erie wastewater-effluent field studies. Relations among percent injuries and treatments in field studies of wastewater effluent from the Easterly Wastewater Treatment Plant incubated in Lake Erie in May and August 1994 were examined by use of ANOVA (fig. 8). In the May field study (fig. 8A), percent injuries in the chlorinated and dechlorinated samples were statistically higher than percent injuries in the unchlorinated samples. In contrast, in the August 1994 field study (fig. 8B), percent injuries in the chlorinated samples were statistically higher than percent injuries in the unchlorinated and dechlorinated samples. Therefore, in May 1994, when water temperatures were lower and bacteria metabolic rates were slower than those in August 1994, many fecal coliforms in chlorinated and dechlorinated samples were unable to repair chlorineinduced injuries and regrow on culture media. In August 1994, a large proportion of fecal coliforms in dechlorinated samples were able to repair injuries caused by chlorination and regrow on culture media; percent injuries equaled those found in the unchlorinated population. However, even in the warm August waters, fecal coliforms in chlorinated samples were unable to repair their injuries and regrow on culture media.

\section{Percent injury of fecal coliforms during Cuyahoga River wastewater-effluent field studies.} Relations among percent injuries, treatments, and sites in field studies of wastewater effluent from Southerly Wastewater Treatment Plant were examined by use of a two-way ANOVA (fig. 9). Field studies were done in June 1994 and August 1995 at two Cuyahoga River sites, Peninsula and West Third.

In June 1994 and August 1995, treatment affected percent injury, site did not, and no interaction effects were found between treatment and site. In the June 1994 field study (fig. 9A), a statistically significant difference was found in percent injuries between unchlorinated and chlorinated samples only at the Peninsula site $(p<0.01)$; all other paired comparisons were not statistically significant at $\alpha=0.05$. In the June 1994 field study, however, $p$-values near $\alpha=0.05$ were found between two other comparisons: (1) unchlorinated and dechlorinated samples at the Peninsula site $(p=0.07)$ and (2) unchlorinated and chlorinated samples at the West Third site $(p=0.07)$. In the August 
A. UNCHLORINATED SAMPLES
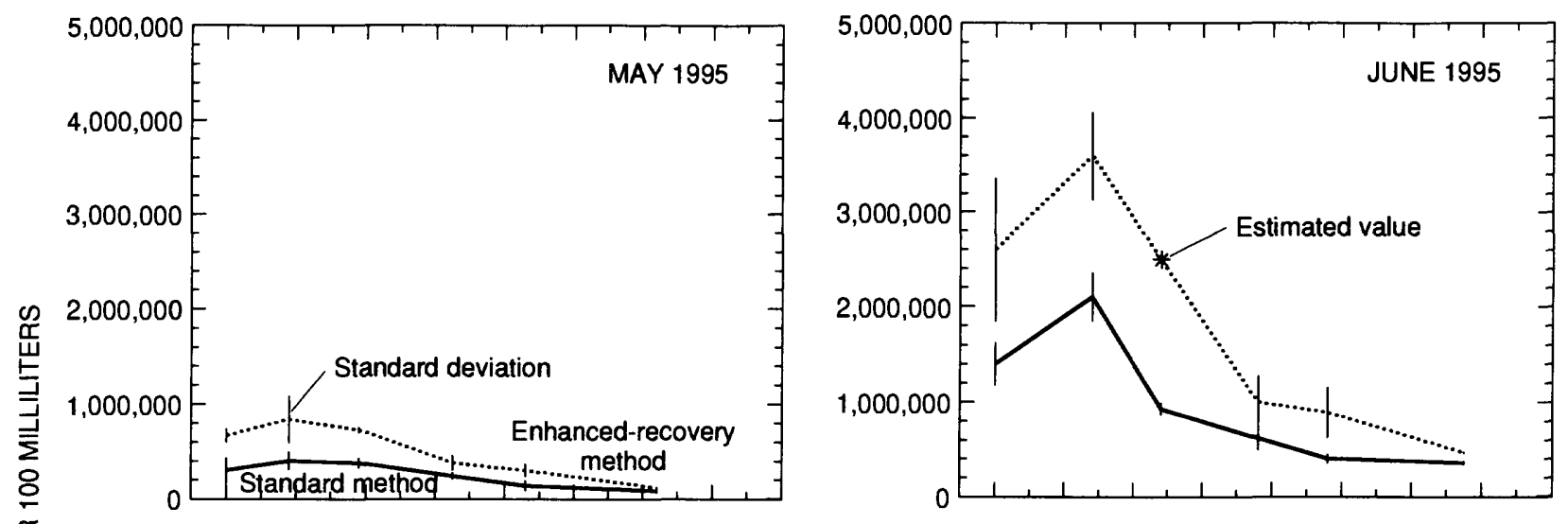

B. CHLORINATED SAMPLES
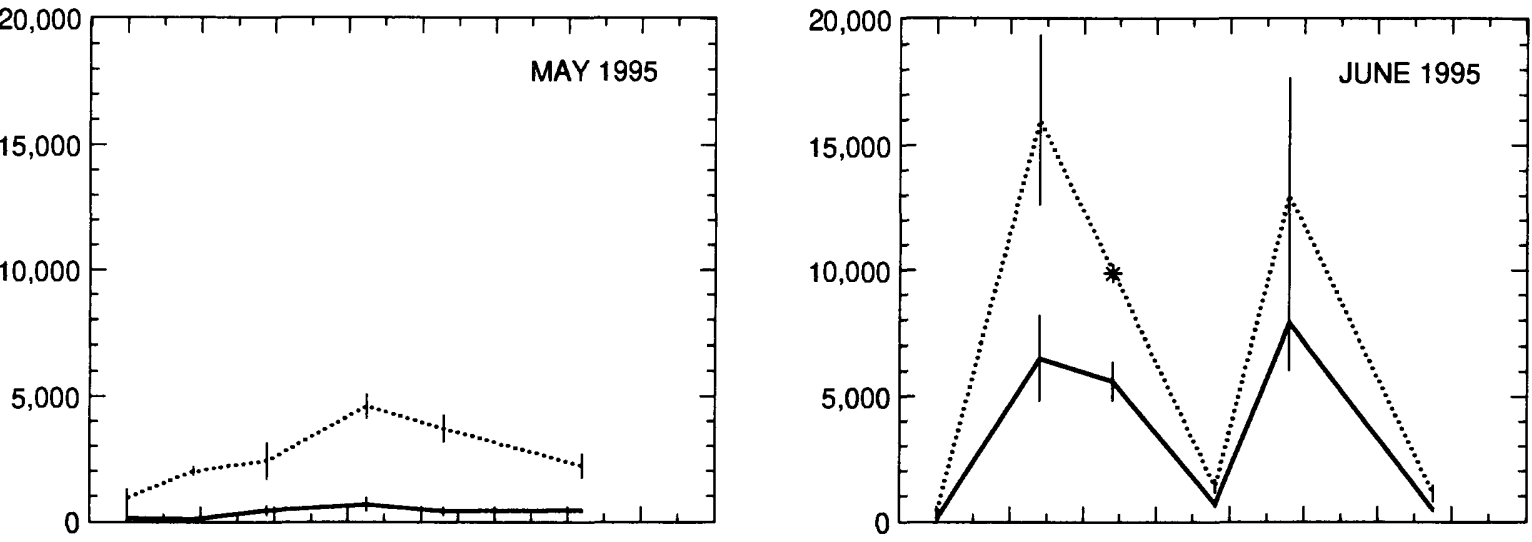

C. DECHLORINATED SAMPLES

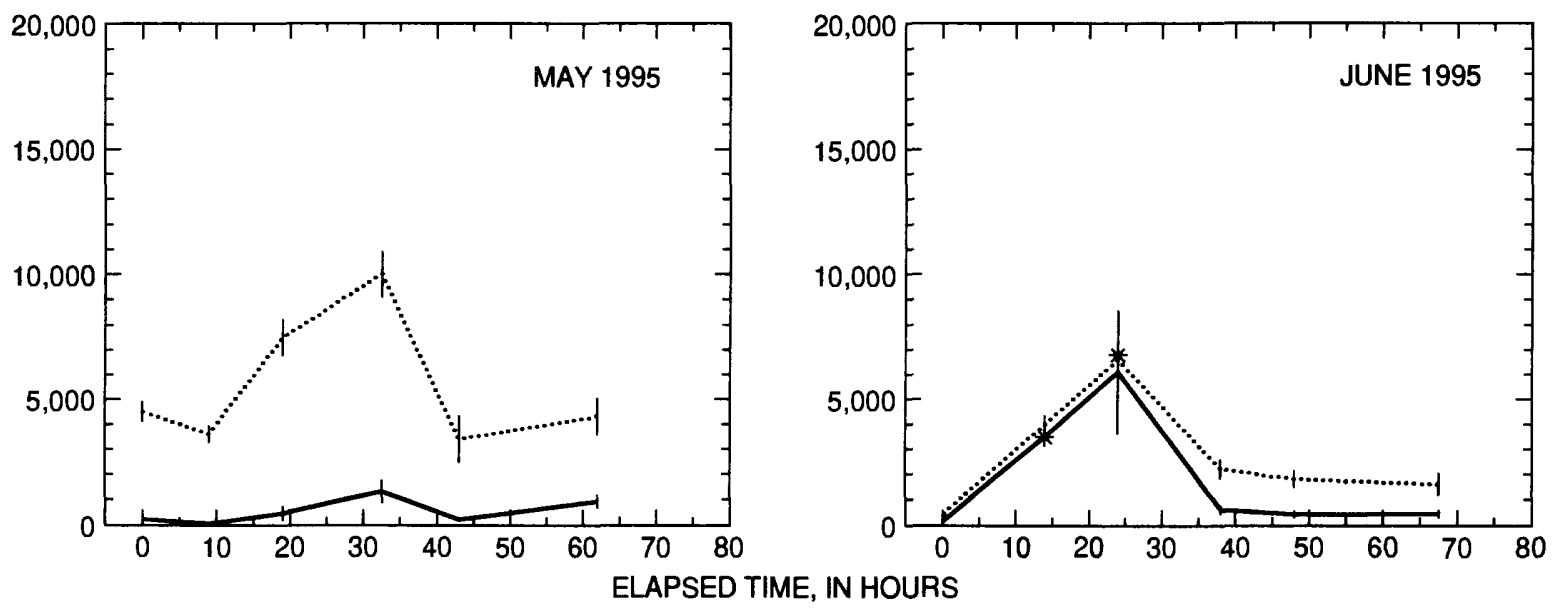

Figure 7. Mean fecal-coliform concentrations by use of standard and enhanced-recovery methods in combined-sewer-overflow effluent during May and June 1995 field studies at Cuyahoga River at Independence, Ohio: (A) unchlorinated, (B) chlorinated, and (C) dechlorinated (Different scales were used for different magnitudes of data to enhance visual interpretation.) 
Table 5. Mean percent injury of fecal coliforms in unchlorinated, chlorinated, and dechlorinated wastewater or combinedsewer-overflow effluent field studies

[Percent injury is computed as [1-(SSM/ERM)] $\times 100$, where SSM is colonies per 100 milliliters recovered by standard-selective method and ERM is colonies per 100 milliliters recovered by enhanced-recovery method. ND, not determined]

\begin{tabular}{|c|c|c|c|c|c|c|c|c|c|}
\hline \multirow[b]{3}{*}{ Treatment } & \multirow{2}{*}{\multicolumn{2}{|c|}{$\begin{array}{l}\text { Wastewater, } \\
\text { Lake Erie at } \\
\text { Cleveland, Ohio }\end{array}$}} & \multicolumn{5}{|c|}{ Wastewater, Cuyahoga River } & \multirow{2}{*}{\multicolumn{2}{|c|}{$\begin{array}{l}\text { Combined-sewer } \\
\text { overflow, Cuyahoga } \\
\text { River at Independenc }\end{array}$}} \\
\hline & & & \multicolumn{2}{|c|}{ Peninsula } & \multicolumn{2}{|c|}{ West Third } & \multirow{2}{*}{$\begin{array}{c}\text { Independence } \\
\begin{array}{c}\text { Sept. } \\
1995\end{array}\end{array}$} & & \\
\hline & $\begin{array}{l}\text { May } \\
1994\end{array}$ & $\begin{array}{l}\text { Aug. } \\
1994\end{array}$ & $\begin{array}{l}\text { June } \\
1994\end{array}$ & $\begin{array}{l}\text { Aug. } \\
1995\end{array}$ & $\begin{array}{l}\text { June } \\
1994\end{array}$ & $\begin{array}{l}\text { Aug. } \\
1995\end{array}$ & & $\begin{array}{r}\text { May } \\
1995\end{array}$ & $\begin{array}{l}\text { June } \\
1995\end{array}$ \\
\hline Unchlorinated & 51.2 & 49.8 & 51.2 & 34.8 & 54.8 & 40.5 & 51.5 & 45.0 & 39.8 \\
\hline Chlorinated & 72.8 & 76.6 & 78.2 & 55.9 & 72.1 & 51.0 & ND & 84.5 & 53.7 \\
\hline Dechlorinated & 80.1 & 48.1 & 71.7 & 62.6 & 68.6 & 56.2 & 46.3 & 90.3 & 71.7 \\
\hline
\end{tabular}

1995 field study (fig. 9B), the data sets were smaller and percent injury differences between groups were not as pronounced as those in the June data set. The only statistically significant difference was found between percent injuries in unchlorinated and dechlorinated samples at the Peninsula site $(p=0.03)$.

In both the June 1994 and August 1995 Cuyahoga River studies, no statistically significant differences were found in percent injuries between dechlorinated and chlorinated samples. Therefore, in the warm-weather Cuyahoga River studies, and unlike the warm-weather Lake Erie field study, dechlorination did not enhance the repair and regrowth of chlorine-injured fecal coliforms over chlorination alone. This bacterial response may be due to water-quality differences between Lake Erie and the Cuyahoga River. During field studies, concentrations of nutrients and total organic carbon were somewhat lower and concentrations of total nonfilterable residue were considerably lower in the lake than in the river (table 3). Because of lower suspended materials in the lake, transmission of ultraviolet light, which is bactericidal, would be enhanced in the lake and not in the river.

The different levels of treatment of wastewater effluents from the Easterly Plant (Lake Erie field studies) compared to the Southerly Plant (Cuyahoga River field studies) may have also contributed to different responses of the dechlorinated and chlorinated populations. Secondary-treated wastewater effluent was used in Lake Erie field studies, whereas tertiary-treated wastewater effluent was used in Cuyahoga River studies. The increased residence time of bacteria in tertiary-treated effluent over secondary-treated effluent may have resulted in different physiological states of bacteria cells. In addition, activated sludge from the Easterly Plant is pumped to the Southerly plant for treatment; thus, the wastewater stream in the Southerly plant may have had higher concentrations of metals than the wastewater stream in the Easterly Plant. More work needs to be done to determine why dechlorination enhanced the repair and regrowth of chlorineinjured fecal coliforms over chlorination alone in the warm-weather lake studies, but not in the river studies.

\section{Percent injury of fecal coliforms during} Cuyahoga River combined-sewer-overflow effluent field studies. Relations among percent injuries and treatments were examined in field studies of CSO effluent collected from Mill Creek and incubated at the Cuyahoga River at Independence in May and June 1995 (fig. 10). Statistically significant differences were found in percent injuries between all possible pairs of treatment groups in each field study. In both studies, the lowest percent injuries were found in unchlorinated samples, and the highest percent injuries were found in dechlorinated samples. Contrary to what was found in wastewater-effluent field studies, the results from CSO studies indicated that dechlorination may reduce the ability of organisms to recover and regrow on culture media compared with chlorination alone. The presence of untreated waste and high concentrations of solids in CSO effluent may have contributed to this result. As explained earlier, solid materials in the chlorinated samples may have broken apart, releasing nutrients and bacteria into the chamber. Why this did not happen in the dechlorinated samples was not determined. Because of the uncertain nature of CSO effluents, however, more work needs to 
A. MAY 1994

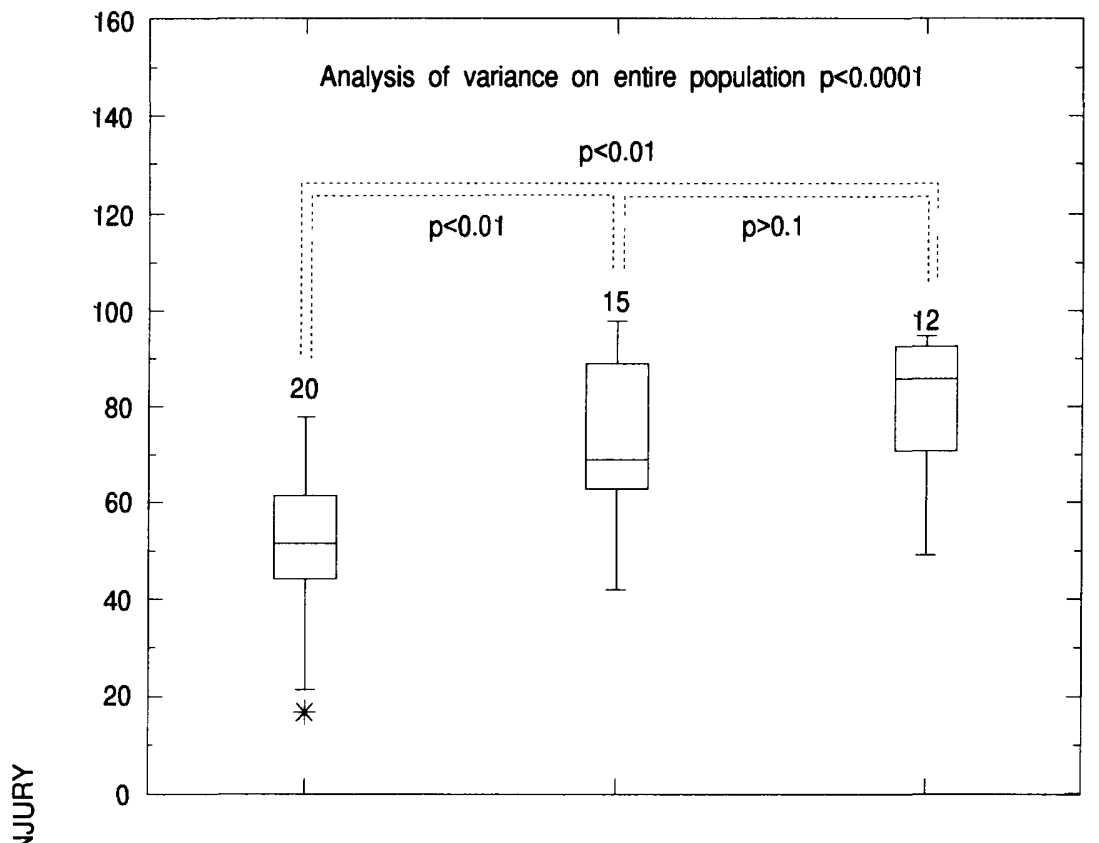

\section{EXPLANATION}

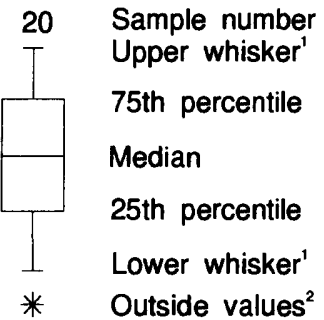

'Upper whisker is defined as the largest data point less than or equal to the upper quartile plus 1.5 times the interquartile range. Lower whisker is minus 1.5 times the interquartile range.

${ }^{2}$ An outside value is defined as greater than 1.5 and less than or equal to 3 interquartile ranges from the box.

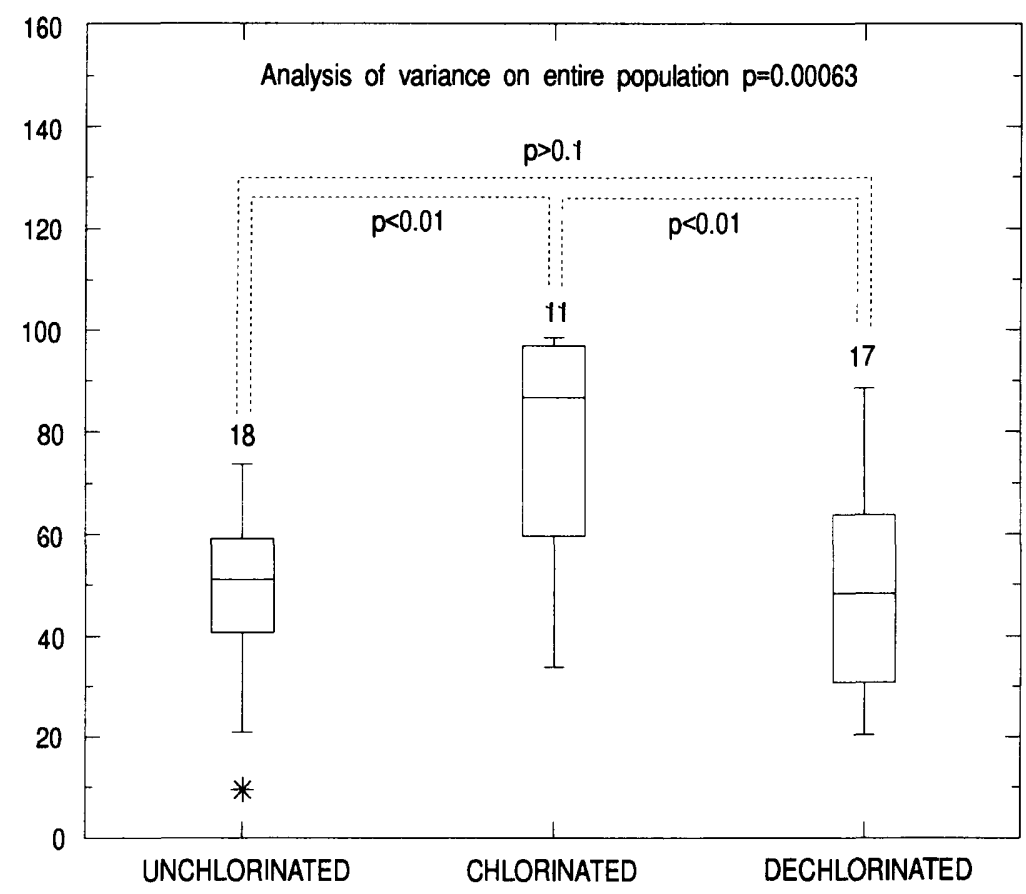

Figure 8. Percent injury of fecal-coliforms in relation to treatment type in wastewater effluent from Easterly Wastewater Treatment Plant and incubated at Lake Erie, Cleveland, Ohio field site in (A) May 1994 and (B) August 1994. (Dashed lines indicated results of paired Tukey's multiple comparison tests.) 
A. JUNE 1994

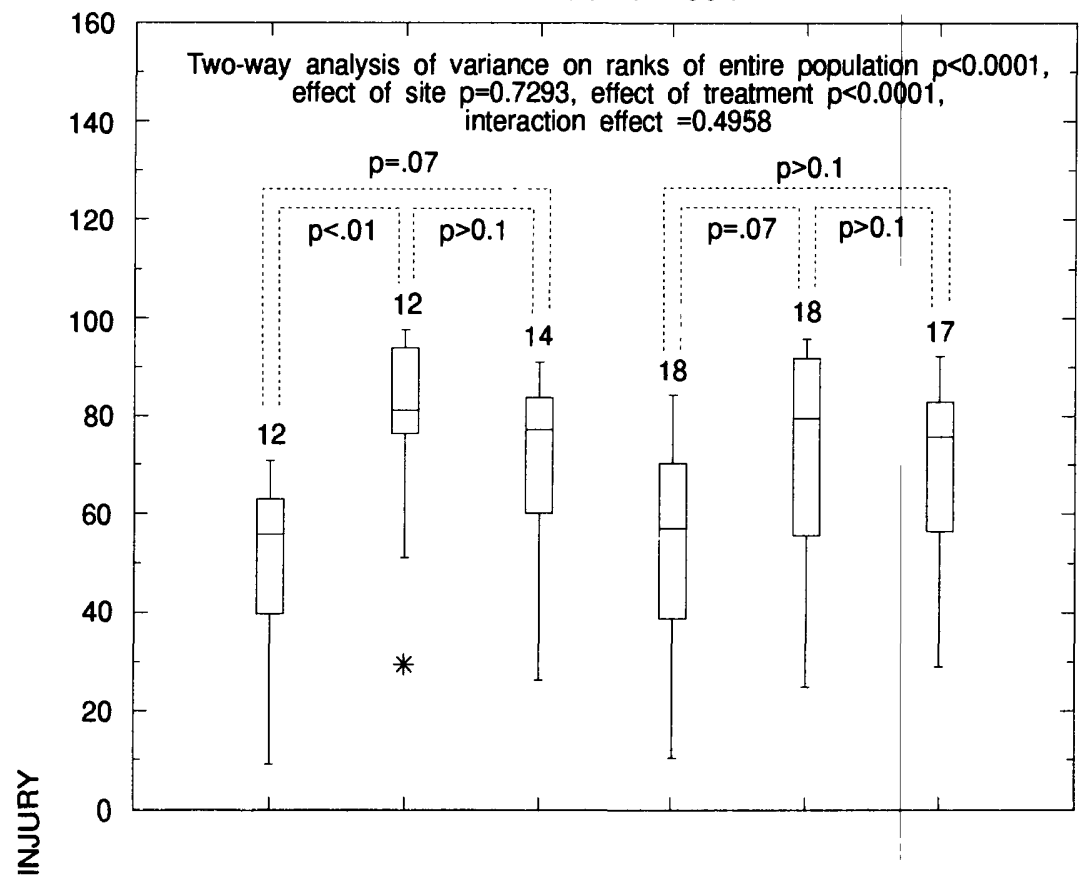

\section{B. AUGUST 1995}

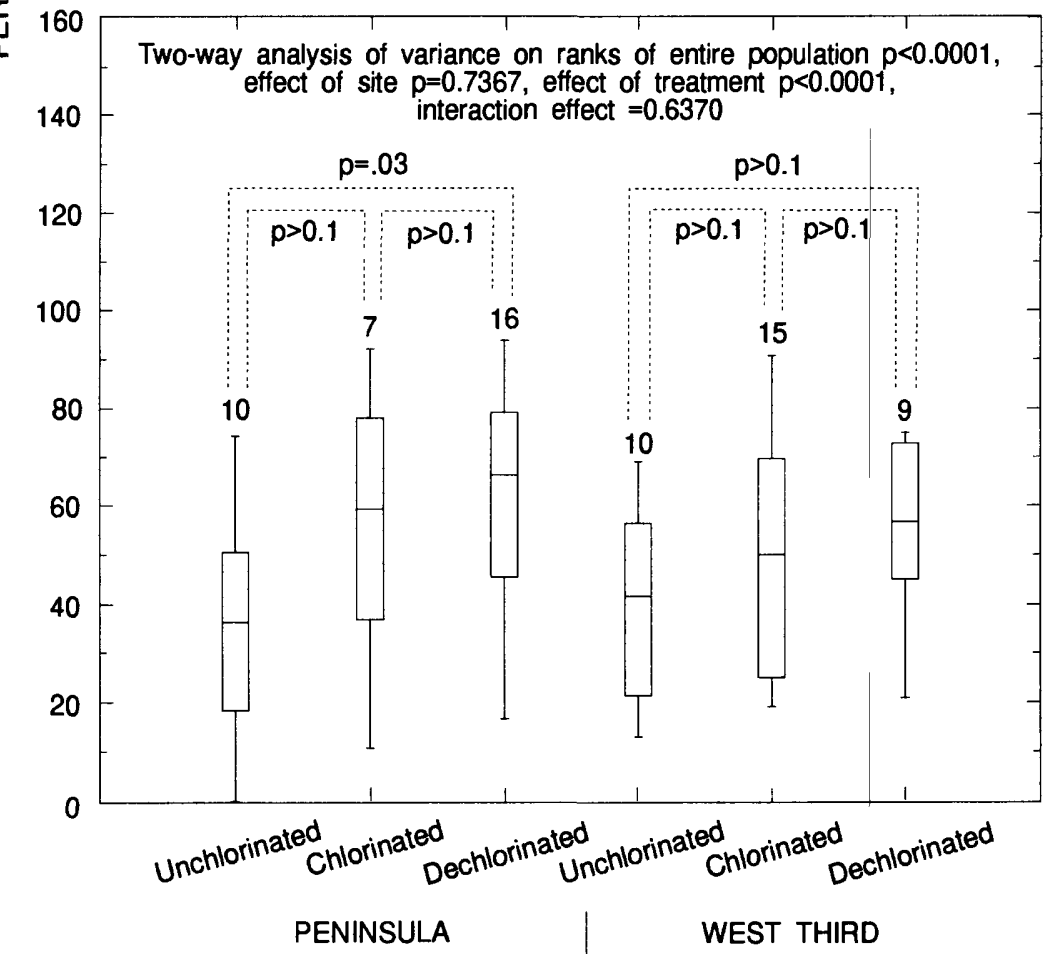

\section{EXPLANATION}

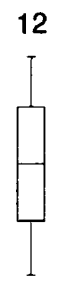

Sample number Upper whisker' 75th percentile Median 25th percentile Lower whisker' Outside values ${ }^{2}$

'Upper whisker is defined as the largest data point less than or equal to the upper quartile plus 1.5 times the interquartile range. Lower whisker is minus 1.5 times the interquartile range.

${ }^{2}$ An outside value is defined as greater than 1.5 and less than or equal to 3 interquartile ranges from the box.

Figure 9. Percent injury of fecal-coliforms in relation to treatment type in wastewater effluent from Southerly Wastewater Treatment Plant and incubated at Cuyahoga River at Peninsula and West Third, Cleveland, Ohio field sites in (A) June 1994 and (B) August 1995. (Dashed lines indicated results of paired Tukey's multiple comparison test.) 
A. MAY 1995

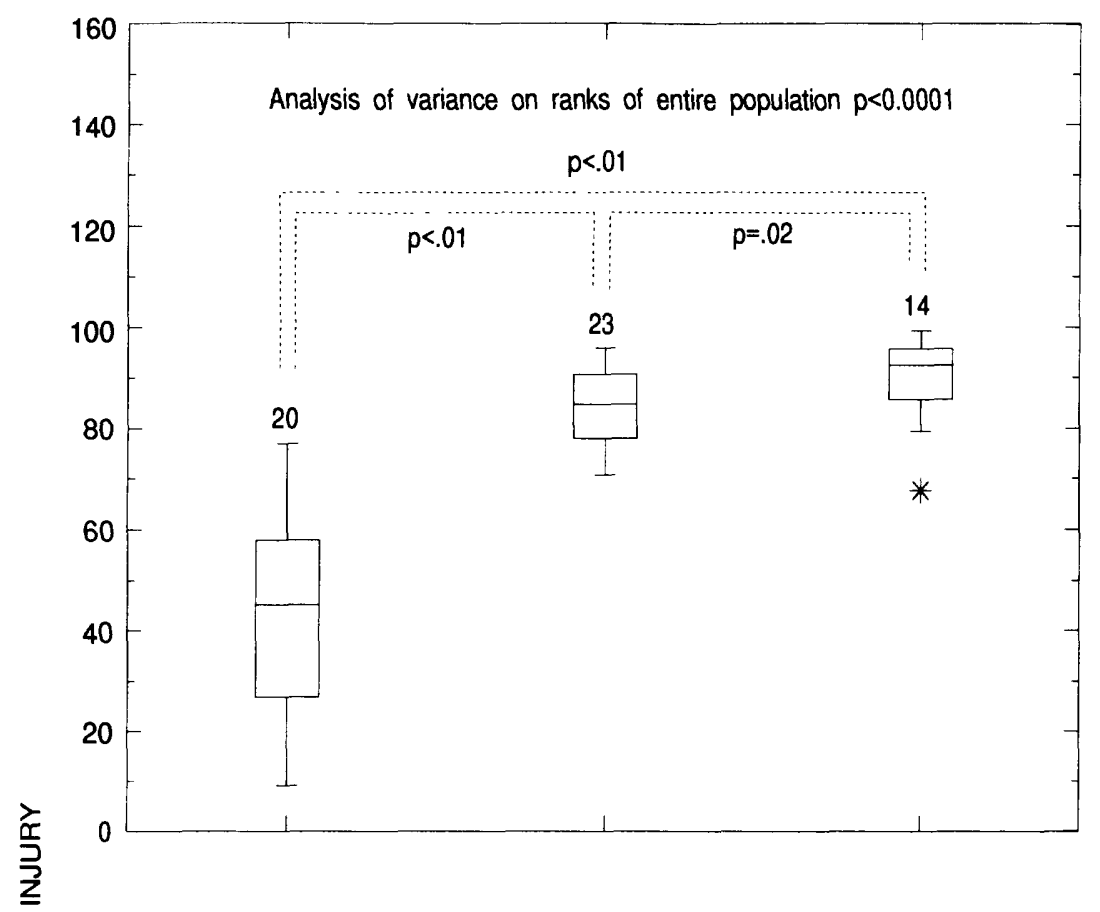

\section{EXPLANATION}

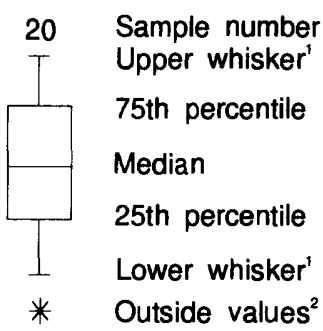

'Upper whisker is defined as the largest data point less than or equal to the upper quartile plus 1.5 times the interquartile range. Lower whisker is minus 1.5 times the interquartile range.

${ }^{2}$ An outside value is defined as greater than 1.5 and less than or equal to 3 interquartile ranges from the box.

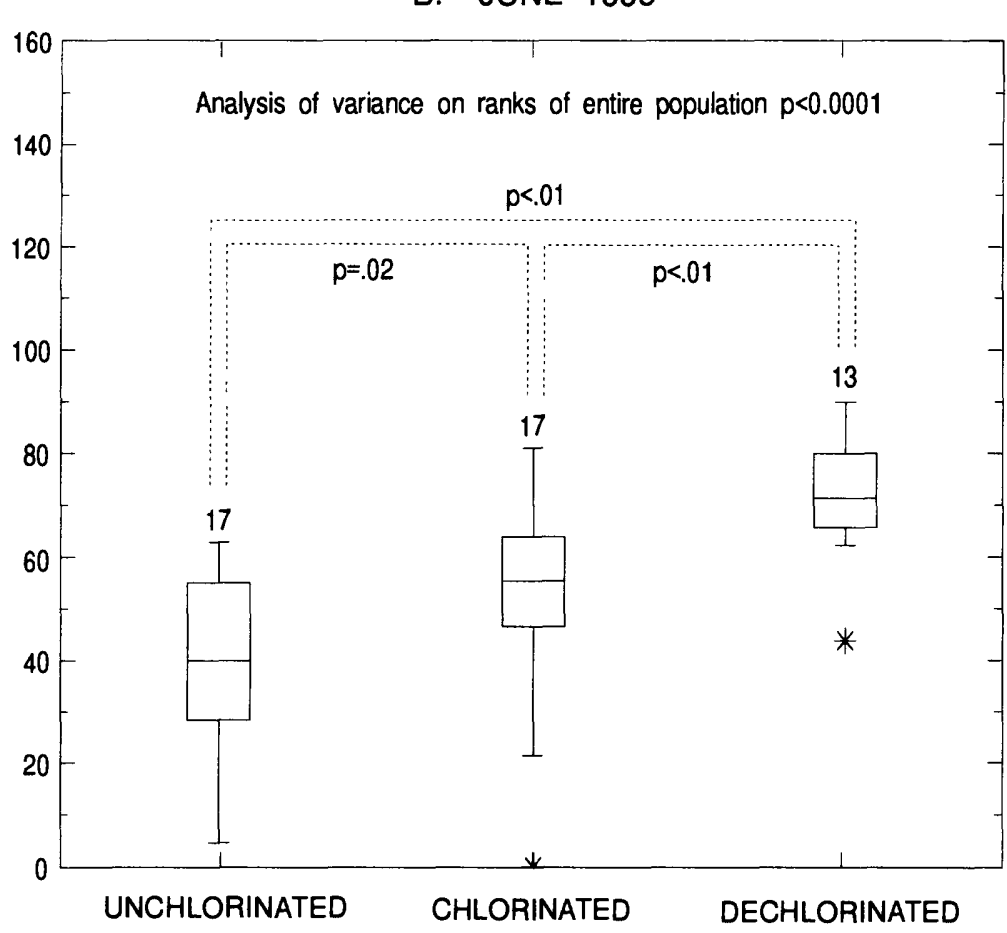

Figure 10. Percent injury of fecal-coliforms in relation to treatment type in combined sewer overflow effluent collected from Mill Creek and incubated at Cuyahoga River at Independence, Ohio in the Cleveland area: (A) May 1995 and (B) June 1995. (Dashed lines indicated results of paired Tukey's multiple comparison test.) 
be done before the effect of dechlorination and chlorination on reducing fecal-coliform concentrations in CSO effluents can be confirmed.

\section{Percent Survival of Fecal-Indicator Bacteria}

Percent survival at each timestep was calculated as a percentage of the mean concentration from the enhanced-recovery method in the initial unchlorinated sample. Mean percent survival is a measure of the ability of fecal coliforms to survive in the aquatic environment after being discharged from the wastewater treatment plant or the CSO. For chlorinated and dechlorinated samples, mean percent survival is also a measure of the effectiveness of treatment in reducing fecal-coliform concentrations.

Mean percent survival was calculated for each field study by treatment and site (table 6 ). The highest percent survivals were found in unchlorinated samples, some values greater than 100 percent. (Mean percent survivals greater than 100 percent indicate that cells replicated after the initial timestep.) Mean percent survivals in unchlorinated CSO-effluent samples were generally less than those found in unchlorinated wastewater-effluent samples, an indication that fecal coliforms in CSO effluent were not able to survive in the aquatic environment as well as fecal coliforms from wastewater effluent. In all but one field study
(June 1995 CSO field study), mean percent survivals were greater in dechlorinated samples than in chlorinated samples. Therefore, chlorination alone was generally more effective than dechlorination in reducing fecal-coliform concentrations after treatment and (or) reducing survival of fecal coliforms in the aquatic environment.

ANOVA was used to examine relations among percent survival, treatment, and site. For all studies, statistically significant differences were found in mean percent survivals among the three treatments, except in the June 1995 CSO field study where no statistical difference $(p>0.10)$ was found in percent survivals between the chlorinated and dechlorinated populations. During this study, a second atypical peak in fecal-coliform concentrations was found in chlorinated samples (see fig. 7B).

In the June 1994 Cuyahoga River field study, no statistically significant differences were found in percent survivals between the Peninsula and West Third sites. In the August 1995 field study, however, percent survivals in the dechlorinated population at West Third (mean percent survival=18.2) were statistically higher $(p<0.01)$ than those in the dechlorinated population at Peninsula (mean percent survival=10.6). During this field study, mean water temperature and total organic carbon concentrations were higher and mean dissolved-oxygen and total nonfilterable residue concentrations were lower at West Third than at Peninsula

Table 6. Mean percent survival of fecal coliforms in unchlorinated, chlorinated, and dechlorinated wastewater or combinedsewer-overflow effluent in field studies

[Survival is computed as $\left[\mathrm{ERM}_{\mathrm{t}} /\left(\mathrm{ERMun}_{0}\right)\right] \mathrm{x} 100$, where $\mathrm{ERM}$ is enhanced-recovery method, $\mathrm{ERM}_{t}$ is colonies per 100 milliliters recovered at selected timesteps, and $\mathrm{ERMun}_{0}$ is mean colonies per 100 milliliters recovered at time $\mathrm{e}_{0}$ in unchlorinated samples; mean percent survival is the mean for all timesteps in each study]

\begin{tabular}{|c|c|c|c|c|c|c|c|c|c|}
\hline \multirow[b]{3}{*}{ Treatment } & \multirow{2}{*}{\multicolumn{2}{|c|}{$\begin{array}{c}\text { Wastewater, } \\
\text { Lake Erie at } \\
\text { Cleveland, Ohio }\end{array}$}} & \multicolumn{5}{|c|}{ Wastewater, Cuyahoga River } & \multirow{2}{*}{\multicolumn{2}{|c|}{$\begin{array}{l}\text { Combined-sewer } \\
\text { overflow, Cuyahoga } \\
\text { River at Independence }\end{array}$}} \\
\hline & & & \multicolumn{2}{|c|}{ Peninsula } & \multicolumn{2}{|c|}{ West Third } & \multirow{2}{*}{$\begin{array}{c}\text { Independence } \\
\begin{array}{c}\text { Sept. } \\
1995\end{array}\end{array}$} & & \\
\hline & $\begin{array}{l}\text { May } \\
1994\end{array}$ & $\begin{array}{l}\text { Aug. } \\
1994\end{array}$ & $\begin{array}{l}\text { June } \\
1994\end{array}$ & $\begin{array}{l}\text { Aug. } \\
1995\end{array}$ & $\begin{array}{l}\text { June } \\
1994\end{array}$ & $\begin{array}{l}\text { Aug. } \\
1995\end{array}$ & & $\begin{array}{l}\text { May } \\
1995\end{array}$ & $\begin{array}{l}\text { June } \\
1995\end{array}$ \\
\hline Unchlorinated & 86.3 & 137.9 & 155.2 & 43.3 & 160.3 & 67.4 & 139.3 & 83.0 & 64.4 \\
\hline Chlorinated & 3.3 & 1.6 & 3.2 & 1.4 & 3.5 & 1.5 & .1 & .4 & $.3^{b}$ \\
\hline Dechlorinated & 23.2 & 47.0 & 26.2 & $10.6^{\mathrm{a}}$ & 19.0 & $18.2^{\mathrm{a}}$ & .6 & .9 & $.1^{\mathrm{b}}$ \\
\hline
\end{tabular}

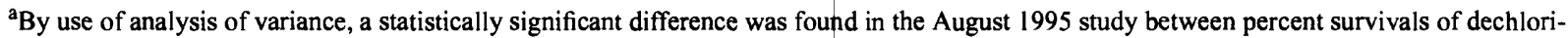
nated samples at Peninsula and West Third; no other statistically significant difference in percent survivals between sites was found.

${ }^{b}$ By use of analysis of variance, a statistically significant difference was found between unchlorinated, chlorinated, and dechlorinated samples in all studies, but no statistically significant difference was found in the June 1995 combined-sewer-overflow effluent field study between percent survival of chlorinated and dechlorinated samples.
} 
(table 3). Whether or not these water-quality differences affected fecal-coliform survival is unknown; however, during these field studies, water-quality differences between Peninsula and West Third were less influential than treatment in affecting the survival of fecal coliforms.

\section{Implications for Assessment of Recreational Water Quality}

\section{Relation of Enhanced-Recovery Method Concentrations to Standard-Method Concentrations}

Currently, recreational water quality in Ohio is monitored by use of the standard method for fecal coliforms (Ohio Environmental Protection Agency, 1990). Enhanced-recovery methods, however, were found to be superior to the standard method in recovering chlorine-injured organisms in other investigations (Rose and others, 1975; Green and others, 1977; LeChevallier and others, 1983, 1984) and in this investigation. If the concentration of fecal coliforms determined by use of the enhanced-recovery method can be predicted accurately from the concentration found by use of the standard method, then increased monitoring and expense to detect chlorine-injured organisms would be unnecessary. However, if the concentration of fecal coliforms found by use of the enhanced-recovery method cannot be predicted accurately from the concentration found by use of the standard method, water-resource managers could possibly misinterpret the health risk of swimming in some waters, especially those waters with a high proportion of chlorine-injured, undetected fecal coliforms.

Data from seven field studies (not grouped). The data from the seven field studies described in this report are shown on a scatterplot (fig. 11), and associated regression statistics are shown in table 7. Each data point on the scatterplot represents a pair of logtransformed standard and enhanced-recovery fecalcoliform concentrations from a single sample for all field studies. The concentration found by use of the standard method was highly correlated with the concentration found by use of the enhanced-recovery method $(r=0.962)$. The slope $(0.906)$ is a measure of the rate of change in log standard method concentration with change in log enhanced-recovery method concentration. The $y$-intercept $(0.795)$ is the value for log enhanced-recovery method that corresponds to a zero value for log standard method. These values seem reasonable in sign and magnitude, and $t$ - tests $(\alpha=0.05)$ indicate that the slope and $y$-intercept were statistically different than zero (unpublished data on file at USGS, Columbus, Ohio). The standard error of the regression (also known as the standard deviation of the residuals) measures the degree of deviation of observed values from the regression line and is an indicator of the level of uncertainty associated with a prediction, expressed as a percentage of the predicted mean. The standard error indicated that predicted enhanced-recovery concentrations can vary as much as 34.2 percent. The coefficient of determination, or $R^{2}$ (0.932), showed that a large amount of the variation in results from the enhanced-recovery method was explained by results from the standard method. An overall $F$-test of the regression indicated that the regression relation was statistically significant and that the relation between the two variables was not likely due to chance alone (unpublished data on file at USGS, Columbus, Ohio).

In spite of these statistics, however, regression diagnostics indicated that the regression model on the entire data set was inadequate. Regression residuals, the differences between observed and predicted values, for enhanced-recovery method concentrations were calculated. A PPCC plot of the residuals showed a large departure from normality with a probability of less than 0.01 (table 7). When the residuals were plotted against the predicted values (fig. 12A), heteroscedasticity (nonconstant variance) was strongly indicated. The variance was greater for smaller predicted concentrations and decreased as predicted concentrations increased. When the residuals were plotted against elapsed time (fig. 12B), there appeared to be a small decrease in variance with samples collected late in the field studies as compared to samples collected early in the field studies. When residuals were put into boxplots by treatment type (unchlorinated, chlorinated, and dechlorinated), greater residuals, wider interquartile ranges, and more outside values were found in chlorinated and dechlorinated sample pairs than in unchlorinated sample pairs (fig. 12C). In addition, 6 outliers with standard deviations greater than 2 were found among the 382 observations in the data set (unpublished data on file at USGS, Columbus, Ohio). The outliers were all from chlorinated and dechlorinated sample pairs and the first 20 hours of incubation; however, because the data sets were large, the outliers 


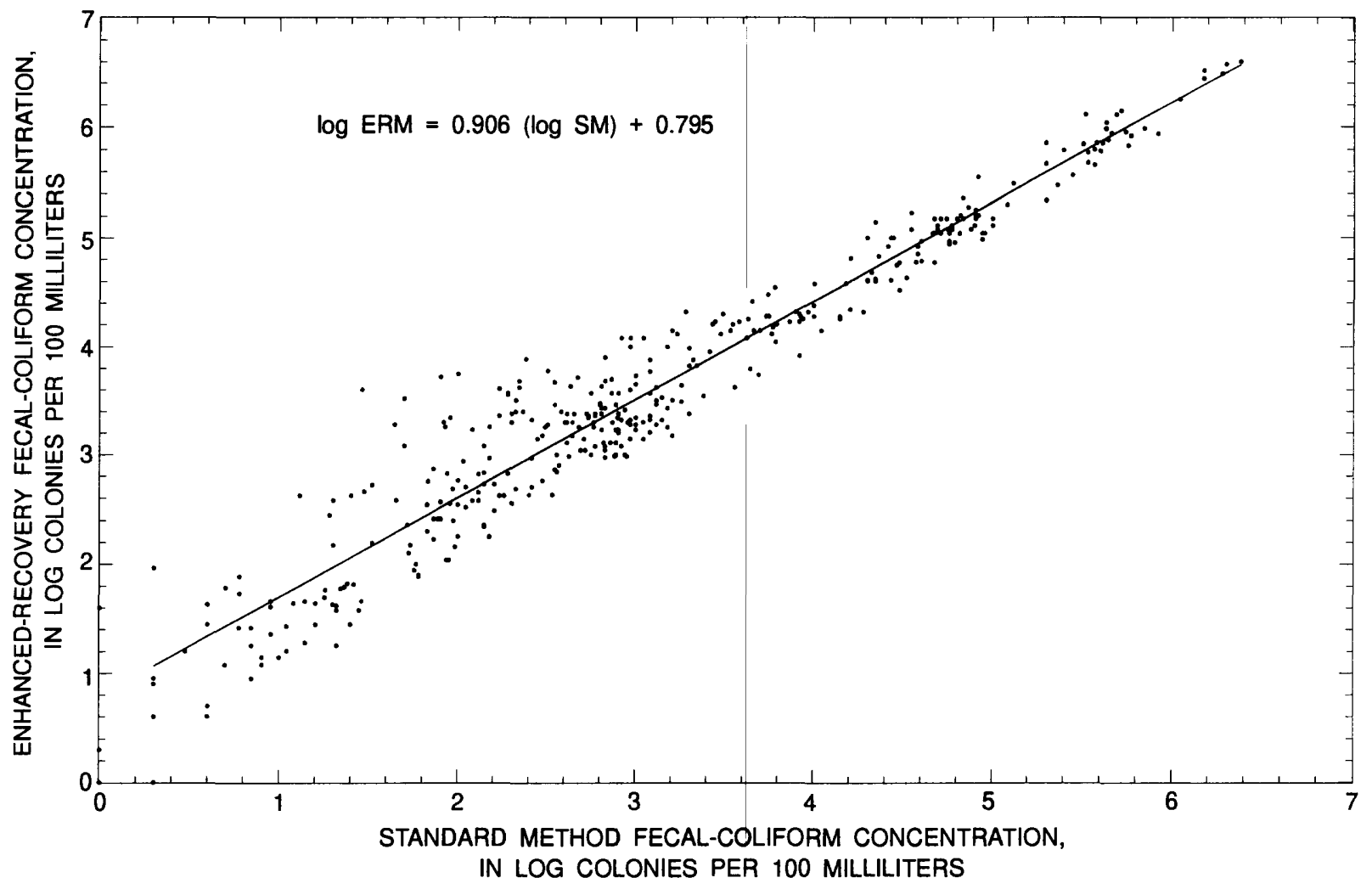

Figure 11. Regression relation between enhanced-recovery (ERM) and standard-method (SM) concentrations of fecal coliforms in seven field studies of wastewater and combined-seweroverflow effluent collected in the Cleveland area, Ohio. 
Table 7. Regression statistics for enhanced-recovery and standard-method concentrations of fecal coliforms in wastewater and combined-sewer-overflow effluent collected in the Cleveland area, Ohio

\begin{tabular}{|c|c|c|c|c|c|c|c|}
\hline Data set & $\begin{array}{l}\text { Sample } \\
\text { size }\end{array}$ & $\mathbf{r}$ & $\begin{array}{c}\mathbf{S} \\
\text { (percent) }\end{array}$ & $\begin{array}{c}\text { Slope } \\
\text { (log units) }\end{array}$ & $\begin{array}{l}y \text {-intercept } \\
\text { (log units) }\end{array}$ & $R^{2}$ & $\begin{array}{l}p \text {-value for } \\
\text { normality of } \\
\text { residuals }\end{array}$ \\
\hline \multicolumn{8}{|l|}{ All data: } \\
\hline $\begin{array}{l}\text { SM concentration as explanatory } \\
\text { variable }\end{array}$ & 382 & 0.962 & 34.2 & 0.906 & 0.795 & 0.932 & $<0.01$ \\
\hline $\begin{array}{l}\text { SM concentration and time as } \\
\text { expanatory variables }\end{array}$ & 382 & .968 & 33.3 & $\begin{array}{l}0.906 \text { (SM conc.) } \\
-.004 \text { (time) }\end{array}$ & .901 & .936 & $<.01$ \\
\hline \multicolumn{8}{|c|}{ Data grouped by magnitude of standard method concentration: } \\
\hline SM concentraton $<5,000$ & 256 & 0.897 & 39.50 & 0.943 & 0.722 & 0.804 & $<0.01$ \\
\hline SM concentration $>5,000$ & 117 & .968 & 16.03 & .924 & .683 & .936 & .305 \\
\hline \multicolumn{8}{|l|}{ Data grouped by treatment type: } \\
\hline Unchlorinated & 131 & 0.988 & 16.74 & 0.984 & 0.378 & 0.976 & 0.126 \\
\hline Chlorinated & 125 & .904 & 41.41 & .948 & .746 & .817 & $<.01$ \\
\hline Dechlorinated & 126 & .930 & 37.23 & .930 & .770 & .866 & $<.01$ \\
\hline
\end{tabular}

exhibited low leverage and influence on the regression relation.

A departure of residuals from normality results in hypothesis tests that have low power (slopes or explanatory variables will be falsely declared statistically insignificant), and results in a false estimate of confidence or prediction intervals (Helsel and Hirsch, 1992, p.236). Heteroscedasticity of residuals results in the failure of the model to accurately predict enhanced-recovery concentrations for all standardmethod concentrations. Decreasing residuals with larger predicted values, decreasing residuals over time, and a larger spread of residuals for chlorinated and dechlorinated samples indicate that additional explanatory variables should be included in the model. Therefore, the regression model on the entire data set does not adequately explain the relation between standard-method concentrations and enhanced-recovery concentrations.

Time was included as an explanatory variable, in addition to log standard-method concentration, in the regression model. The addition of time as an explanatory variable resulted in an additional variable in the regression equation with a slope of -0.004 (table 7); this slope was found to be statistically different than zero. It also resulted in a change in the y-intercept of the regression model from 0.795 to 0.901 . The other regression statistics generated with two explanatory variables were similar to those resulting from one explanatory variable. Most important, the inclusion of time as an explanatory variable did not reduce heteroscedasticity of the residuals (unpublished data on file at USGS, Columbus, Ohio). Therefore, the model that included time did not explain the variation in enhanced-recovery concentrations any better than the model containing log standard-method concentration alone as the explanatory variable.

Other factors that may influence the enhancedrecovery concentration are not appropriately expressed as continuous variables. The data were placed into groups based on two such factors: (1) magnitude of standard-method concentration and (2) treatment. These factors were individually tested to determine their importance as explanatory variables. ANCOVA was done to determine if the regression equations generated by each group were statistically different in terms of slopes and y-intercepts. An Fratio was tabulated from an analysis of variance of regression coefficients over groups. If the $F$-ratio tabulated was statistically significant $(p<0.05)$, then the regression equations generated by the grouped data (the complex model) improved the fit of the model compared to the equation generated by the entire data set (simple model). Diagnostics also were done on residuals generated from regressions of the grouped data.

Data grouped by magnitude of standardmethod concentration. Data were placed into two groups on the basis of magnitude of standard-method concentration. For Ohio, the single-sample secondarycontact recreational standard is $5,000 \mathrm{col} / 100 \mathrm{~mL}$ (Ohio Environmental Protection Agency, 1990). This is the highest recreational water-quality standard; for samples whose fecal-coliform concentration is less 


\section{A. PRECIDTED ENHANCED-RECOVERY CONCENTRATIONS}

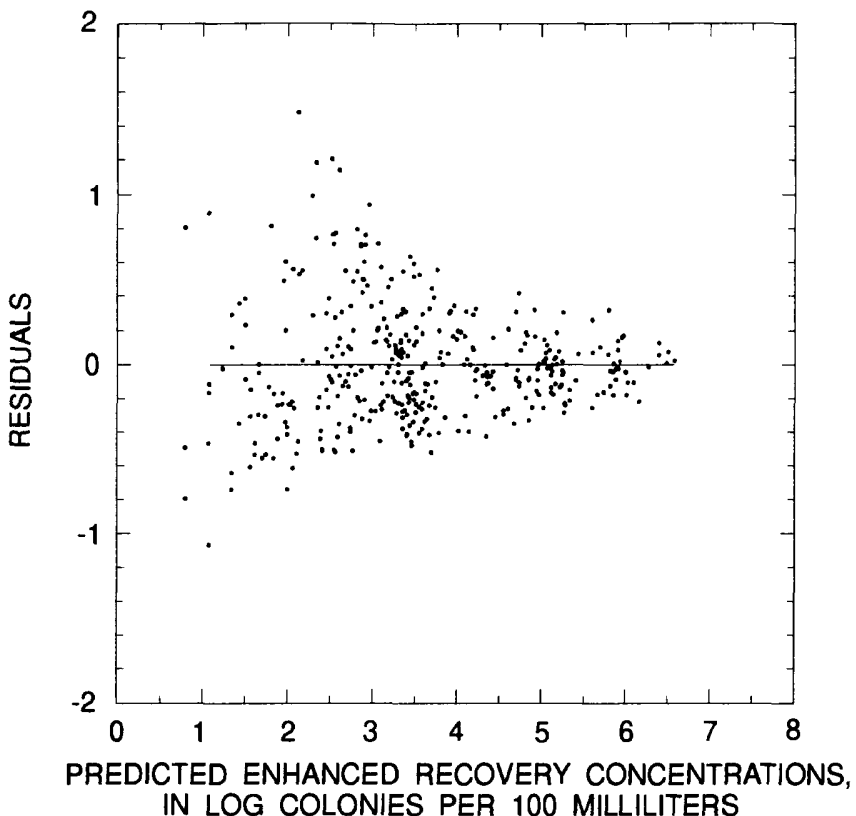

C. TREATMENT TYPE

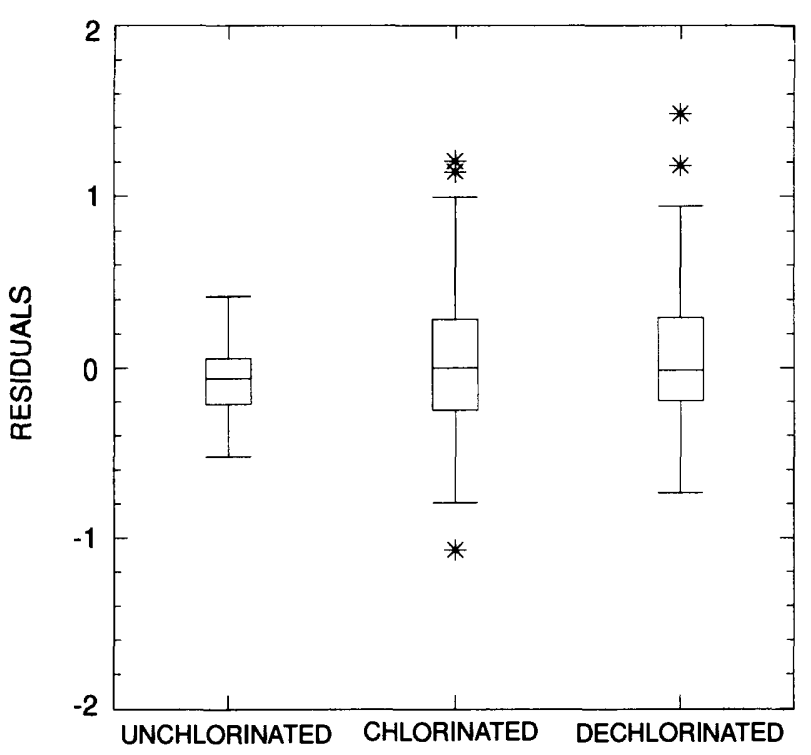

B. ELAPSED TIME

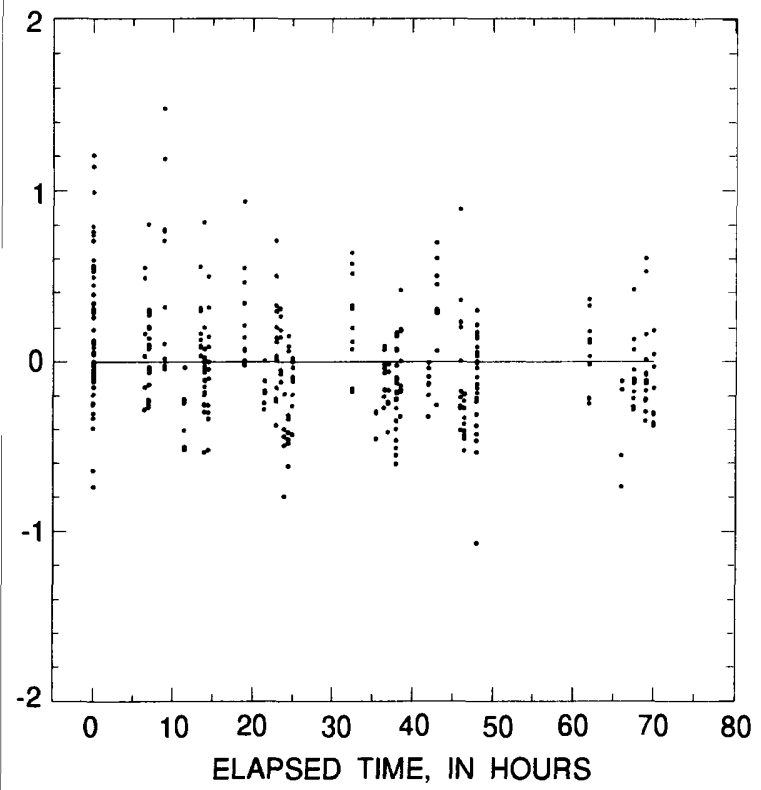

\section{EXPLANATION}

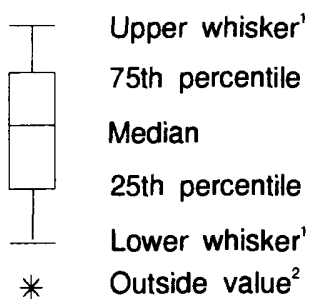

'Upper whisker is defined as the largest data point less than or equal to the upper quartile plus 1.5 times the interquartile range. Lower whisker is minus 1.5 times the interquartile range.

${ }^{2}$ An outside value is defined as greater than 1.5 and less than or equal to 3 interquartile ranges from the box.

Figure 12. Residuals from regression relation between enhanced-recovery and standard-method concentrations of fecal coliforms in seven field studies against: (A) predicted enhanced-recovery concentrations, (B) elapsed time, and (C) treatment type. (Data for wastewater and combinedsewer-overflow effluent, Cleveland area, Ohio.) 
than this standard, it is important to accurately predict enhanced-recovery concentrations from standardmethod concentrations. Therefore, data were placed into two groups on the basis of magnitude of standardmethod concentration: (1) less than or equal to 5,000 $\mathrm{col} / 100 \mathrm{~mL}(\leq 5,000)$ and $(2)$ greater than 5,000 $\mathrm{col} / 100 \mathrm{~mL}(>5,000)$. The data representing the two groups are shown on scatterplots (fig. 13) and regression statistics are included in table 7.

The model generated from $>5,000$ data set (fig. 13B) provided a better linear fit of the data than the model generated from $\leq 5,000$ data set (fig. 13A). The correlation coefficient was higher for $>5,000$ data set $(0.968)$ than $\leq 5,000$ data set $(0.897)$; the standard error of the regression was lower for $>5,000$ data set (16.03 percent) than for $\leq 5,000$ data set ( 39.5 percent); and the coefficient of variation was larger for $>5,000$ data set $(0.936)$ than for $\leq 5,000$ data set $(0.804)$ (table 7 ). In addition, the residuals from the $>5,000$ data set were normally distributed, whereas the residuals generated from the $\leq 5,000$ data set were not (table 7 ). The residuals generated from the model with data $>5,000$ (fig. 13B) were smaller in magnitude and less heteroscedastic than residuals generated with $\leq 5,000$ data (fig. 13A). However, the $F$-ratio calculated from analysis of variance of regression coefficients $(F$ ratio $=1.713$ ) resulted in a $p$-value of 0.179 , indicating that the slopes or $y$-intercepts were not statistically different between the regression equations generated from the two groups. Thus, the relation between enhanced-recovery and standard-method concentrations are better represented by the simple model than by the complex model.

Data grouped by treatment. Data were placed in three groups based on type of treatment: (1) unchlorinated, (2) chlorinated, and (3) dechlorinated. For brevity, these data groups are referred to as "unchlorinated data," "chlorinated data," and "dechlorinated data." The data representing the three groups are shown on scatterplots (fig. 14), and regression statistics are included in table 7.

The model generated from unchlorinated data (fig. 14A) provided a better linear fit of the data than the models generated from the chlorinated (fig. 14B) and dechlorinated data (fig. 14C). For the unchlorinated data, the correlation coefficient was higher (0.988), the standard error of the regression was considerably lower (16.74 percent), and the coefficient of variation was larger $(0.976)$ than values generated from chlorinated and dechlorinated data (table 7). The
$F$-ratio calculated from analysis of variance of regression coefficients among the three groups $(F$-ratio $=5.2)$ resulted in a $p$-value of 0.005 , an indication that the slopes or intercepts were statistically different among the regression equations generated from the three groups. Therefore, the data are best represented in regression relations generated from the complex model (data grouped by treatment type).

The residuals generated from the regression on unchlorinated data were normally distributed; those generated from chlorinated and dechlorinated data were not (table 7). The residuals generated from the regression on unchlorinated data (fig. 14A) were homoscedastic, satisfying an important assumption of linear regression; however, the residuals generated from the chlorinated data (fig. 14B) and the dechlorinated data (fig. 14C) showed considerable heteroscedasticity. Therefore, the regression equations generated from the unchlorinated samples met the assumptions of linear regression and provided the best estimate of enhanced-recovery concentrations from standard-method concentrations among the three treatment groups. For the regression equations generated from dechlorinated and chlorinated data, the normality of residual assumption and the equal variance assumption were not met. The assumption of a normal distribution is involved in testing hypotheses (Helsel and Hirsch, 1992) and, in this case, the hypothesis tests of whether the slope coefficient was statistically different than zero generated very high $t$-values of 23.56 (chlorinated) and 28.43 (dechlorinated); therefore, violation of this assumption was not a serious limitation. However, because of considerable heteroscedasticity of residuals, the regression equations generated from dechlorinated and chlorinated data did not provide a good estimate of enhanced-recovery concentrations from standard-method concentrations for all data.

Therefore, it appears that concentrations of fecal coliforms found by the enhanced-recovery method cannot be accurately predicted by standard-method concentrations for all receiving waters in this investigation. Accurate models were not generated for waters that contained high proportions of chlorinated or dechlorinated organisms or waters with low numbers of fecal coliforms. Presently, the standard method for fecal coliforms is the most widely used method to assess recreational water quality; enhanced-recovery methods are not routinely used. Therefore, the results of this investigation indicate that water-resource 
A. LESS THAN OR EQUAL TO 5,000 COLONIES PER 100 MILLILITERS
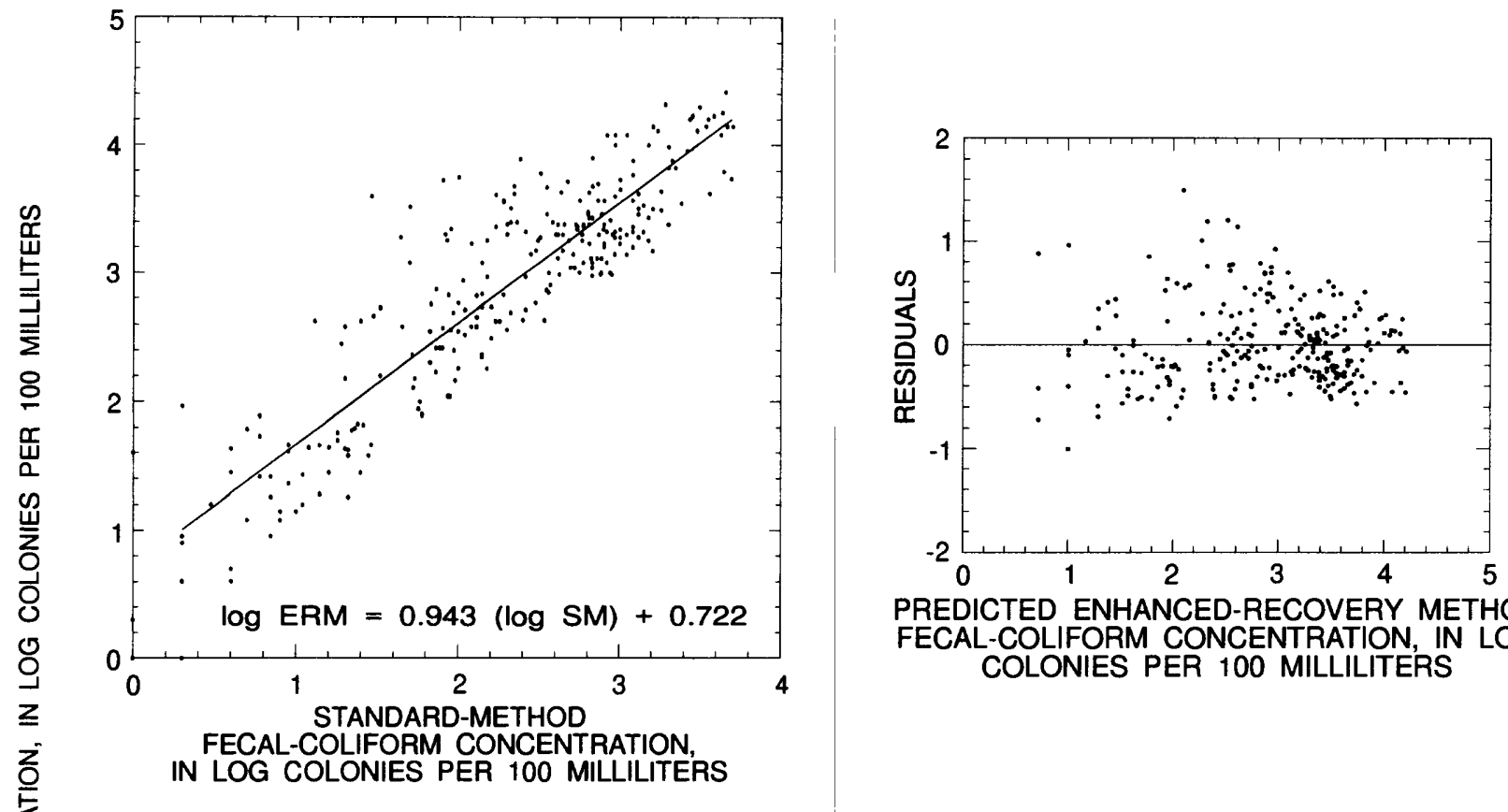

PREDICTED ENHANCED-RECOVERY METHOD FECAL-COLIFORM CONCENTRATION, IN LOG COLONIES PER 100 MILLILITERS

B. GREATER THAN 5,000 COLONIES PER 100 MILLILITERS
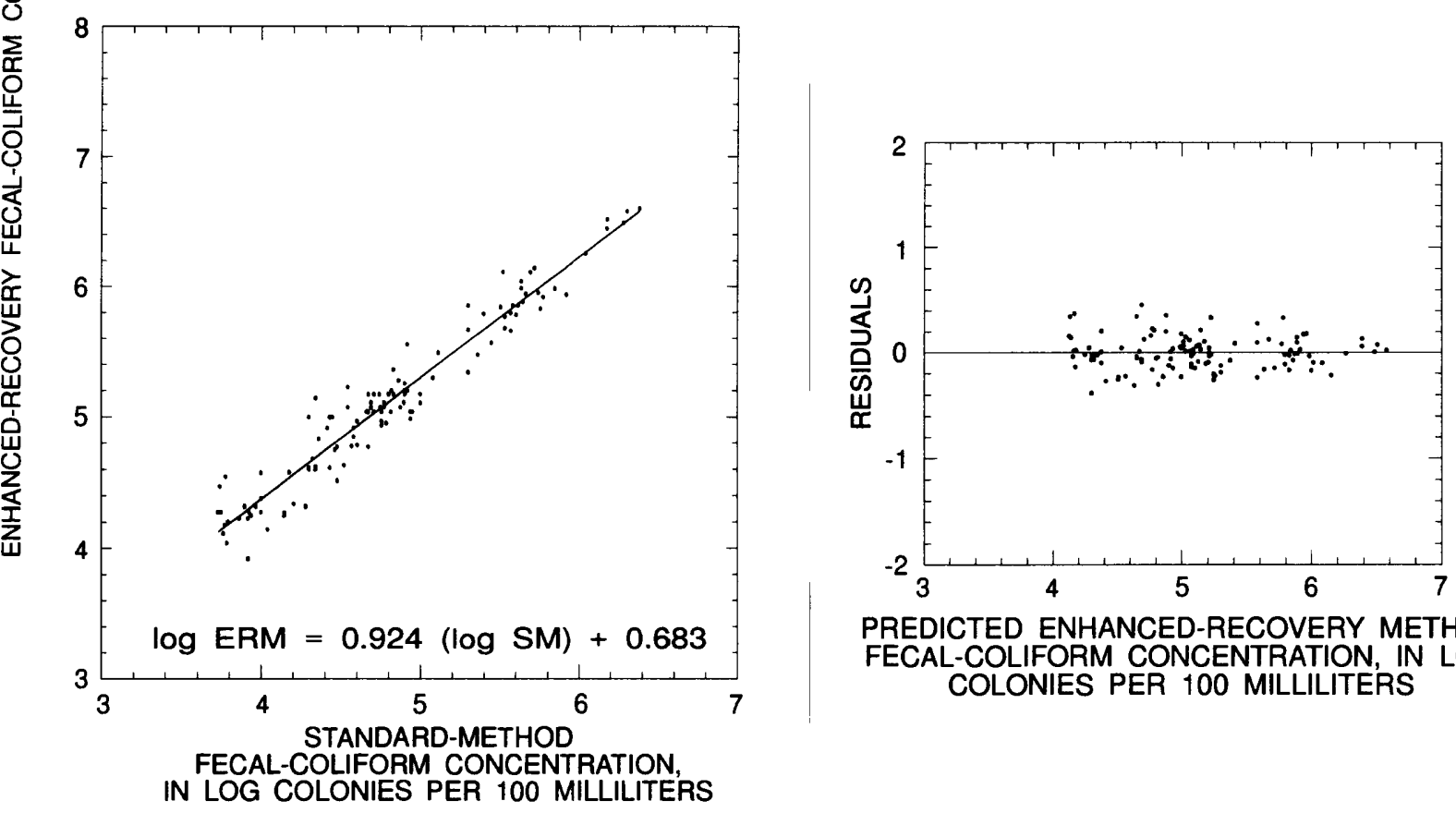

PREDICTED ENHANCED-RECOVERY METHOD FECAL-COLIFORM CONCENTRATION, IN LOG COLONIES PER 100 MILLILITERS

Figure 13. Regression relation between enhanced-recovery (ERM) and standard-method (SM) concentrations of fecal coliforms and associated residuals against predicted ERM concentrations for data grouped by magnitude of SM concentrations: $(A)$ less than or equal to 5,000 colonies per 100 milliliters and (B) greater than 5,000 colonies per 100 milliliters. (Data for wastewater and combined-sewer-overflow effluent, Cleveland area, Ohio.) 


\section{A. UNCHLORINATED}
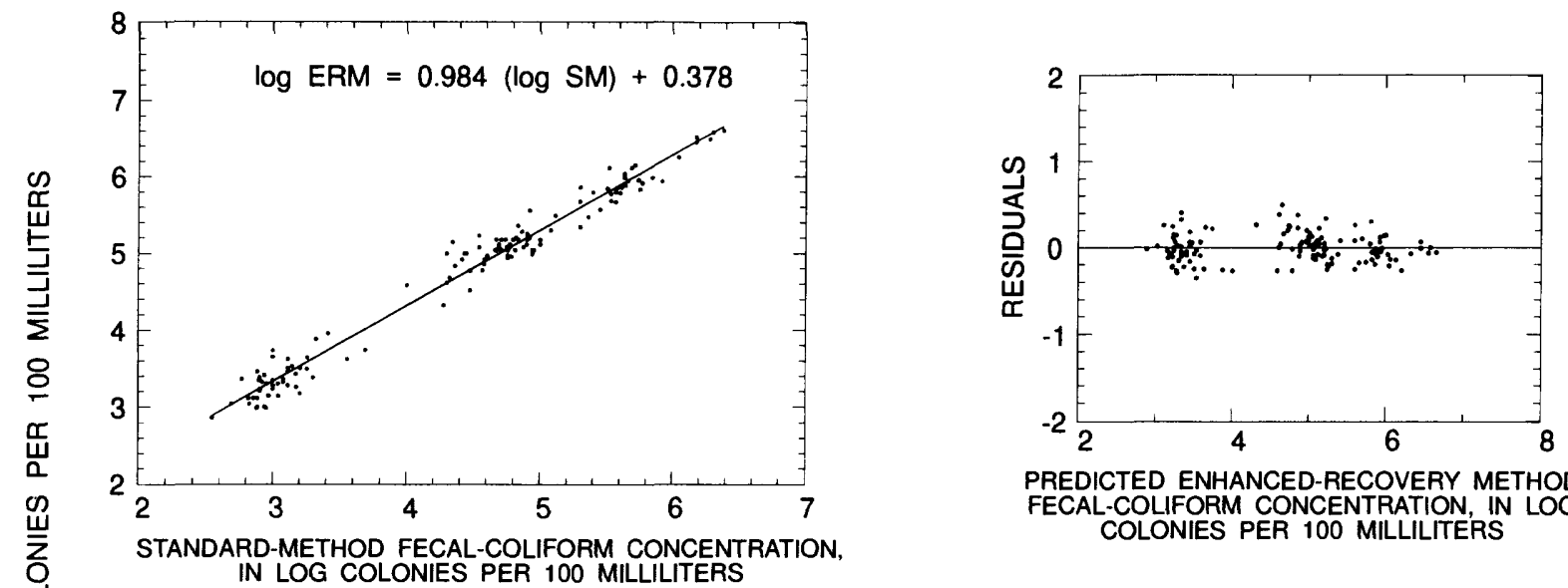

PREDICTED ENHANCED-RECOVERY METHOD FECAL-COLIFORM CONCENTRATION, IN LOG COLONIES PER 100 MILLILITERS

\section{B. CHLORINATED}
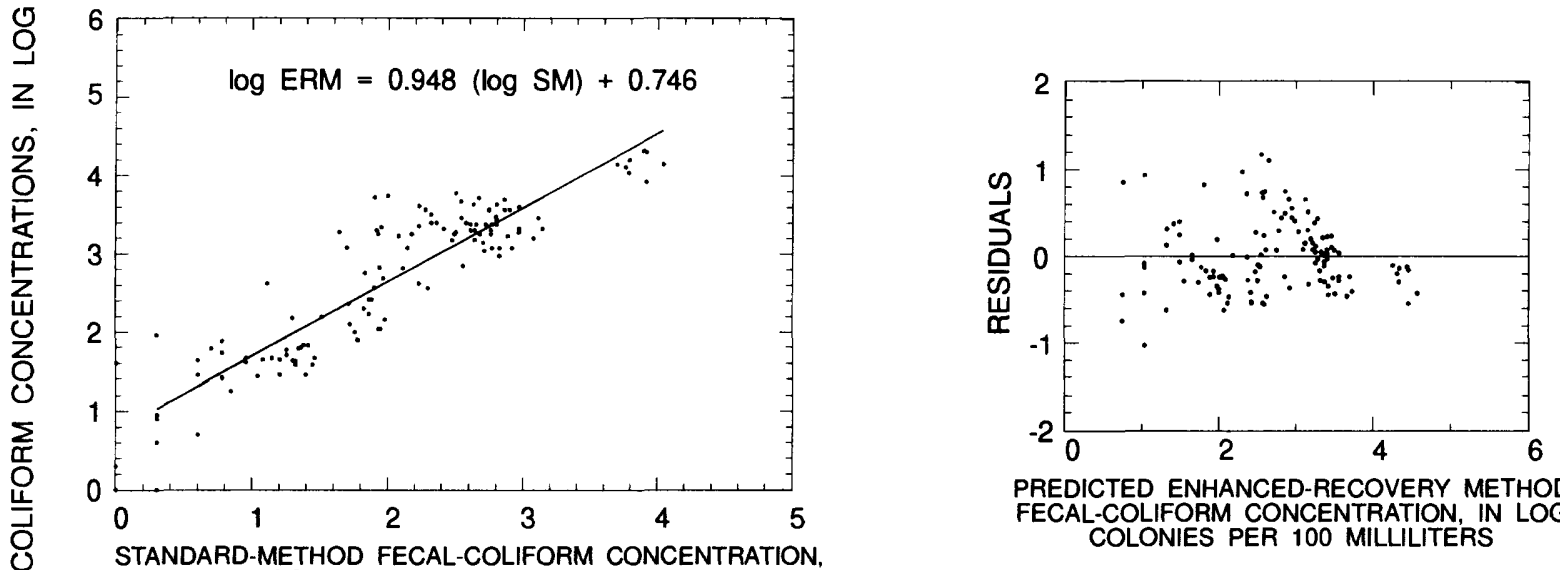

PREDICTED ENHANCED-RECOVERY METHOD FECAL-COLIFORM CONCENTRATION, IN LOG COLONIES PER 100 MILLILITERS IN LOG COLONIES PER 100 MILLILITERS

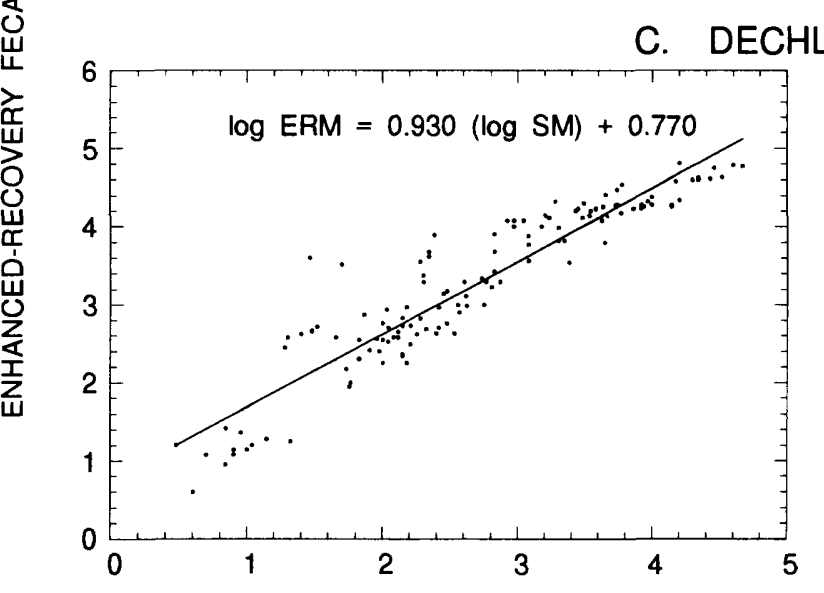

STANDARD-METHOD FECAL-COLIFORM CONCENTRATION,

IN LOG COLONIES PER 100 MILLILITERS

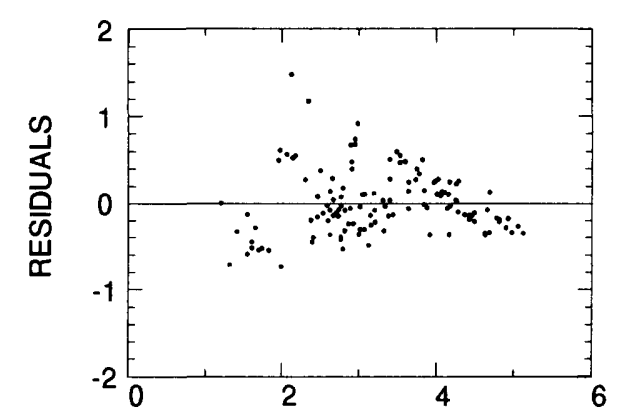

PREDICTED ENHANCED-RECOVERY METHOD FECAL-COLIFORM CONCENTRATION, IN LOG COLONIES PER 100 MILLILITERS

Figure 14. Regression relation between enhanced-recovery (ERM) and standard-method (SM) concentrations of fecal coliforms and associated residuals against predicted enhanced-recovery concentrations for data grouped by treatment: (A) unchlorinated, (B) chlorinated, and (C) dechlorinated. (Data for wastewater and combined-sewer-overflow effluents, Cleveland area, Ohio.) 
managers may not have enough information about concentrations of injured fecal coliforms to correctly interpret the health risk of swimming in waters with high proportions of chlorinated or dechlorinated organisms.

\section{Relation of Enhanced-Recovery and Standard-Method Concentrations to Ohio Recreational Water-Quality Standards}

Fecal-coliform concentrations found in the seven field studies were evaluated in terms of Ohio water-quality standards (Ohio Environmental Protection Agency, 1990). The investigators calculated the percentage of samples in each field study by treatment type that met Ohio's single-sample bathing water (fig. 15), primary-contact (fig. 16), or secondary-contact (fig 17) fecal-coliform recreational standards by use of the standard or enhanced-recovery methods.

Unchlorinated, chlorinated, and dechlorinated samples were placed in the following categories:

1. samples whose fecal-coliform concentration met recreational water-quality standards, regardless of method,

2. samples whose fecal-coliform concentration met recreational water-quality standards if the standard method was used but exceeded the standards if the enhanced-recovery method was used (referred to as mixed category), and

3. samples whose fecal-coliform concentration exceeded recreational water-quality standards, regardless of method.

Samples that fall into the mixed category are particularly troublesome. These samples may lead to misinterpretations of the health risk of swimming in contaminated waters if only results from standard methods are used to assess risk.

For all samples, patterns emerged that placed the field studies into three categories based on results of meeting or exceeding recreational-water quality standards. The observed patterns were the following:

1. field studies of wastewater effluents with low concentrations of fecal coliforms-concentrations were $<10,000 \mathrm{col} / 100 \mathrm{~mL}$ throughout each field study (May 1994, August 1995, and September 1995);

2. field studies of wastewater effluent with high concentrations of fecal coliforms--initial unchlorinated sample concentrations were $>10,000 \mathrm{col} / 100$ $\mathrm{mL}$ and increased at least tenfold throughout the field study (June 1994 and August 1994); and
3. CSO field studies (May and June 1995).

Single-sample bathing-water standard. Bathing waters are defined as those waters suitable for swimming and other full-body contact where a lifeguard or bathhouse is present (Ohio Environmental Protection Agency, 1990). Fecal-coliform concentrations in most of the unchlorinated samples exceeded the single-sample bathing-water standard of 400 $\mathrm{col} / 100 \mathrm{~mL}$ (fig. 15). All chlorinated samples from wastewater-effluent field studies with low concentrations of fecal coliforms (fig. 15A), met the bathingwater standard regardless of the method used to determine those concentrations. However, of the dechlorinated samples, 75 percent in May 1994 and 48 percent in August 1995 were in the mixed category. In contrast, all the dechlorinated samples from wastewatereffluent field studies with high concentrations of fecal coliforms (fig. 15B) exceeded the bathing-water standard regardless of method; however, a considerable percentage of chlorinated samples fell into the mixed category. Dechlorinated and chlorinated samples from the May 1995 CSO field study (fig. 15C) either exceeded the standard regardless of method or were in the mixed category; thus, none of these samples met the bathing-water single-sample standard. In the June 1995 CSO field study, dechlorinated and chlorinated samples were in all categories.

Generalizations on the health risk of swimming in receiving waters during this investigation based on the single-sample bathing-water standard can be made. The data indicate that the health risk of swimming in waters receiving unchlorinated effluent was high. Chlorination of wastewater effluents that had low concentrations of fecal coliforms resulted in receiving waters meeting bathing-water single-sample standards, even if enhanced-recovery methods were used. However, risks associated with dechlorinated, lowfecal-coliform effluents were unclear because many of the dechlorinated samples were in the mixed category. For wastewater-effluent field studies with high concentrations of fecal coliforms in dechlorinated effluents, interpretation of the health risk of swimming in receiving waters was simpler because these samples did not meet the bathing-water standard by use of either method. However, for chlorinated, high-concentration effluents, the health risk of swimming in receiving waters was uncertain because many of these samples were in the mixed category. In this investigation, interpretation of the health risk of swimming in CSO-contaminated waters was generally difficult, 


\section{A. WASTEWATER EFFLUENT, LOW CONCENTRATIONS OF BACTERIA}
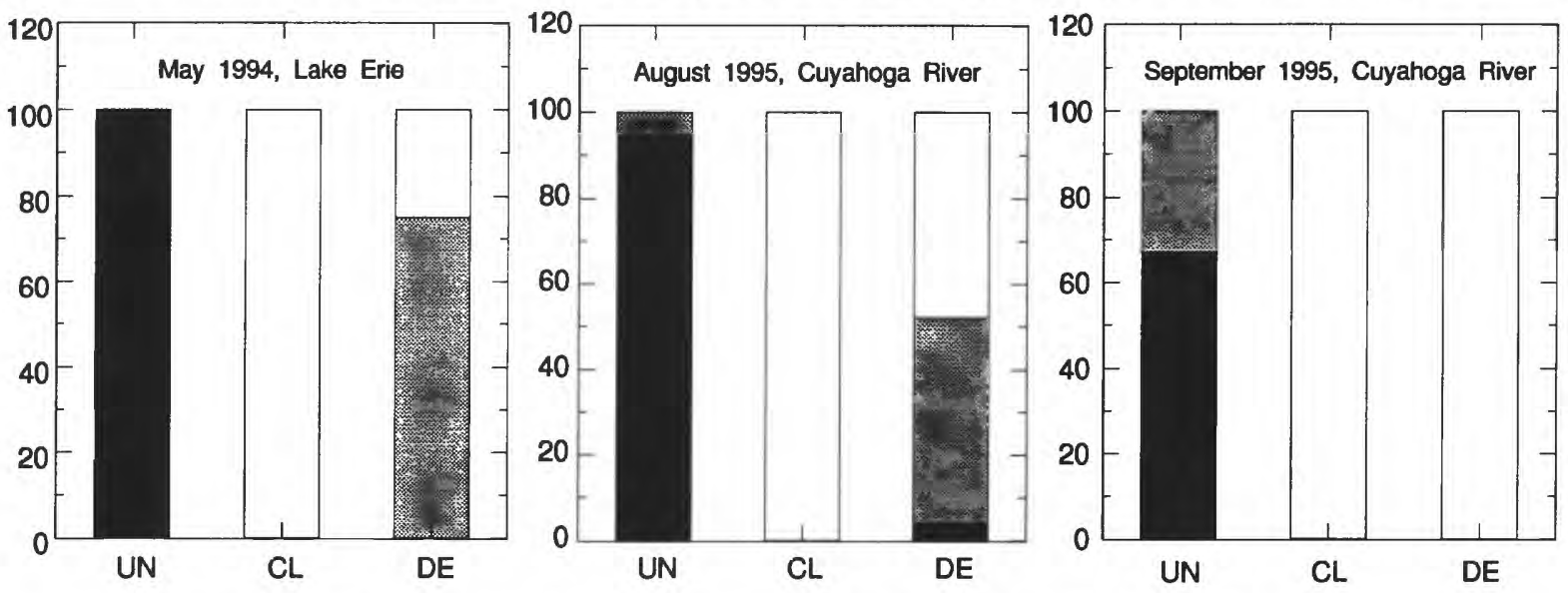

\section{B. WASTEWATER EFFLUENT, HIGH CONCENTRATIONS OF BACTERIA}

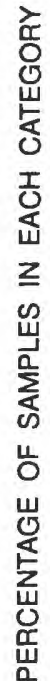
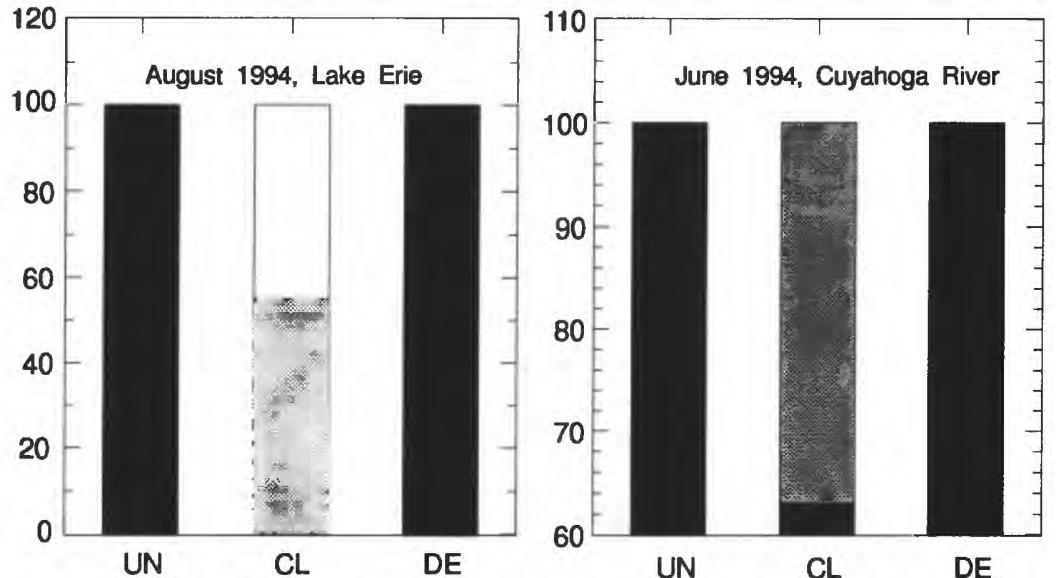

C. COMBINED-SEWER OVERFLOW EFFLUENT

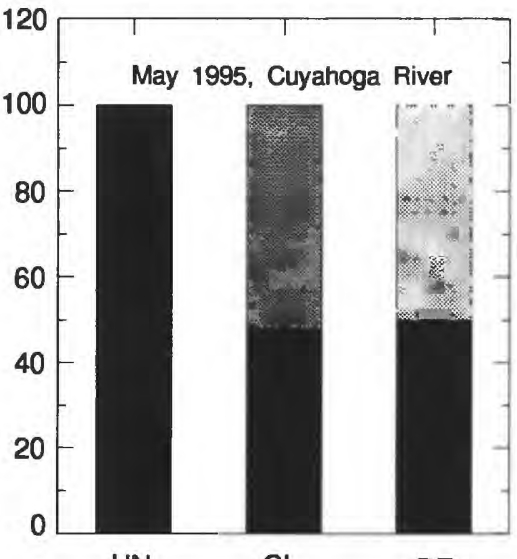

UN

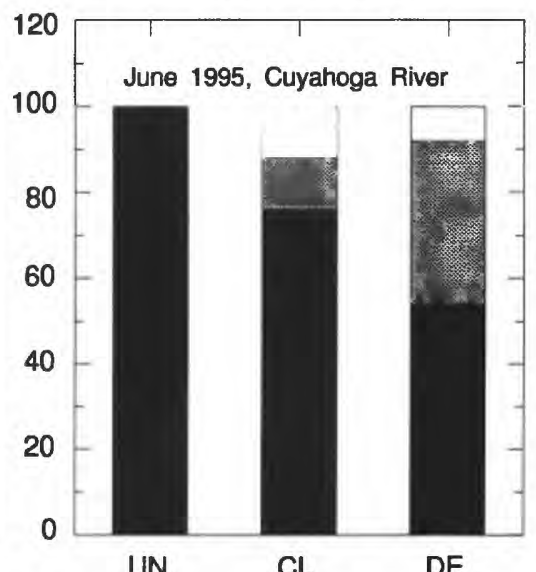

UN

$\mathrm{CL}$

TREATMENT

Figure 15. Percentage of samples, by treatment type, in which fecal-coliform concentrations determined by standard and enhanced-recovery methods met and exceeded Ohio's bathingwater single-sample standard: (A) wastewater effluent, low concentrations of bacteria, (B) wastewater effluent, high concentrations of bacteria, and (C) combined-sewer-overflow effluent. (UN is unchlorinated; CL is chlorinated; and DE is dechlorinated.) 
A. WASTEWATER EFFLUENT, LOW CONCENTRATIONS OF BACTERIA
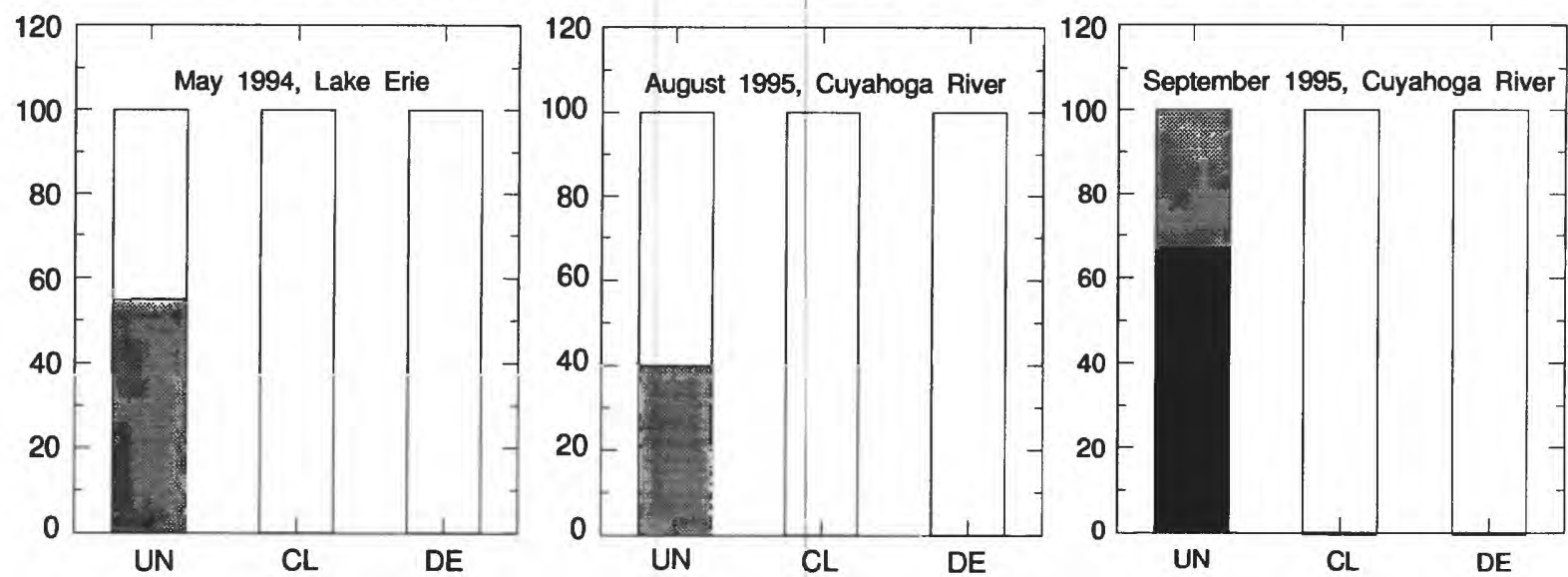

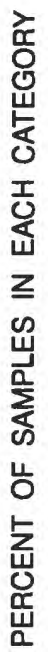

B. WASTEWATER EFFLUENT, HIGH CONCENTRATIONS OF BACTERIA
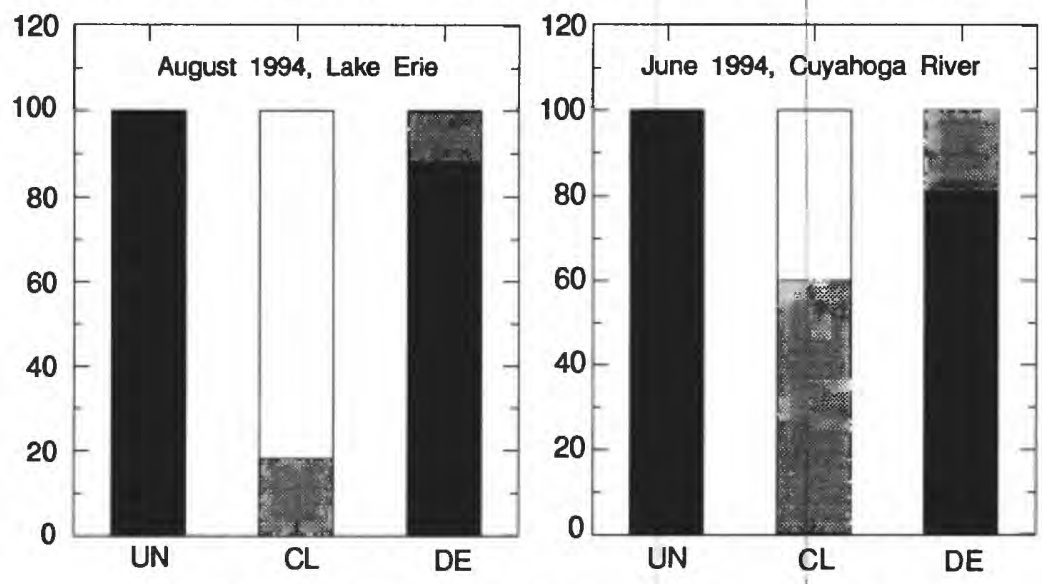

C. COMBINED-SEWER OVERFLOW EFFLUENT
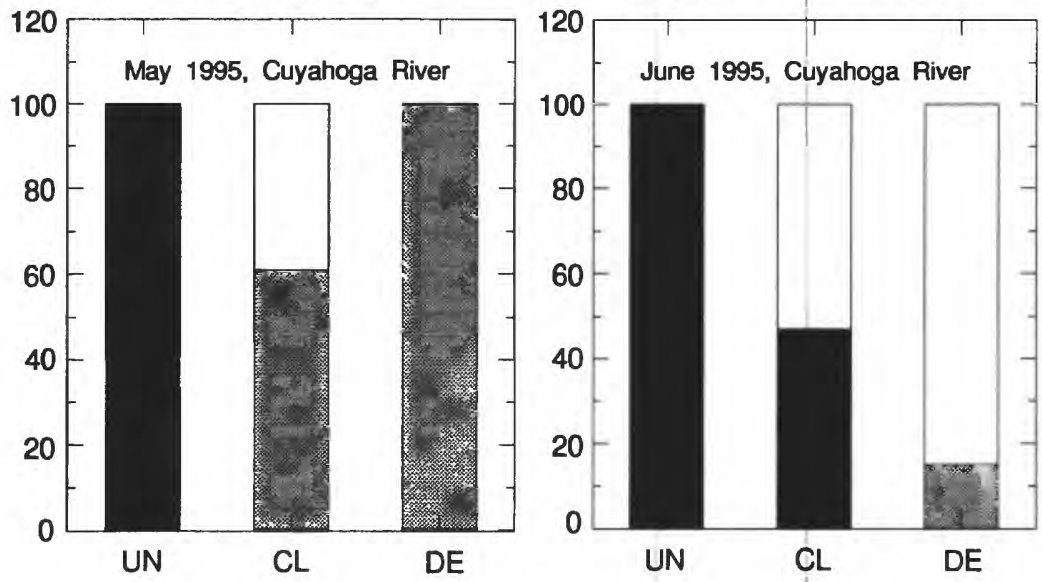

EXPLANATION

Concentration met primarycontact standard

Concentration from standard method met primary-

contact standard, and concentration from enhanced-recovery method exceeded primary-contact standard (mixed category)

Concentration exceeded primary-contact standard

Figure 16. Percentage of samples, by treatment type, in which fecal-coliform concentrations determined by standard and enhanced-recovery methods met and exceeded Ohio's primary-contact single-sample standard: (A) wastewater effluent, low concentrations of bacteria, (B) wastewater effluent, high concentrations of bacteria, and (C) combined-sewer overflow effluent. (UN is unchlorinated; $\mathrm{CL}$ is chlorinated; and $\mathrm{DE}$ is dechlorinated.) 


\section{A. WASTEWATER EFFLUENT, LOW CONCENTRATIONS OF BACTERIA}
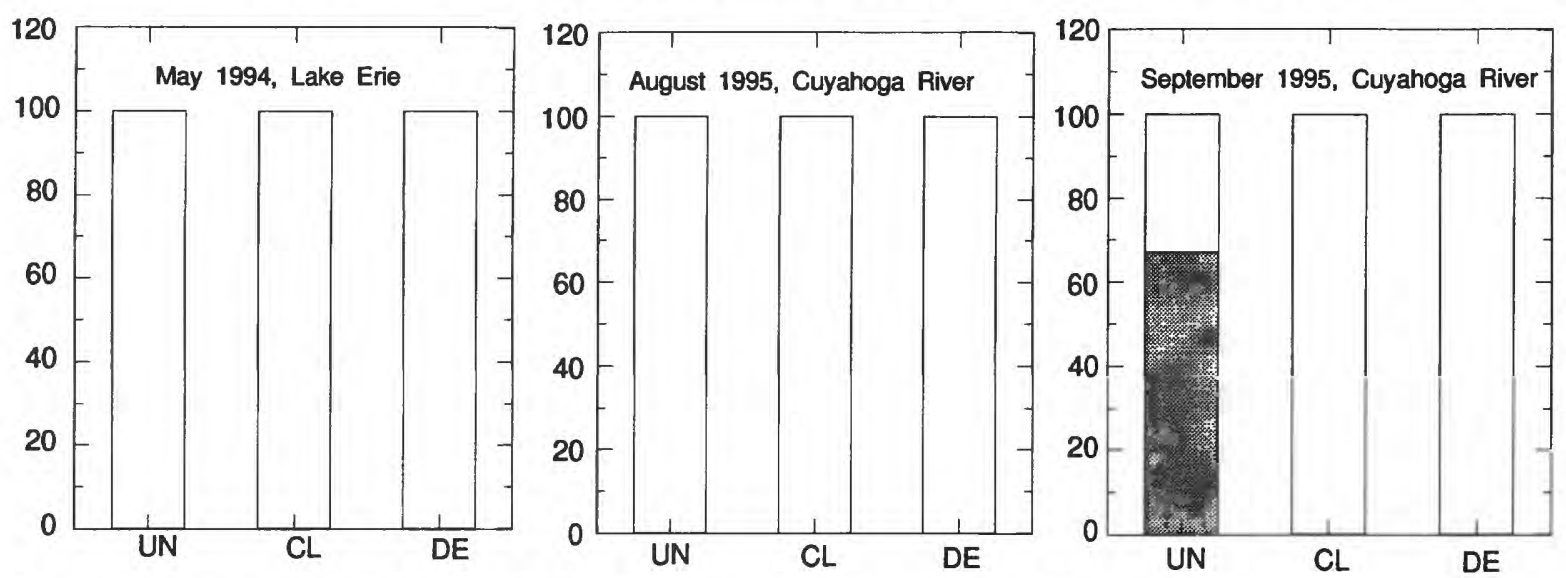

B. WASTEWATER EFFLUENT, HIGH CONCENTRATIONS OF BACTERIA

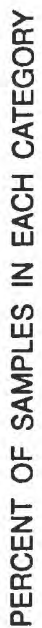
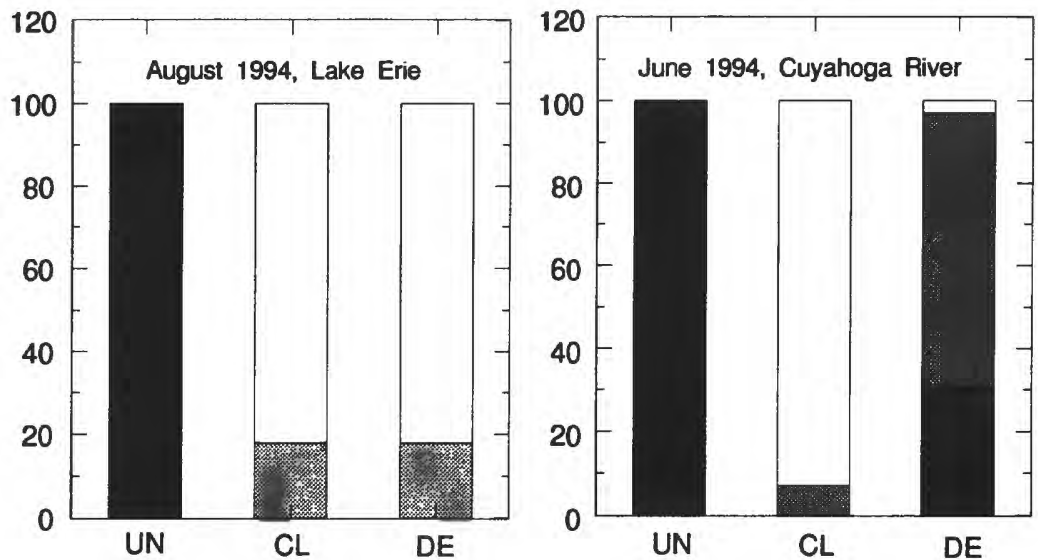

EXPLANATION

\section{COMBINED-SEWER-OVERFLOW EFFLUENT}
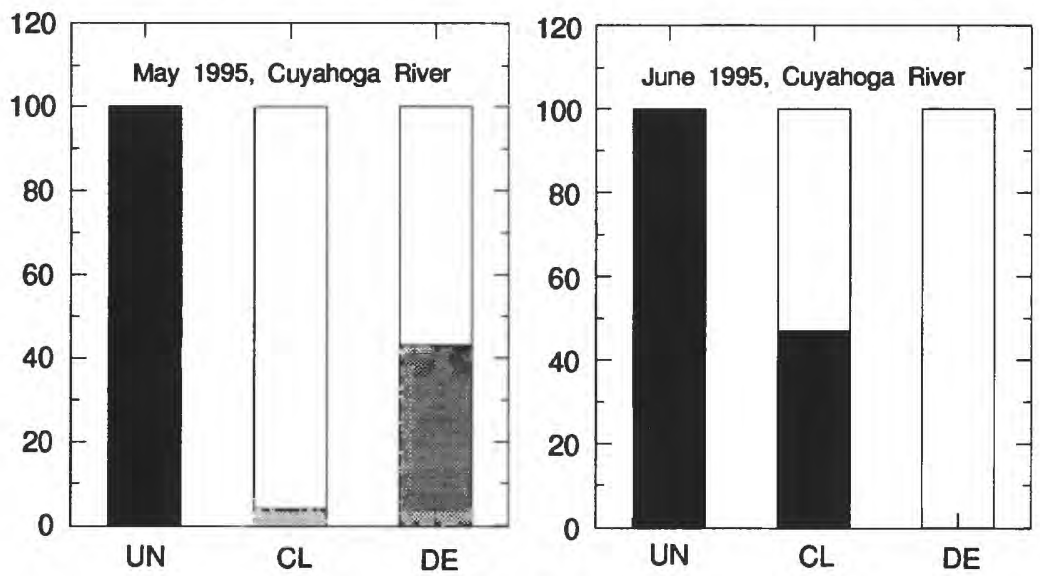

TREATMENT

Figure 17. Percentage of samples, by treatment type, in which fecal-coliform concentrations determined by standard and enhanced-recovery methods met and exceeded Ohio's secondarycontact-single-sample standard: (A) wastewater effluent, low concentrations of bacteria, (B) wastewater effluent, high concentrations of bacteria, and (C) combined-sewer-overflow effluent. (UN is unchlorinated; $C L$ is chlorinated; and DE is dechlorinated.) 
because many of the chlorinated and dechlorinated samples fell into the mixed category.

Single-sample primary-contact standard. The Ohio Environmental Protection Agency (1990) defines primary-contact waters as those waters suitable for full-body contact, such as swimming, canoeing, and scuba diving. The single-sample primarycontact standard in Ohio for fecal coliforms is 2,000 $\mathrm{col} / 100 \mathrm{~mL}$ (Ohio Environmental Protection Agency, 1990). For unchlorinated samples, the primary-contact standard was sometimes met in wastewater-effluent field studies where concentrations of fecal coliforms were low (fig. 16A); however, the standard was exceeded in unchlorinated samples from wastewater-effluent field studies where concentrations of fecal coliforms were high (fig. 16B) and in CSO field studies (fig. 16C). All chlorinated and dechlorinated samples from wastewater-effluent field studies where concentrations of fecal coliforms were low (fig. 16A) met the primary-contact standard by use of either the standard or enhanced-recovery method. In contrast, in wastewater-effluent field studies where concentrations of fecal coliforms were high (fig. 16B), 12-60 percent of the chlorinated and dechlorinated samples were in the mixed category; the remaining chlorinated samples met the standard and the remaining dechlorinated samples exceeded the standard. Therefore, with regard to the single-sample primary contact standard and waters receiving wastewater with high concentrations of fecal coliforms, chlorination alone was more effective than chlorination followed by dechlorination in reducing fecal-coliform concentrations to acceptable levels in these field studies. No pattern emerged from the evaluation of the CSO effluents in terms of the primary-contact standard (fig. 16C), probably because of the uncertain composition of CSO materials. As with the bathing-water standards, many CSO effluent samples in this investigation fell within the mixed category, thus making the evaluation of the health risk of swimming in CSO-contaminated waters difficult.

\section{Single-sample secondary-contact standard.} The Ohio Environmental Protection Agency (1990) defines secondary-contact waters as those waters that are suitable for partial-body contact, such as wading. The single-sample secondary-contact standard is 5,000 col/100 mL (Ohio Environmental Protection Agency, 1990). Most samples collected from wastewater-effluent field studies with low concentrations of fecal coliforms met this standard (fig. 17A). Wastewater effluents containing low concentrations of fecal coliforms are often released during cool weather, when secondary contact is the common water-based recreational activity. For wastewater-effluent field studies where concentrations of fecal coliforms were high (fig. 17B), all the unchlorinated samples exceeded the secondary-contact standard, most of the chlorinated samples met the secondary-contact standard, and the dechlorinated samples were within all three categories. Similarly, CSO effluent samples were within all three categories (fig. 17C), again owing to the uncertain composition and unpredictability of CSO materials. In the June 1995 CSO field study, the dechlorinated samples met the secondary-contact standard more often than chlorinated samples did.

\section{Summary and Conclusions}

To meet new chlorine water-quality standards required by the U.S. Environmental Protection Agency, many wastewater treatment plants in Ohio and elsewhere must now dechlorinate effluents before discharging them to inland waterways. However, there is little information on the effect of dechlorination on the repair of injury and survival of chlorine-injured fecal-indicator bacteria in receiving waters and on their regrowth on growth medium.

Seven field studies were done during the recreational seasons of 1994 and 1995 at one Lake Erie location and three Cuyahoga River locations in the Cleveland, Ohio metropolitan area to study fecalcoliform injury, survival, and regrowth. Incubation chambers, containing unchlorinated, chlorinated, or dechlorinated wastewater or combined-sewer overflow (CSO) effluents were placed in river or lake water. The contents of the chambers were analyzed for concentrations of injured and healthy fecal coliforms by use of standard and enhanced-recovery membranefiltration (MF) methods. Standard methods support the growth of healthy organisms, whereas enhancedrecovery methods support the growth of both healthy and injured organisms. The enhanced-recovery method selected for the field studies differed from the standard method in that rosalic acid was omitted from the medium and a 4-hour resuscitation at $35^{\circ} \mathrm{C}$ preceded incubation at $44.5^{\circ} \mathrm{C}$.

Field studies were done in May 1994 and in August 1994 at the Lake Erie site with wastewater effluent from the Easterly Wastewater Treatment Plant. In May, when mean water temperature was 
$12.8^{\circ} \mathrm{C}$, fecal-coliform concentrations in all samples remained fairly constant, probably because of slow bacteria metabolic rates. In August 1994, when mean water temperature was $22.6^{\circ} \mathrm{C}$, concentrations in unchlorinated and dechlorinated samples increased during the first 10 to 13 hours. In contrast, in August 1994 in chlorinated samples, concentrations on enhanced-recovery media dropped off sharply during the first 7 hours, indicating that the chlorinated organisms were unable to repair injuries and regrow on enhanced-recovery media.

Field studies were done in June 1994 and August 1995 at two Cuyahoga River sites_Peninsula and West Third- with wastewater effluent from the Southerly Wastewater Treatment Plant. During both field studies, mean dissolved-oxygen concentrations were 2-3 $\mathrm{mg} / \mathrm{L}$ higher at Peninsula than at West Third. In June 1994 at both sites, fecal-coliform concentrations generally increased slightly or remained the same after the initial timestep. However, in August 1995 at West Third, unchlorinated concentrations decreased, whereas chlorinated and dechlorinated concentrations increased and decreased, an indication that the increases in concentrations in chlorinated and dechlorinated samples were due in part to repair of chlorine-injured cells and regrowth on culture media.

Field studies were done in May 1995 and June 1995 at the Cuyahoga River at Independence with CSO effluent collected from Mill Creek. In May 1995, mean water temperature was $15.6^{\circ} \mathrm{C}$, whereas in June 1995 , mean water temperature was $23.1^{\circ} \mathrm{C}$. In May 1995 , in dechlorinated and chlorinated samples but not in unchlorinated samples, fecal-coliform concentrations by use of the enhanced-recovery method increased more rapidly from about 20-32 hours than those by use of the standard method. This finding indicates that repair of chlorine-induced injuries may have enabled some previously undetected organisms in dechlorinated and chlorinated samples to grow on enhanced-recovery media. In the chlorinated samples in June 1995, fecal-coliform concentrations peaked at 14 hours and again at 48 hours. CSO effluent samples contain more solid materials than treated wastewater effluent; perhaps the second, atypical fecal-coliform concentration peak in chlorinated samples was due to solids breaking apart and releasing a reservoir of bacteria and nutrients in the water.

The effects of wastewater treatment and site on percent injury of fecal coliforms were determined by use of analysis of variance (ANOVA). At the Lake
Erie site in May 1994, percent injuries in the dechlorinated and chlorinated samples were statistically higher than percent injuries in the unchlorinated samples. In contrast, in August 1994 at Lake Erie, percent injuries in the chlorinated samples were statistically higher than percent injuries in the unchlorinated and dechlorinated samples. Therefore, in May 1994, the rate of repair and regrowth on culture media was lower in chlorinated and dechlorinated samples than in unchlorinated samples. In August 1994, however, fecal coliforms in dechlorinated samples were able to repair injuries caused by chlorination and regrow on culture media, whereas those in chlorinated samples could not.

ANOVA on the data from two Cuyahoga River sites in June 1994 and August 1995 showed that treatment did affect percent injury, site did not affect percent injury, and there was no interaction effect between site and treatment. In both studies, statistically significant differences in percent injuries were found between some unchlorinated as compared to dechlorinated and chlorinated samples; however, no statistically significant differences were found between dechlorinated and chlorinated samples. Therefore, in the warm-weather Cuyahoga River field studies (unlike the warm-weather Lake Erie field study), dechlorination did not enhance the repair and regrowth of chlorine-injured fecal coliforms over chlorination alone. This result may be due to waterquality differences between the lake and river or due to the quality of the wastewater effluents used in lake and river field studies.

ANOVA on the data from CSO field studies in May and June 1995 revealed statistically significant differences in percent injuries between all possible pairs of treatment groups. The highest percent injuries were found in dechlorinated samples, contrary to what was found in wastewater-effluent field studies. Dechlorination, therefore, appeared to reduce the ability of organisms to recover and regrow on culture media over chlorination alone. The presence of untreated waste and high solid concentrations may have contributed to this result.

The effects of wastewater treatment and site on percent survival were determined by ANOVA. Mean percent survivals were highest in the unchlorinated population for all field studies. Mean percent survivals were higher in the dechlorinated than chlorinated populations, except in the June 1995 CSO field study. Statistically significant differences in mean percent 
survivals were found between treatments for all field studies except in June 1995, wherein no statistically significant difference was found between chlorinated and dechlorinated samples. In the June 1994 Cuyahoga River wastewater-effluent field study, no statistically significant differences were found in percent survivals between Peninsula and West Third sites. In the August 1995 Cuyahoga River wastewater-effluent field study, however, percent survivals in the dechlorinated samples at the West Third site were statistically higher than those found in the dechlorinated samples at the Peninsula site. Water-quality differences, however, were not as influential a factor as treatment in affecting the survival of fecal coliforms.

Linear regression analysis of data from the seven field studies showed that standard-method and enhanced-recovery method concentrations were highly correlated and that the regression relationship was statistically significant; however, regression diagnostics indicated heteroscedasticity (nonconstant variance) of the residuals. Upon further analysis, it was found that the data were best represented in regression relations generated from data grouped by treatment type. The model generated from the unchlorinated data met the assumptions of linear regression and provided the best estimate of enhanced-recovery concentrations from standard-method concentrations.

However, the residuals generated from regression of the chlorinated and dechlorinated data showed considerable heteroscedasticity. Therefore, concentrations of fecal coliforms determined by the enhanced-recovery method probably cannot be accurately predicted from standard-method concentrations for all receiving waters. The results of this investigation indicate that water-resource managers may not have enough information about concentrations of injured fecal coliforms from standard-method concentrations to correctly interpret the health risk of swimming in waters with high proportions of chlorinated or dechlorinated organisms.

The investigators determined whether concentrations obtained by standard and enhanced-recovery methods were comparable as indicators of recreationwater quality in the seven field studies. The percentage of samples by treatment types in which fecalcoliform concentrations met and exceeded Ohio's bathing-water, primary-contact, and secondary contact single-sample standards were classified in three categories: (1) samples whose fecal-coliform concentration met recreational water-quality standards regardless of the method used to determine that concentration, (2) samples whose fecal-coliform concentration met recreational water-quality standards if the standard method was used but exceeded the standards if the enhanced-recovery method was used (referred to as mixed category), and (3) samples whose fecalcoliform concentration exceeded recreational waterquality standards regardless of the method used. Samples in the mixed category may lead to misinterpretations of the health risk of swimming in contaminated waters if results from standard methods only are used to assess water quality.

For all samples, patterns emerged that placed the field studies into three categories based on results of meeting or exceeding recreational-water quality standards: (1) field studies of wastewater effluents with low concentrations of fecal coliforms (May 1994, August 1995, and September 1995); (2) field studies of wastewater effluent with high concentrations of fecal coliforms (June 1994 and August 1994); and (3) CSO field studies (May and June 1995). In wastewater-effluent field studies where concentrations were low, chlorinated samples met the recreational-water quality standards regardless of the method used; however, dechlorinated and unchlorinated samples were placed in all three categories. In wastewater-effluent field studies where concentrations were high, unchlorinated samples exceeded the standards regardless of the method used; however, many chlorinated samples and some dechlorinated samples were placed in the mixed category. In CSO effluent studies, although all unchlorinated samples exceeded the standards, no pattern emerged in terms of chlorinated and dechlorinated samples meeting and exceeding any of the standards, and many of the chlorinated and dechlorinated samples were placed in the mixed category. Therefore, evaluation of fecal-coliform concentrations found in field studies in terms of Ohio recreational water-quality standards showed that concentrations obtained by standard and enhanced-recovery methods were not always comparable.

Therefore, determining the health risk of swimming in receiving waters is difficult if information on enhanced-recovery method concentrations is not available. Wastewater treatment affects the injury, survival, and regrowth of fecal-indicator bacteria; receivingwater quality at the two Cuyahoga River sites had little effect on these processes. Dechlorination enhanced the repair of injuries and survival of chlorine-injured fecal coliforms over chlorination alone in the lake, but not 
in the river. Whether this was because of water-quality differences between the lake and the river or because of the quality of the wastewater effluents used in the lake and river field studies was not determined in this investigation. Patterns of concentration increases and decreases in CSO effluents were atypical, so the effects of wastewater treatment on injury, survival, and regrowth in CSO effluents could not be determined.

\section{References Cited}

American Public Health Association, American Water Works Association, and Water Pollution Control Federation, 1992, Standard methods for the analysis of water and wastewater (18th ed.): Washington, D.C., American Public Health Association, p. III.

Bissonnette, G.K., Jezeki, J.J., McFeters, G.A., and Stuart, D.G., 1975, Influence of environmental stress on enumeration of indicator bacteria from natural waters: Applied Microbiology, v. 29, no. 2, p. 186-194.

Braswell, J.R., and Hoadley, A.W., 1974, Recovery of Escherichia coli from chlorinated secondary sewage: Applied Microbiology, v. 28, p. 328-329.

Britton, L.J., and Greeson, P.E., eds., 1989, Methods for collection and analysis of aquatic biological and microbiological samples: U.S. Geological Survey Techniques of Water-Resources Investigations, book 5, chap. A4, $363 \mathrm{p}$.

Brock, T.D., and Madigan, M.T., 1988, The biology of microorganisms: Englewood Cliffs, N.J., PrenticeHall, Inc., p. 330.

Calabrese, J.P., and Bissonnette, G.K., 1990, Improved membrane filtration method incorporating catalase and sodium pyruvate for detection of chlorine-stressed coliform bacteria: Applied and Environmental Microbiology, v. 56, no. 11, p. 3,558-3,564.

Camper, A.K., and McFeters, G.A., 1979, Chlorine injury and the enumeration of waterborne coliform bacteria: Applied and Environmental Microbiology, v. 37, no. 3, p. 633-641.

Carillo, M., Estrada, E., and Hazen, T.C., 1985, Survival and enumeration of fecal indicators-Bifidobacterium adolescentis and Escherichia coli in a tropical rain forest watershed: Applied and Environmental Microbiology, v. 50, no. 2, p. 468-476.

Conover, W.J., and Iman, R.L., 1981, Rank transformation as a bridge between parametric and nonparametric statistics: American Statistician, v. 35, no. 3, p. 124-129.

Flint, K.P., 1987, The long-term survival of Escherichia coli in river water: Journal of Applied Bacteriology, v. 63, p. 261-270.
Green, B.L., Clausen, E.M., and Litsky, W., 1977, Two-temperature membrane filter method for enumerating fecal coliform bacteria from chlorinated effluents: Applied and Environmental Microbiology, v. 33, no. 6, p. 1,259-1,264.

Haas, C.N., Sheerin, J.G., Lue-Hing, C., Rao, K.C., and O'Brien, P., 1988, Effects of discontinuing disinfection on a receiving water: Journal of the Water Pollution Control Federation, v. 60, no. 5, p. 667-673.

Hazen, T.C., and Esch, G.W., 1983, Effect of effluent from a nitrogen fertilizer factory and a pulp mill on the distribution and abundance of Aeromonas hydrophila in Albemarle Sound, North Carolina: Applied and Environmental Microbiology, v. 45, no. 1, p. 31-42.

Helsel, D.R., and Hirsch, R.M., 1992, Statistical methods in water resources: New York, Elsevier Science Publishing Company, $522 \mathrm{p}$.

Heukelekian, H., 1951, Disinfection of sewage with chlorine, IV - aftergrowth of coliform organisms in streams receiving chlorinated sewage: Sewage and Industrial Wastes, v. 23, p. 273-277.

Kinney, E.C., Drummond, D.W., and Hanes, N.B., 1978, Effects of chlorination on differentiated coliform groups: Journal of Water Pollution Control Federation, v. 50, p. $2,307-2,312$.

LeChevallier, M.W., Cameron, S.C., and McFeters, G.A., 1983, New medium for improved recovery of coliform bacteria from drinking water: Applied and Environmental Microbiology, v. 45, no. 2, p. 484-492.

LeChevallier, M.W., Jakanoski, P.E., Camper, A.K., and McFeters, G.A., 1984, Evaluation of $\mathrm{m}-\mathrm{T} 7$ agar as a fecal coliform medium: Applied and Environmental Microbiology, v. 48, no. 2, p. 371-375.

Lin, Shundar, 1973, Evaluation of coliform tests for chlorinated secondary effluents: Journal of the Water Pollution Control Federation, v. 45, no. 3, p. 498-506.

Looney, S.W., and Gutledge, T.R., 1985, Use of the correlation coefficient with normal probability plots: American Statistician, v. 39, p. 75-79.

McFeters, G.A., and Stuart, D.G., 1972, Survival of coliform bacteria in natural water-field and laboratory studies with membrane-filter chambers: Applied Microbiology, v. 24, no. 5, p. 805-811.

Mowat, Anne, 1976, Most probable number versus membrane filter on chlorinated effluents: Journal of the Water Pollution Control Federation, v. 48, no. 4, p. 724-728.

Ohio Environmental Protection Agency, 1990, Numerical and narrative criteria for recreational use designations: Ohio Administrative Code, chap. 3745-1, May 1, 1990, p. 07-07 and 07-34.

Ott, R.L., 1993, An introduction to statistical methods and data analysis (4th ed.): Belmont, Calif., Duxbury Press, $1,051 \mathrm{p}$. 
Presswood, W.G., and Strong, D.K., 1978, Modification of m-FC medium by eliminating rosolic acid: Applied and Environmental Microbiology, v. 36, no. 1, p. 9094.

Rose, R.E., Geldreich, E.E., and Litskey, W., 1975, Improved membrane filter method for fecal coliform analysis: Applied Microbiology, v. 29, no. 4, p. 532536.

Shuval, H.I., Cohen, Judith, and Kolodney, Robert, 1973, Regrowth of coliforms and fecal coliforms in chlorinated wastewater effluent: Water Research, v. 7, p. 537-546.

Silvey, J.K.G., Abshire, R.L., and Nunez III, W.J., 1974, Bacteriology of chlorinated and unchlorinated wastewater effluents: Journal of the Water Pollution Control Federation, v. 46, no. 9, p. 2,153-2,162.

U.S. Environmental Protection Agency, 1978, Microbiological methods for monitoring the environment-water and wastes: Cincinnati, Ohio, U.S. Environmental Protection Agency, EPA-600/8-78-017, 338 p.
U.S. Environmental Protection Agency, 1979a, Methods for chemical analysis of water and wastes, 1978: Cincinnati, Ohio, U.S. Environmental Protection Agency, EPA-600/4-70-020, $440 \mathrm{p}$.

$-1979 b$, Handbook for analytical quality control in water and wastewater laboratories: Cincinnati, Ohio, U.S. Environmental Protection Agency, Office of Research and Development, EPA/600/4-79-019, p. 6-1 to 6-18.

U.S. Environmental Protection Agency, 1985, Ambient water quality standards for chlorine-1984: Washington, D.C., U.S. Environmental Protection Agency, EPA/A440/5-84-030, $57 \mathrm{p}$.

Ward, J.R., and Harr, C.A., 1990, Methods for collection and processing of surface-water and bed-material samples for physical and chemical analyses: U.S. Geological Survey Open-File Report 90-140, p. 5-14.

Wershaw, R.L., Fishman, M.J., Grabbe, R.R., and Lowe, L.E., 1987, Methods for the determination of organic substances in water and fluvial sediments: U.S. Geological Survey Techniques of Water-Resources Investigations, book 5, chap. A3, $80 \mathrm{p}$. 